\section{ilim}

Center for Urban Transportation Research

College of Engineering

University of South Florida

4202 E. Fowler Avenue, CUT100

Tampa, FL 33620-5375

(813) $974-3120$, fax (813) 974-5168

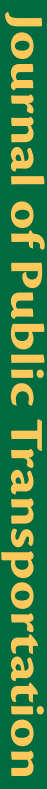

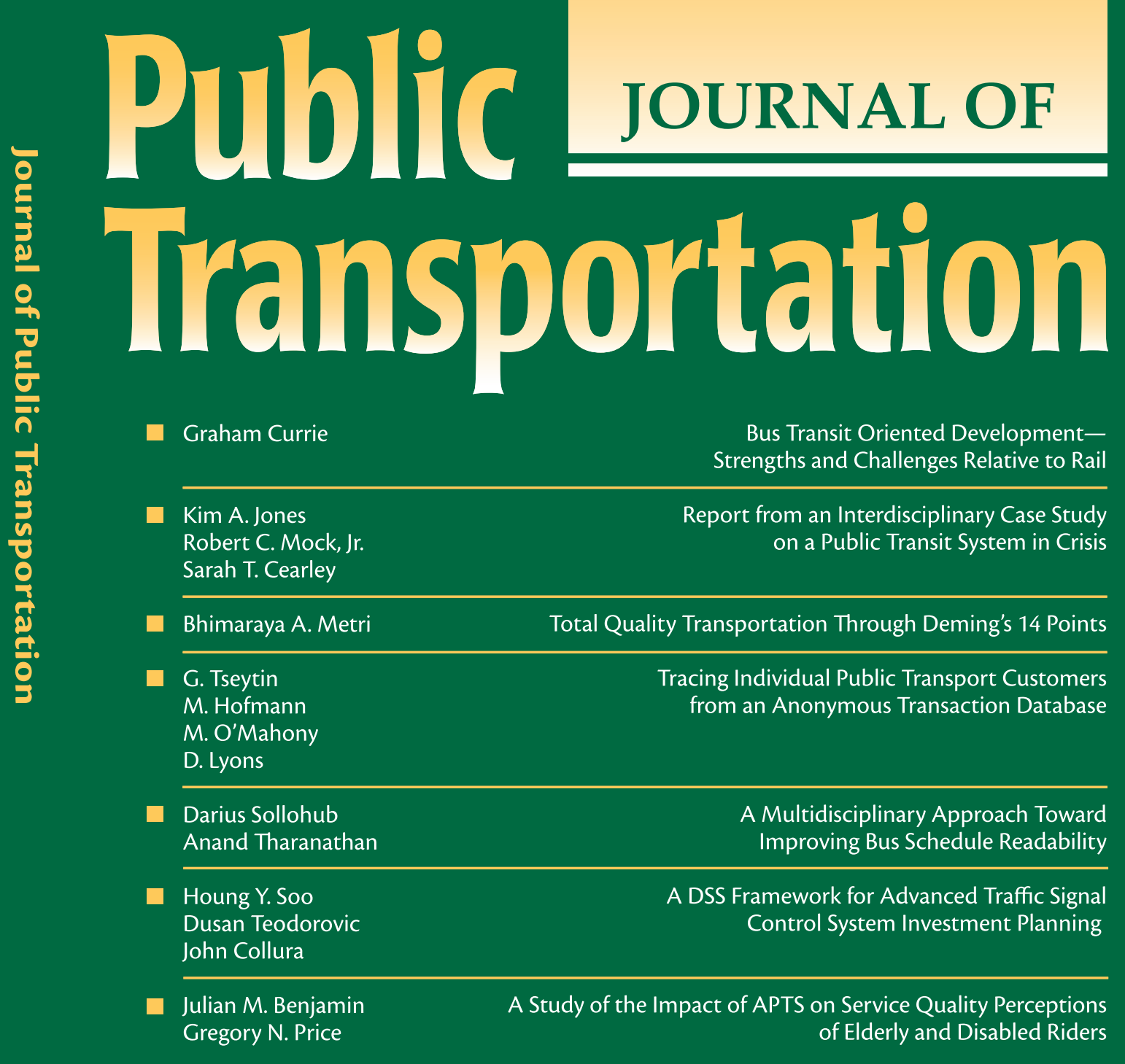

USF

UNIVERSITY OF

National Center for Transit Research 


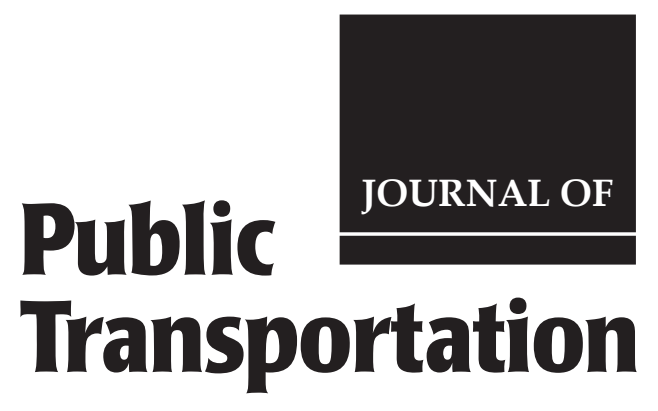

Volume 9, No. 4, 2006

ISSN 1077-291X

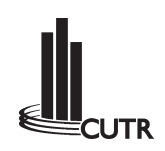

The Journal of Public Transportation is published quarterly by

National Center for Transit Research

Center for Urban Transportation Research

University of South Florida • College of Engineering

4202 East Fowler Avenue, CUT100

Tampa, Florida 33620-5375

Phone: $813 \cdot 974 \cdot 3120$

Fax: $813 \cdot 974 \cdot 5168$

Email: jpt@cutr.usf.edu

Website: www.nctr.usf.edu/journal.htm

(c) 2006 Center for Urban Transportation Research 



\section{CONTENTS}

\section{Bus Transit Oriented Development-Strengths and Challenges Relative to Rail}

Graham Currie 1

Report from an Interdisciplinary Case Study on a Public Transit System in Crisis

Kim A. Jones, Robert C. Mock, Jr., Sarah T. Cearley.

Total Quality Transportation Through Deming's 14 Points

Bhimaraya A. Metri. .35

Tracing Individual Public Transport Customers from an Anonymous

Transaction Database

G. Tseytin, M. Hofmann, M. O'Mahony, D. Lyons

A Multidisciplinary Approach Toward Improving Bus Schedule Readability

Darius Sollohub, Anand Tharanathan.

\section{A DSS Framework for Advanced Traffic Signal Control System} Investment Planning

Houng Y. Soo, Dusan Teodorovic, John Collura

Errata: A Study of the Impact of APTS on Service Quality Perceptions of Elderly and Disabled Riders

Julian M. Benjamin, Gregory N. Price.

Our troubled planet can no longer afford the luxury of pursuits confined to an ivory tower. Scholarship has to prove its worth, not on its own terms, but by service to the nation and the world.

-Oscar Handlin 



\section{Bus Transit Oriented Development- Strengths and Challenges Relative to Rail}

Graham Currie, Institute of Transport Studies, Monash University

\section{Abstract}

While rail has been the focus of most planning for Transit Oriented Development (TOD), there has been recent interest in bus-related TOD with an emphasis on new bus rapid transit (BRT) systems in North and South America and Australia. This article takes a critical look at the strengths and challenges of bus-based transit systems compared to rail in relation to TOD. It includes a review of the literature and an assessment of TOD-related developments. The performance of BRT systems in relation to TOD is considered with specific reference to BRT systems in Australia. In addition, TOD related to local suburban bus service is examined. The article describes the general concept of TOD and how this relates to features of transit modes, outlines the literature relevant to bus-based TOD, and identifies the strengths and challenges of bus-based transit systems in relation to TOD. It concludes by summarizing the relative strengths and challenges of BRT and local bus services compared to rail. The findings of the review are used to identify ways in which bus-based TOD might be better planned and implemented. 


\section{Introduction}

Transit Oriented Development (TOD) is a significant way of improving the effectiveness of transit as well as supporting community goals and improving accessibility (Cervero et al. 2004). In general, TOD initiatives have focused on rail TOD (RTOD); bus TOD (BTOD) is clearly a minor subset of TOD implementation and is not well covered in the research literature (Cervero et al. 2004). There is evidence of an increase in the profile of BTOD. BTOD is seen as an important feature of the growing bus rapid transit (BRT) field (Levinson et al. 2003). Almost 8 percent of the TOD initiatives identified in a U.S. survey were BTODs (Cervero et al. 2004). So what is the potential for TOD in relation to bus services? How far can TOD be realistically applied in the bus industry?

This article identifies the strengths and challenges of BTOD through a literature review and an assessment of development experience. 'It provides an objective assessment of the capabilities and issues of bus in relation to TOD. Comparative assessment to rail is undertaken as a means of exploring these issues (not to advocate bus in preference to rail or vice versa).

Assessing the relative merits of bus and rail requires some generalizations regarding the nature of these modes. In practice there are a very wide range of bus/rail service types. The article considers bus in two forms.

- BRT with an emphasis on frequent, high-quality mass transit systems with much fixed infrastructure including stations/guideways, and

- local/suburban bus with low frequency services operating on-street in suburban settings with minimal fixed infrastructure.

In general, rail services examined refer to urban commuter mass transit systems.

Market climate and development opportunity are key success factors in TOD (Cervero et al. 2004) rather than the relative features of rail versus bus. This article examines bus/rail issues in isolation of these factors as a means of exploring modal influences on TOD. However, it is recognized that financing and risk assessment will remain principal factors affecting TOD regardless of the transit mode involved.

The article begins with an overview of the BTOD literature. Challenges of BTOD compared to rail are then discussed followed by a discussion of strengths. The conclusion summarizes key findings and discusses ways in which BTOD might be better planned. 


\section{Research Literature}

A casual reader of the TOD literature might be forgiven for thinking that bus services play no role in the field. However, bus-based TOD has been identified in typologies of TOD characteristics. Calthorpe (1993) identified both an "urban TOD" associated with rail stations and a "neighborhood TOD" associated with bus. Dittmar and Ohland (2004) suggest a hierarchy of transit modes related to a hierarchy of TOD types. While bus services are provided at every level, rail is more closely related to high-density/large-scale development and bus with low density/small-scale development. This is repeated in much of the literature. The term "development oriented transit"' (i.e., associating low density with bus) has also been associated with this. A review of TOD residential density thresholds (Cervero et al. 2004) identified consistently lower density expectations for bus than light rail in San Diego, Portland, and Washington County, Oregon.

The colocation of bus services and bus terminals at some major rail stations has been suggested as a potential spur for TOD (Porter 1997). BTOD was also commonly associated with bus stations in cities without rail.

BTOD is more commonly associated with busways or BRT. The ability of largescale bus transit systems to encourage land development has been identified as a major benefit of these forms of transit technology (Levinson et al. 2003).

The Ottawa transit system is a major icon of BTOD. Ottawa's policy of combining integration of land use and transport planning with an emphasis on transit development over road construction is to be admired regardless of the transit modes involved. Nevertheless, it was a busway that achieved densification of development around busway stations (Bonsall 1997).

Curitiba and Bogotá are the other major icons of both BRT and associated BTOD. Evidence of development benefits of these systems has been identified (Rodriguez and Targa 2004; Smith and Raemaekers 1998).

While BTOD has been successful with large-scale BRT, the relevance of these examples is questionable. Henry (1989) notes strong land-use controls as a major factor influencing successful TOD in Ottawa. This level of control is considered "formidable" and "most unlikely" in U.S. land-use planning.

So what is the practical and realizable potential for BTOD? The next sections consider BTOD challenges and strengths. 


\section{Challenges}

This section addresses challenges or weaknesses of bus in relation to TOD relative to rail. In each case, the significance of challenges are graded as "low," "medium" to "high," based on a judgmental assessment of the arguments presented by the author. Where there is some uncertainty, this is indicated.

\section{Permanence, Magnitude, and Implications for Development Risk}

Many sources question the permanence of bus compared to rail. "Developers and home buyers alike seem to be attracted to the permanence of rail transit" (Dittmar and Ohland 2004). "Because the locations of bus routes are not fixed or permanent, this greatly increases the risk of investing in transit-supportive land-use development" (California Department of Transportation [CDOT] 2002).

Development scale and magnitude is purported to be significantly higher for rail than bus and is suggested as a major spur for RTOD compared to BTOD (CDOT 2002). Certainly, significant investment suggests significant commitment. Commitment and developer risks are linked. However, Hensher (1999) asks, "What makes for permanence?" He questions whether busways are less permanent than light rail since few busways have been removed. Niles and Nelson (1999) state, "It is not easy to draw the conclusion that rail transit is both more permanent and a greater attractor of development than is bus transit." They note that historical studies demonstrate much change and evolution of transit systems of all types. Evidence is quoted of Chicago bus routes that have existed for almost a century. Reference is also made to the numerous streetcar systems removed in post-war North America.

Some conclusions emerge from these points.

- Suburban bus systems operating at low frequency with minimal fixed infrastructure lack magnitude and permanence for successful large-scale BTOD. This creates risk for large development. This is a concern of "high" significance.

- This does not mean that small/low density development is not possible or desirable in some cases where suburban buses operate.

- The argument that fixed rail infrastructure has more magnitude and permanence compared to busways is weak. The Ottawa system provides strong evidence to the contrary. 


\section{Newness}

The "newness" of rail investments was cited by the CDOT (2002) as being a factor that provided an advantage over BTOD. An important difference between bus and rail is that rail (and light rail in particular) is often introduced as an entirely new mode and usually replaces an existing bus-based service. Most BRT systems replace local bus systems with vehicles that are also buses. Hence, while busways may have significant new infrastructure, they often employ the same bus vehicles on that infrastructure. While the development of some new bus vehicle types is an important part of BRT system design, few BRT systems use radically new-looking vehicles (e.g., the Australasian BRT systems) (Currie 2005c).

Newness is important to TOD where a significant change from existing obsolescent land uses is required; however, this is not a requirement for all TODs. Clearly, this issue is also of less relevance to large-scale BRT operations and systems employing new-looking vehicles (e.g., Civis). In contrast, TOD based on suburban bus with limited fixed infrastructure is likely to be a poor performer in relation to the newness factor particularly where TOD is focusing on urban renewal. This view conflicts with the experience of the Central Ohio Transit Authority (Duffy 2002) who cite the successful redevelopment of the Linden Center from the "worst case of urban blight" into a successful (local) bus based transit center. While there is some cause to identify newness as a factor reducing the effectiveness of particularly suburban bus, the significance of this factor in affecting the success of BTOD is likely to be "low" to "medium."

\section{Different Markets}

It has been argued (CDOT 2002) that rail and bus riders are demographically different and that rail attracts "choice"2 riders who tend to have higher incomes. It is suggested that rail can target a more affluent market for TOD investments and, hence, will be better suited to TOD in more affluent suburbs or successful downtown development.

Currie (2005c) compared demographic data from a series of Adelaide public transport corridors including the O-Bahn busway (BRT), on street bus and rail. Rail carried more choice passengers than on street bus. However, busway users tend to have characteristics more like rail markets than bus markets. This could suggest that the potential yield from BRT systems in terms of TOD development may be similar to rail. 
Relationships between affluent riders and more successful TOD are unclear. While higher yield customers are good for any business, it does not follow that the market for TOD properties is well represented by higher income groups. Certainly in Australia there is no clear relationship between high development density and affluence. Indeed, the contrary is quite often the case.

In conclusion, local bus caters to different markets than rail; there are fewer choice and more low-income characteristics. Some researchers suggest that RTOD is more successful as a result. However, this supposition is not yet supported because of lack of evidence. This weakness is thus rated "low" and "questionable" on this basis.

\section{Park and Ride}

Park and ride (P\&R) has been identified as a factor that limits TOD opportunities (Dittmar and Ohland 2004). More than 57 percent of rail transit agencies involved in U.S. TOD identified P\&R as a moderate to significant factor affecting the success of TOD. The main concern is conflict between large parking lot needs, road capacity needs, the volume of car access, the desire for prime development space, and the need for quality uninterrupted walk access.

P\&R is a significant access mode to rail, as well as to busways. Interestingly, as Figure 1 suggests, it is less of an influence on local bus than on rail or busways. Some BRT systems are P\&R based and others are not. It could be argued that rail has a disadvantage in relation to $P \& R$ while bus has an advantage. However, the results suggest different systems have different characteristics and that generalizations about modes are unclear (and unhelpful).

The following conclusions are made:

- Rail and some BRT systems have high P\&R access, which limits successful TOD.

- On-street bus has a low P\&R access, which may be a benefit of BTOD over some RTODs.

- The design of BRT systems needs to exclude or manage P\&R where BTOD is to be implemented.

\section{Industry TOD Capabilities}

There is some evidence that implementing successful BTOD is more difficult than RTOD. "Making bus TODs work will require a focused approach and an extra level of leadership and intervention than a comparable rail TOD" (CDOT 2002). A 


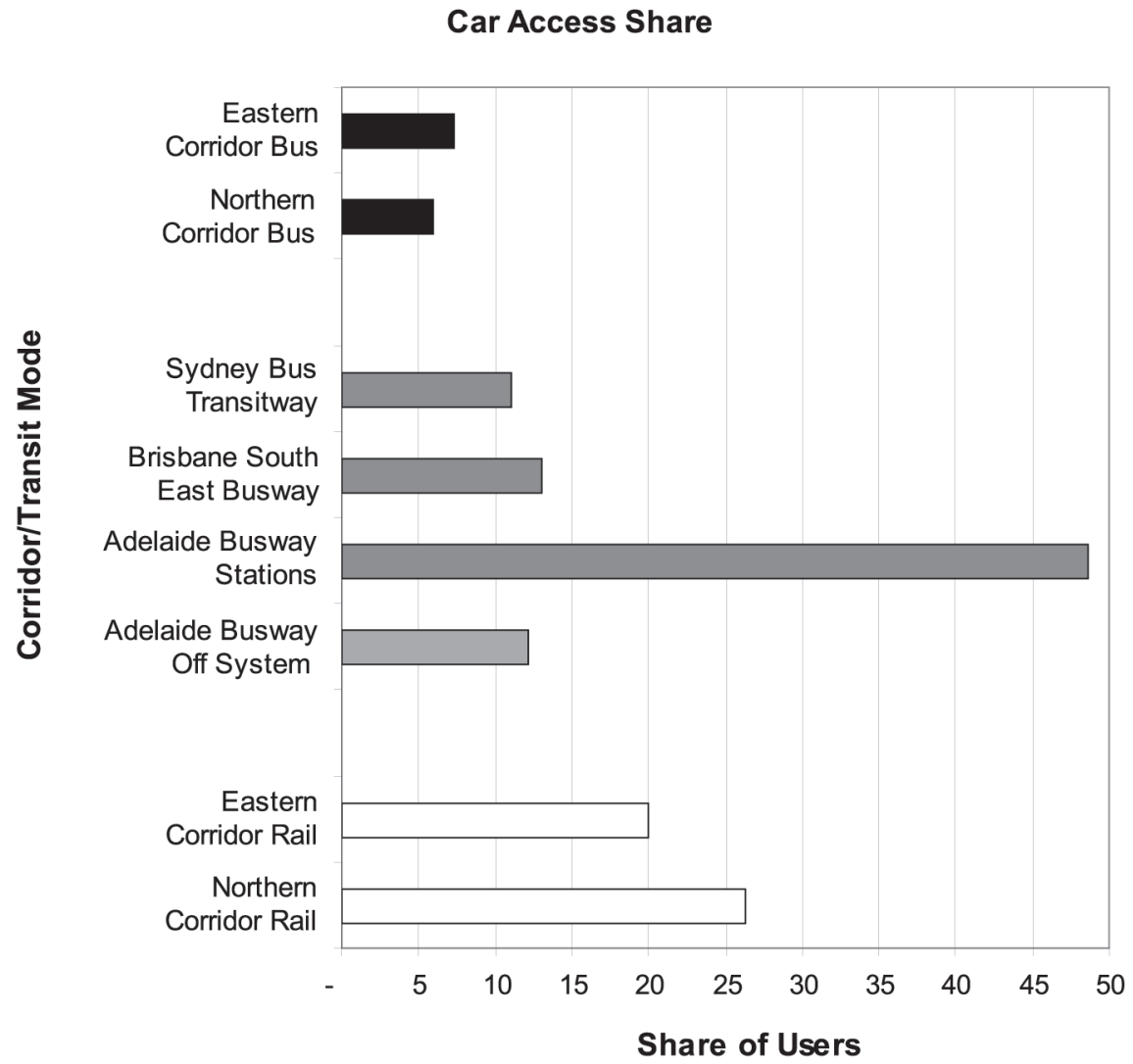

Source: State Transport Authority (1992, 1994), Travers Morgan (1991), McCormick Rankin Cagney, (2002), Parsons Brinckerhoff (2005).

\section{Figure 1. Comparative Share of Park and Ride Access-Adelaide Busway, Bus and Rail Corridors, Brisbane South East Busway and Sydney Transitways}

review of TOD in the United States (Cervero et al. 2004) has found that only three percent of transit agencies engaged in BTOD had full-time staff to run BTOD programs. The proportion for rail agencies was 42 percent.

Lack of bus industry capabilities to manage BTOD is rated a "high" weakness in relation to BTOD. 


\section{Pedestrian Access}

High-quality, grade-separated direct walk access is an important feature of successful TOD (Cervero et al. 2004). This can be difficult to achieve with bus. A bus station can have numerous lines with significant bus movements. Large bus vehicles operating at high frequency in streets with pedestrians can be dangerous. Their activity requires careful management and is certainly unattractive from an environmental, street quality, and amenity viewpoint.

Difficulties in providing quality pedestrian access are more likely to be an issue for local bus systems, particularly at major bus stations (where BTOD is often focused). Only a few BRT systems have addressed this problem.

The significance of the issue should probably be rated as "moderate" rather than "high." While quality pedestrian access is a desirable part of successful TOD, there is no evidence that it is essential.

\section{Parking Restraint}

Parking restraint policies are a useful addition to TOD strategies. They enhance attractiveness by limiting road congestion and are useful in providing more land for development. Links between RTOD success and parking constraint have been identified (Porter 1997). Parking restraint is easier to apply in high-density, railbased locations because the problems of excessive parking demand are evident. In lower density nodes (more typical of suburban bus), enacting parking restraint practices is difficult because problems of congestion are often less evident and bus service levels are low. Without a quality public transport alternative, it can be argued that parking restraint in smaller urban development is less justified.

The differential capability of bus and rail to influence parking restraint is probably influential only with suburban bus services. BRT-based systems should be able to justify higher density development where parking restraint is feasible.

The significance of this is probably "high" since parking restraint is an effective means of encouraging transit use. Car access can also have secondary influences on pedestrian quality and quality of the environment.

\section{Urban Density}

Urban density is the critical driver of transit ridership (Seskin and Cervero 1996). Luscher (1995) identified urban density as a key factor affecting TOD's ability to reduce auto usage and noted that bus-based services tended to be provided in areas with lower density development. Bus services, notably suburban services, will 
therefore be less successful at achieving patronage growth and in reducing private auto travel in TOD than rail. This is not necessarily true for BRT services, depending on the success of BRT in encouraging higher densities.

The significance of this factor is probably "moderate" to "high." While suburban bus services may not achieve rail-like patronage, TOD can still occur. However, it is likely to have a less significant impact than that experienced for rail and BRT.

\section{Scale Dilution}

A potential disadvantage of BTOD is that it is difficult to concentrate development activity around the large number of bus stops in cities (e.g. 3,400 bus stops are identified in San Diego) (CDOT 2002) compared to the small number of rail (49 light rail stops). This effect is termed "scale dilution."

There are two sides to this issue. While scale dilution appears plausible, it is also conceivable that concentration of TODs at a few sites is limiting. Luscher (1995) modelled the impacts of RTOD and BTOD projects in reducing auto use in San Francisco. A 5 percent reduction in auto VKMs was achieved with 82 RTODs combined with 246 BTODs. More than 60 percent of total reductions in VKMs occur because of BTODs not RTODs. ${ }^{3}$ Although each RTOD is more effective than a BTOD, the sheer volume of BTOD sites is so much larger than the RTOD's that overall BTODs have a greater effect.

Scale dilution could reduce the effectiveness of RTODs. While there is no evidence of this, it is certainly an issue worth considering. Having the option of smaller scale BTODs as well as larger scale RTODs also provides greater choice for TOD developers and customers.

While scale dilution is an important issue for BOD, it is only likely to affect local bus systems. BRT stations should be as limited in number as rail stations. However, the significance of this issue to bus is probably "unimportant" to "low." While the significantly larger number of sites for BTOD is a problem, it is also an opportunity for cities to obtain the higher benefit from TOD on a systemwide basis. It also increases the community's range of choice.

\section{Noise and Pollution}

Noise and fumes emitted from transit vehicles are generally associated with bus, not rail. Rail usually has the advantage of "clean" electric power over diesel-based bus. While rail vehicles, particularly heavy rail vehicles, can often be noisier than buses, it is the closer on-street proximity of buses where pedestrians roam and 
the frequency of bus movements that generates greater noise impact. Rail-based vehicles often generate noise on rights-of-way, which are remote from major pedestrian areas (e.g., tunnels).

There is some substance to this issue. Where buses use alternative fuels or operate in areas removed from pedestrians, these issues may not be so important. However, in general, this is rare.

The significance of this issue on the performance of BTOD is "moderate" to "high." Successful TOD requires an environment in which people want to live and work. Bus noise and pollution, unless appropriately managed, creates places which are not attractive.

\section{Frequency and Speed}

Regarding TOD, Dittmar and Ohland (2004) note, "After density, the most important questions about transit have to do with service frequency and speed." Rail tends to operate at higher frequencies than suburban bus. In addition, most modern rail systems operate in exclusive rights-of-way with long station spacing. Local bus tends to operate in mixed traffic with frequent stops. As a result, bus speeds are low compared to rail.

While low frequency and speed are valid concerns for local bus, they do not apply to $B R T$, although this depends on the degree of right-of-way segregation applied. Indeed, a positive attribute of BRT relative to rail is that service frequencies on busways are much higher than rail due to vehicle capacity and the number of vehicles required to meet demand. Many busways operate at headways below one minute, whereas rail services require longer headways due to larger vehicle capacity and train separation requirements. This can limit heavy rail systems to headways above two minutes.

The significance of this issue on local bus services is "moderate" to "high." It is a strength, not a weakness relative to BRT. The impact of transit on development requires an effective service offering. Without this, the transit element of TOD has little to offer.

\section{Bus Stigmatization}

Buses have a bad image. "The bus rapid transit program is trying to change this, but buses are still stigmatized as second-class forms of transport" (CDOT 2002). A key question is: Does bus stigmatization affect potential TOD investors and TOD transit customers? 
The effect on customers has been illustrated by Currie (2005a), who examined empirical evidence on how transit riders perceived travel by on-street bus, BRT, light rail and heavy rail. A preference for rail over on-street bus was evidenced; an average benefit valued at between 4 to 10 minutes of travel time was indicated. However, this work also demonstrated similar preferences for BRT compared to on-street bus (although BRT research evidence was limited). This suggests that BRT shares passenger preferences of rail above on-street bus.

This evidence does not concern investors in TOD. It is possible that TOD developers have negative views of bus compared to rail and that developers influence TOD as much as transit riders.

While the significance of bus stigmatization is currently "high," it does not need to be a long-term issue. It is likely to afflict on-street local bus services more than BRT systems.

\section{Track Record}

BTOD does not have as long a record as RTOD. Also, little is known about the impacts of BTOD. Some doubt the performance of BTOD. "Experience in California, like the rest of the country, tends to be somewhat mixed regarding bus TODs" (CDOT 2002). Others provide positive reports (Duffy 2002; Cervero et al. 2004). Objective independent assessment of BTOD schemes is rare, so some caution is appropriate. Some are likely assessing the performance of BTOD, particularly BTOD associated with suburban bus, in similar terms to RTOD. The evidence from the discussion in this article suggests that local bus TODs are unlikely to perform as well as RTOD. But this does not mean that BTOD, in these circumstances, is not a positive program to implement.

Overall lack of a track record is considered to have "moderate" to "high" significance for all types of bus services. While it might be theorized that BRT is likely to show good performance relative to rail, evidence on its track record is limited.

\section{Strengths}

\section{Complementarity and Ubiquitousness}

Ubiquitousness is the converse of the scale dilution weakness. Luscher's results (see earlier) demonstrated that BTOD can work alongside RTOD to achieve higher citywide TOD benefits than by operating RTOD schemes alone. In effect, BTOD and RTOD are complementary. 
These comments must be tempered by doubts about the effectiveness and ease of implementation of numerous concurrent BTODs. Nevertheless, joint BTOD and RTOD approaches seem an appropriate package of TOD initiatives on a metropolitanwide basis.

The significance of these strengths is considered "high" for all forms of bus service.

\section{Flexibility-Choice}

Dittmar and Ohland (2004) suggested that BTOD schemes may be an attractive option where communities do not want high densities. They also suggest BRT as an interim step to build ridership, which may make rail transit more feasible. Both of these points suggest BTOD has elements of flexibility that RTOD may not demonstrate. For example, bus can better mimic the many-to-many nature of suburban trip patterns than rail.

The significance of these issues to BTOD must be "high," particularly to communities looking for alternative options to high-density living. Overall flexibility should add an extra capability and strength to the TOD planning approach since a wider range of options for implementation are available.

\section{Flexibility-Adaptiveness to Change}

The ability to cost-effectively redesign and adapt BRT systems to changing market circumstances compared to rail has been highlighted by many researchers (e.g., CDOT 2002). Hensher (1999) notes a dichotomy between flexibility and permanence: "The cost of producing flexible service capable of potentially responding to changing geographic activity patterns is the price of reduced commitment to the facility."

There is little research valuing the benefits of adaptability. However, there must be some benefit from providing a flexible planning future, particularly when futures are uncertain and capabilities to invest in expensive rail projects are limited. These points suggest a "moderate" significance rating for this BRT strength.

\section{Cost-Effectiveness}

Local bus services are more cost-effective in lower density areas than rail. In addition, there is evidence that BRT systems are more cost-effective to build and operate than light rail (U.S. General Accounting Office 2001). The case for costeffectiveness in relation to heavy rail is less clear. The higher capacity of heavy rail could be too costly for buses to match. 
Cost-effectiveness is possibly the most significant variable that can be associated with the assessment of transit systems. Thus, this benefit has a "high" significance.

\section{Service Frequency}

High frequency makes transit attractive in TOD. While frequency is a challenge for local bus, BRT can have superior frequency compared to rail. This strength is considered "high" but applies only to BRT systems. It is a weakness for suburban bus.

\section{Transfers}

An additional feature of busway-based BRT is that it often does not require passenger transfers to access the main trunk system since buses pick up in the suburbs then proceed onto the busway right-of-way without the need for a transfer between vehicles. It is impractical to run rail systems down every street in every suburb. Hence, feeder bus services are required, which generate passenger transfers. Passengers dislike transferring. Currie (2005a) collated international evidence on the perceived values of passenger transfers and found average transfer penalty values for bus-light rail of 19 minutes and bus-heavy rail of 13 minutes. Values of this order clearly have a significant impact on travel choices.

The capacity of some busways to reduce transfers is of some value compared to rail. However, this is only one of many parts of a journey; it only applies to certain markets (those making transfers) and also to particular BRT systems (where transfers are not required).

This strength is valued at "low" to "medium" significance.

\section{Assessment of Strengths and Challenges}

Figure 2 shows an assessment of the relative strengths and challenges of bus relative to rail. The significant challenges for effective BTOD are:

- poor bus industry capabilities,

- noise/pollution impacts of buses, and

- poor track record.

BRT systems have less significant weaknesses than local bus ( $P \& R$ access is the only exception to this). There are far fewer strengths of bus compared to weaknesses. Nevertheless, many strengths have "high" significance. BRT has more strengths than local bus. 
BRT with good design can lessen the significance of challenges. On this basis, well-designed BRT could have net advantages compared to rail in some circumstances - an interesting conclusion.

\section{Conclusions}

This article has identified the strengths and challenges of bus in relation to TOD. A large number of challenges have been identified. The lack of dedicated TOD development staff in the bus industry, the noise/pollution impacts of buses, and a poor track record of bus in relation to TOD were the most significant weaknesses identified for bus services as a whole.

It is clear that suburban bus services are more suited to lower density environments. It is also evident that successful implementation of BTOD is a more difficult task than related RTOD initiatives. Nevertheless, BTOD can provide an important complementary function in supporting both RTOD and BRT-based TOD programs by expanding the benefits of TOD on a more comprehensive scale.

This analysis has identified opportunities to improve BTOD planning.

- Bus industry capabilities and dedicated staffing for supporting BTOD initiatives need to be enhanced considerably. This problem is exacerbated by the lack of knowledge and experience in BTOD planning, implementation, and performance.

- While BRT systems are tackling the issue of bus stigmatization, it is important that these leanings "trickle down" into the more conventional bus-based services.

- Noise and pollution remain significant issues for bus. Separation of local bus services from pedestrian areas and use of nonpolluting fuels should be a priority for bus systems hoping to successfully adopt BTOD strategies.

- It may always be difficult for smaller-scale bus services to generate an impression of scale and permanence to large-scale development opportunities. This problem is best addressed at bus stations through innovative designs that challenge the concept of the bus station as a cold and unfriendly location. 


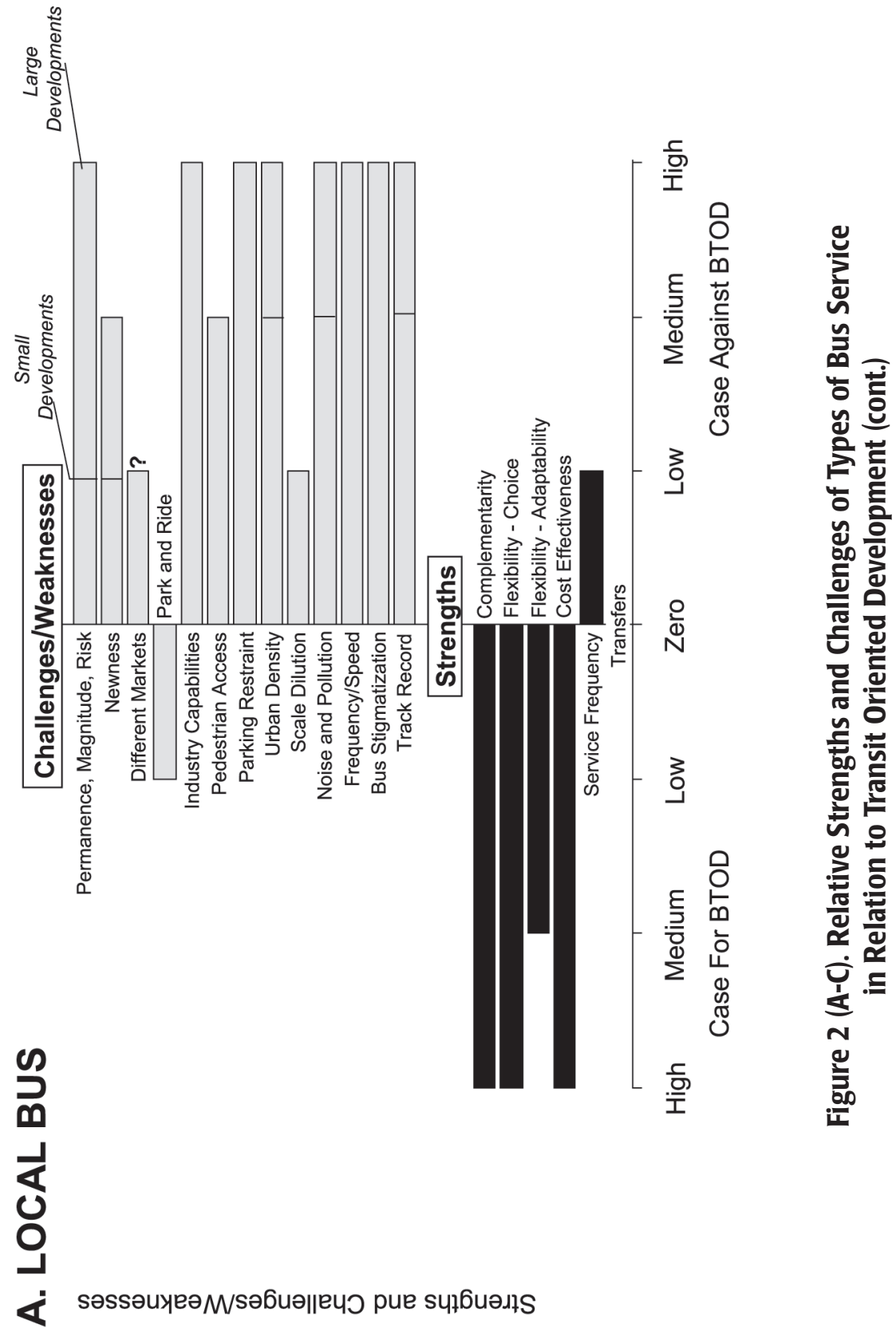




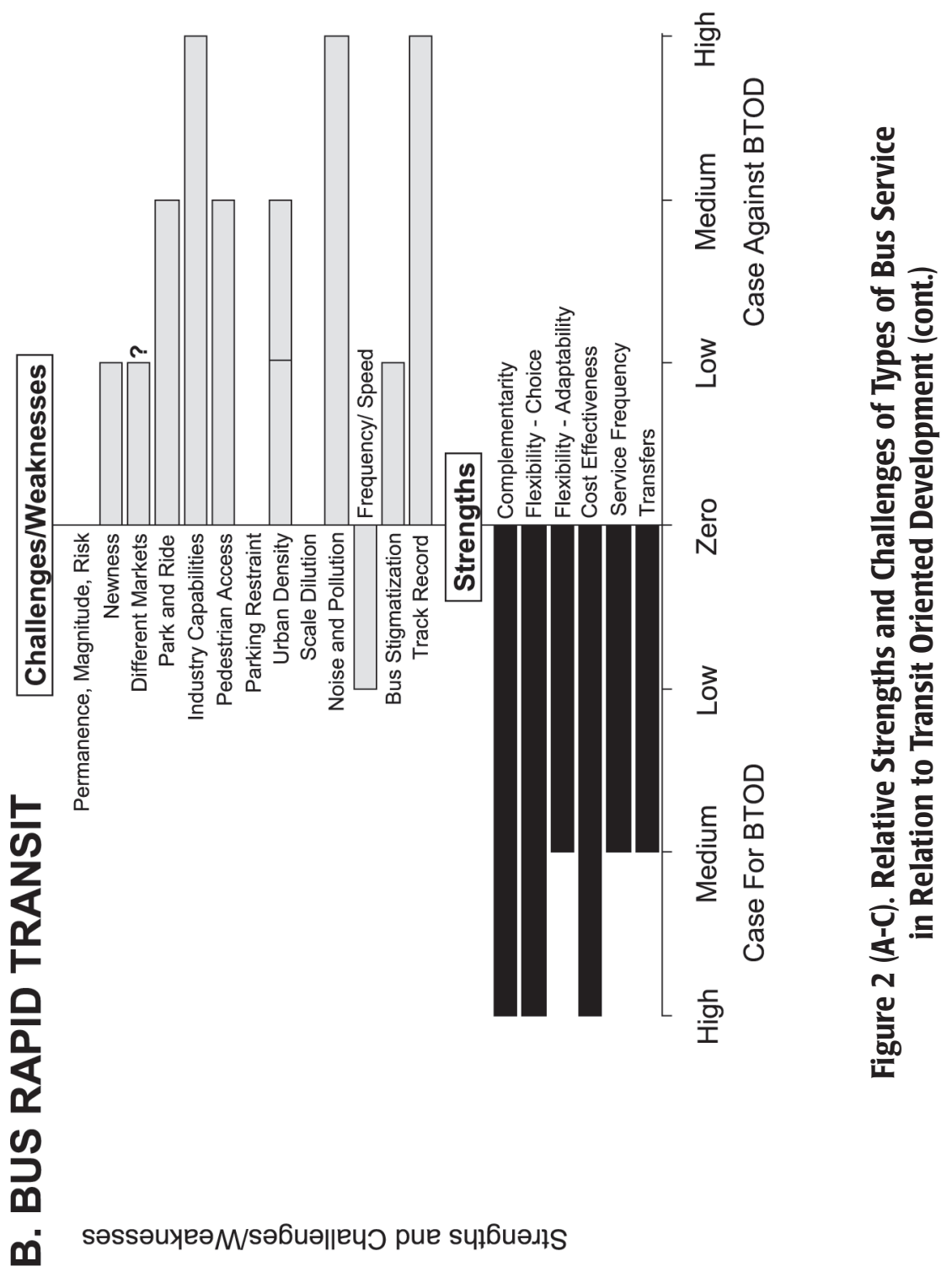




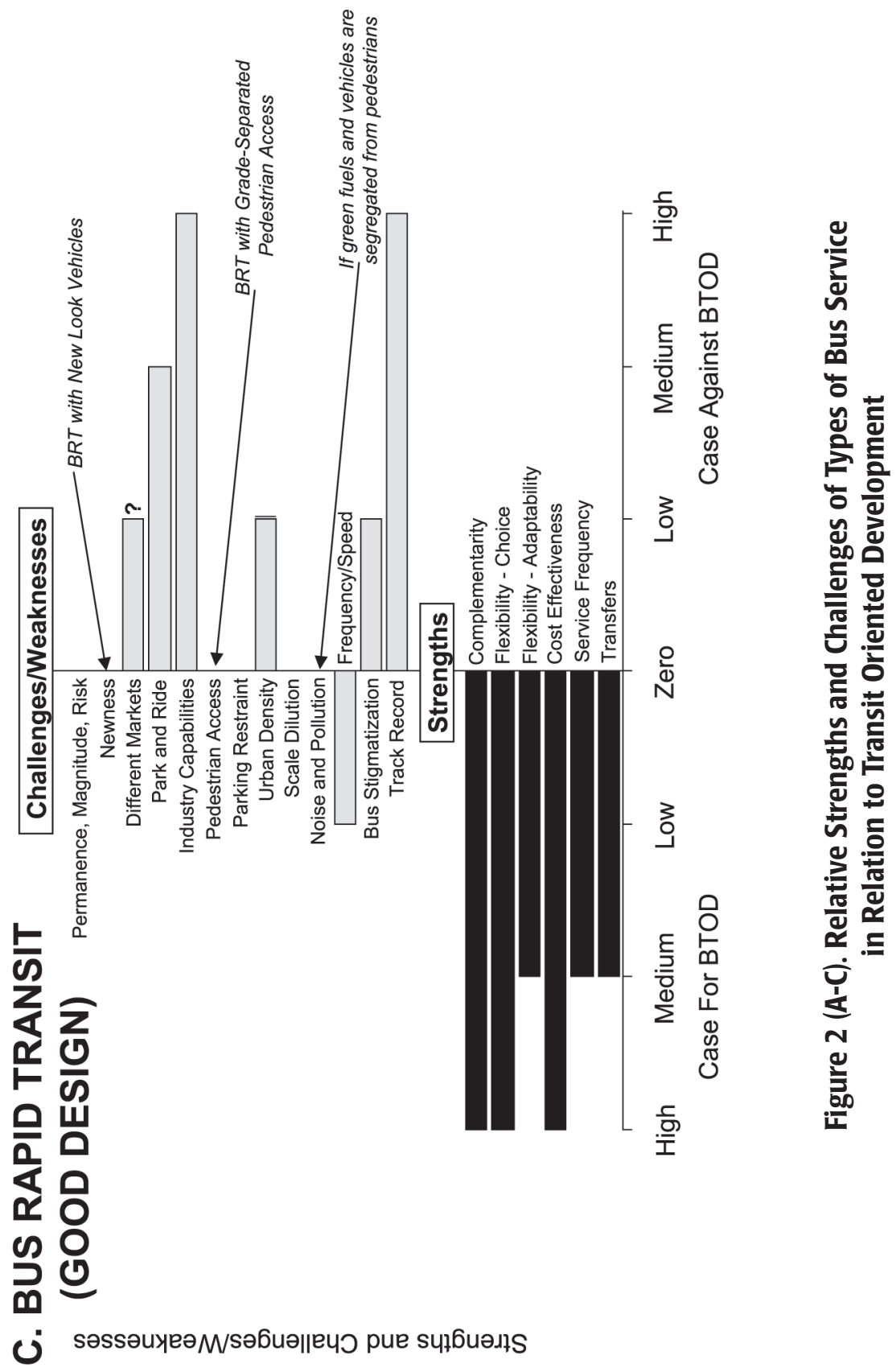


BRT systems have a far stronger capability in relation to BTOD than local bus. However, the design of car access needs to be carefully balanced against the need for BTOD (as it does for rail). Bus noise and pollution issues are also valid concerns for BRT. The trend toward modern high-quality BRT vehicles is to be encouraged in systems seeking successful BTOD.

BTODs have a limited and unclear track record. There is a need to build knowledge and gain and share experiences to better develop, learn, and sell the potential benefits of BTOD to the community and the transit and urban development industry.

\section{End Notes}

${ }^{1}$ This article is an expanded version of a July 2005 conference presentation at the "Transit Oriented Development-Making It Happen" conference in Perth, Western Australia. See also Currie (2005b).

${ }^{2} \mathrm{~A}$ choice passenger is one who has access to a car but decides to use transit.

${ }^{3}$ This is calculated based on Luscher's relative RTOD and BTOD population sizes, the estimated reduction in VKMs identified, and the number of rail and bus TOD developments required for an average performance of TOD to reduce VKMs by 5 percent.

\section{Acknowledgements}

The author thanks Tom Wilson of the Adelaide Department of Transport and Urban Planning and Matt Faber and Terry Lee Williams of Sydney RTA Transitways for advice and input to this article. The author also acknowledges the paper's reviewers for quality input to the work. Any errors are the responsibility of the author. 


\section{References}

Bonsall, J. 1997. Planning for a transit-oriented city: Lessons from Ottawa-Carleton. Transport Engineering in Australia: 12-18.

California Department of Transportation. 2002. Statewide transit-oriented development study-Factors for success in California. Final Report. Business, Transportation and Housing Agency.

Calthorpe, P. 1993. The next American metropolitan; Ecology, community, and the American dream. New York: Princeton Architectural Press.

Cervero, R., S. Murphy, C. Ferrell, N. Goguts, T. Yu-Hsin, G. B. Arrington, J. Boroski, J. Smith-Heimer, R. Golem, P. Peninger, E. Nakajima, R. Chui, R. Dunphy, M. Myrres, S. McKay, and N. Witenstein. 2004. Transit-oriented development in the United States: Experiences, challenges and prospects. TCRP Report 102. Transportation Research Board.

Currie, G. 2005a. The demand performance of bus rapid transit. Journal of Public Transportation 8 (1).

Currie, G. 2005b. Strengths and weakness of bus in relation to transit oriented development. Transit Oriented Development-Making It Happen Conference. Perth, Western Australia.

Currie, G. 2005c. BRT in Australasia: Performance, lessons learned and futures. Institute of Transportation Engineers Annual Meeting. Melbourne, Australia.

Dittmar, H., and G. Ohland. 2004. Defining transit-oriented development: The new regional building block. In Dittmar, H. and G. Ohland, eds., The New Transit Town: Best Practices in Transit Oriented Development. Island Press.

Duffy, J. 2002. Transit-oriented development along Columbus bus routes. Mass Transit.

Henry, L. 1989. Ridership forecasting considerations in comparisons of light rail and motor bus modes. Light Rail Transit: New Systems at Affordable Prices Special Report 221: 163-189. Transportation Research Board.

Hensher, D. A. 1999. A bus-based transitway or light rail? Continuing the saga on choice versus blind commitment. Road and Transport Research 8 (3). 
Levinson, H., S. Zimmerman, J. Clinger, S. Rutherford, R. L. Smith, J. Crcknell, and R. Soberman. 2003. Bus Rapid Transit. TCRP Report 90.Transportation Research Board.

Luscher, D. R. 1995. The odds on TODS-Transit oriented development as a congestion reduction strategy in the San Fransico Bay Area. Berkeley Planning Journal 10: 55-74.

McCormick Rankin Cagney. 2002. Results of the annual busway customer satisfaction survey-2002. Final Report.

Niles, J., and D. Nelson. 1999. Measuring the success of transit-oriented development: Retail market dynamics and other key determinant. Approaching the Millennium. American Planning Association National Conference.

Parsons Brinckerhoff. 2005. Liverpool to Parramatta transitway passenger survey 2004. Final Report. NSW Roads and Traffic Authority-Transitways.

Porter, D.R. 1997. Transit-focused development. TCRP Synthesis 20.Transportation Research Board.

Rodriguez, D. A., and F. Targa. 2004. Value of accessibility to Bogotá's bus rapid transit system. Transport Reviews 24 (5): 587-610.

Seskin, S., and R. Cervero. 1996. Transit and urban form. Washington DC: Federal Transit Administration.

Smith, H., and J. Raemaekers. 1998. Land use pattern and transport in Curitiba. Land Use Policy 15 (3): 233-251.

State Transport Authority. 1992. Eastern corridor market analysis. Adelaide Public Transport Network Study.

State Transport Authority.1994. North East (busway) market analysis report. Adelaide Public Transport Network Study. Alison Anlezark.

Travers Morgan. 1991. Analysis of the Northern suburbs customer survey. Adelaide Public Transport Network Study.

U.S. General Accounting Office. 2001. Bus rapid transit shows promise. GAO-01984. Washington, DC. 


\section{About the Author}

GRAHAM CURRIE (graham.currie@eng.monash.edu.au) is professor and chair in public transport at the Institute of Transport Studies, Monash University, Australia, where he undertakes research in transit planning and is developing postgraduate and industry programs in public transport education. He has more than 25 years experience in transit planning and development. He was a planning officer at London Transport and also with the Midland Metro Light Rail project in the UK. He has been a consultant transit planning specialist for 18 years and has worked on transit development projects in Europe, Asia, and Australasia with Booz Allen Hamilton. Professor Currie is a member of the U.S. Transportation Research Board committees on Bus Transit Systems and Light Rail and is a member of the UITP academic network. He holds a master's degree in transport planning and management from Cranfield University (UK) and a bachelor's degree in geography from Huddersfield University (UK). 
Journal of Public Transportation, Vol. 9, No. 4, 2006 


\title{
Report from an Interdisciplinary Case Study on a Public Transit System in Crisis
}

\author{
Kim A. Jones, Robert C. Mock, Jr., and Sarah T. Cearley, \\ University of Arkansas at Little Rock
}

\begin{abstract}
This article describes how a public transportation system in a mid-sized southern state was assessed in regard to its adequacy in providing transportation services. The article begins by discussing the trends in current transportation patterns, funding of public transit, and special populations served by public transit. A case study is then presented of a transit system that was experiencing what has become a typical problem for similar transit systems across the nation: intensified public and political pressures caused by funding cuts and unfunded mandates from the federal government. Findings from the case study are then provided along with recommendations for change. Finally, the outcome of the study is presented.
\end{abstract}

\section{Introduction}

The personal automobile continues to be the favored mode of transportation in the United States, in spite of public support for mass transit. A recent survey showed that about 10 percent of Americans use public transit regularly (Larwin 2005). Thus, the vast majority of Americans rely on their personal automobiles to meet their transportation needs. Factors that have resulted from increased reliance on automobiles include the expansion of urban boundaries, urban planning that discourages use of public transit, rising numbers of those who own a car, a 
readily available freeway system, and long commuting trips to areas where there is no public transit service. However, there are those who simply do not have access to an automobile and who rely solely on public transit to get them to and from work, medical appointments, child care facilities, and leisure activity sites.

In large metropolitan areas with well-utilized public transit systems, riders are more diverse in regard to socioeconomic status. However, in small to mid-size cities, riders tend to be predominantly poor and live in the innercity. In regard to planning, transit operators across the United States are increasingly pressured to provide transportation services to those with automobiles who live in outlaying areas. This emphasis on commuter-oriented express (both bus and rail), in many respects, directly conflicts with transportation services that are increasingly needed in the innercity. The working poor are particularly at risk in that adequate and reliable transportation is seen as a primary barrier to self-sufficiency (PerryBurney and Jennings 2003), in addition to getting and keeping a job (Brabo et al. 1997).

\section{Conditions for Crisis}

In the United States, public transit service is subsidized to a great extent. However, since 1980 Congress has increasingly reduced transit funding, leaving greater fiscal responsibility on state and local governments for funding public transit services. Additionally, the Americans with Disabilities Act (ADA) placed unfunded mandates on local transit, which were required to provide door-to-door service for those who were disabled. Transit officials also had to expand their fleet of small buses to accommodate this mandate or re-equip existing buses for easier access. More stringent federal emissions regulations required that many buses be replaced with more energy-efficient ones.

When combined, these factors have placed a great deal of pressure on local governments to continue providing quality services, while at the same time experiencing cuts in funding. In several areas of the United States, transit authorities, with support from state legislatures and local government leaders, have attempted to offset these funding cuts with various combinations of state funding, motor vehicle taxes, and the collection of local taxes directed specifically for transit (Chan et al. 2003). The following is a case study of one such public transit system that found itself at the crossroads of having to make significant changes in order to continue offering high-quality and reliable transit services to the population it served. In 
many respects, this case study reflects the realities that are faced by several transit systems in small and mid-sized cities across the United States.

\section{Case Study Background}

In February 2003, a Pulaski County (Arkansas) judge, in conjunction with the mayors of Little Rock, North Little Rock, Maumelle, and Sherwood and the Central Arkansas Transit Authority (CATA) board president, sent a letter to the University of Arkansas at Little Rock (UALR) chancellor requesting that the university conduct an analysis of the adequacy of transit service provided by CATA. Their specific concerns focused on issues of affordability, maintaining standards of service, financing, governance, and future developments in regard to CATA.

In April 2003, the UALR chancellor convened a 10-member multidisciplinary task force comprising those with expertise in business, public administration, organizational design, engineering, finance, communication, social work, marketing, law, political science, and urban studies.

\section{Central Arkansas Transit Authority History of Structure and Governance}

From 1950 to 1972, the transit system in the Little Rock area was privately owned and operated. During this period, three private entities attempted to make a profit on transit operations and failed. A 1971 study recommended that the transit system shift to public ownership under the direction of a regional authority. Area leaders formed a transit policy board (Metroplan), made up of elected officials from Pulaski and surrounding counties, and in 1972 the Central Arkansas Transit Authority (CATA) began operations as a publicly-owned entity (Chan et al. 2003).

In 1986, Pulaski County, along with the cities of Little Rock, North Little Rock, Cammack Village, Maumelle, Sherwood, and Jacksonville (Jacksonville withdrew in 1987) entered into an Interlocal Agreement that established CATA in its current form. The agreement was deemed necessary because these local governments were being asked to infuse increasing amounts of money into CATA and wanted more of a say in the operations. Additionally, at the time it was determined that CATA was not being managed or supervised effectively as a transit operation (Chan et al. 2003). 
The Interlocal Agreement determined that CATA would be governed by a 13member board of directors whose members would be appointed for four-year, staggered terms by the six participating area governments that oversee CATA. Board membership is representative of the funding percentage by each participating government. As the largest financial contributor at the time of this study, Little Rock had five members appointed by the Little Rock board of directors, two of whom were City employees. Three CATA board members were appointed by the mayor of North Little Rock, one of whom was a City employee, and two were appointed by the Pulaski County judge, one of whom was a County employee. Finally, three board members were appointed by the mayors of the three additional communities that CATA served, one of whom was a City employee at the time of this study (Chan et al. 2003).

\section{History of Funding and Finance}

Until the 1970s, federal funds accounted for up to half of operating funds. Starting in 1984, funds were reduced, and then in 1990-1991 there was a total withdrawal of federal operating funds for public transit. CATA, along with transit authorities across the nation, was faced with the dilemma of finding alternative sources of funding. Among the options were taking a portion of highway revenues and applying them to local transit, creating a dedicated funding source, and/or creating a combination of state and local taxes, in addition to fares.

In regard to securing dedicated funding sources for transit, several states have gone to levying sales taxes (Las Vegas; New York City Transit; Mass Bay Transit, Massachusetts), property taxes (Bay Area Rapid Transit, California; New York City Transit), and fuel taxes (Metropolitan Transit, Tennessee; San Diego Transit). In regard to local dedicated funding sources for public transit, several cities have implemented sales taxes (Foothill Transit, Los Angeles County; Norwalk Transit, California), property taxes (Birmingham-Jefferson Transit, Alabama; Orange County Transit, California), and fuel taxes (Los Angeles County Metro; Washington DC Metro) (Federal Transit Administration 2006).

In CATA's case, funding at the local level was established by a mileage formula within the 1986 Interlocal Agreement. Contributions were based on revenue miles, resulting in Little Rock at 73.29 percent; North Little Rock, 18.64 percent; Pulaski County, 7.09 percent; and Maumelle, Sherwood, and Cammack Village all less than 1 percent. Due to operations and capital expenditures, the local governments grew from 1986 to 2002. During that time, Little Rock's appropriations to CATA grew from $\$ 2$ million to $\$ 4.5$ million in 2001. Fiscal crisis and deficits 
prompted reduced service in 2002 and 2003. At the time of this study, 78 percent of CATA funds were obtained at the local level, 20 percent were derived from fares (farebox revenue totaled $\$ 1.3$ million), and approximately 2 percent came from state revenues (Central Arkansas Transit Authority 2002).

Additionally, the ADA created unfunded mandates on local transit to provide door-to-door service for the disabled. A large proportion of funds was needed to equip buses for increased accessibility for those who had disabilities. Finally, tighter federal air emission standards required that CATA replace its fleet of buses to meet the new standards.

As a result of a funding crisis, in 1993 voters of Little Rock adopted a half-cent sales tax earmarked, in part, for public transit. This was a particularly important development, especially since CATA receives a small percentage of its operating budget from the State (Arkansas ranks last among all states in transit spending.). The increased tax revenue was distributed to the general funds of participating cities, where transit funds would compete with police, fire, and solid waste disposal services. During each yearly budgetary session, CATA was placed in the position of lobbying local government leaders for its share of the funds. CATA became engrossed in a year-to-year struggle to maintain even minimal transit services. As operating costs have increased dramatically over the past several years, this process had become quite contentious (Chan et al. 2003).

CATA responded to fiscal stress by reducing its staff (CATA had the smallest professional staff of all comparable systems studied) and cutting back service hours through route contraction. A reduction in service, along with the publicized budget battles, resulted in deterioration of the public's image of and trust in the public transportation system.

\section{Demographics, Current Operations, and Rider Profile}

At the time of this case study, CATA had 45 large buses, 10 small buses, and 18 vans in daily use. The authority provided 21 regular fixed-routes, 10 express routes, and paratransit services. CATA served 8,000 to 9,000 riders per day, of which almost 60 percent were employed full-time, another 15 percent were employed part-time, and 8 percent were students. Thus, 83 percent of CATA consumers were economically active outside the home or were students in preparation for work life.

CATA's standard of bus frequency, regardless of day or whether peak/off peak hours, is that there should be one bus every 30 minutes at designated stops. In 
2002, however, a number of weekday buses typically required more than 30 minutes to make the route.

The income of CATA riders was low, with 56 percent making less than $\$ 20,000$ a year. Those who had incomes between $\$ 10,000$ and $\$ 14,999$ represented the highest percentage of riders. Only 13 percent of riders reported income of $\$ 40,000$ or more. Those who used the bus seven days a week had lower incomes than those who used the bus five or six days a week. Seven-day riders were thus more transit dependent as a result of their low incomes. Seventy-two percent of riders were above the age of 31, and a large percent (73\%) were African American. More than 80 percent of CATA riders lived in households with no car (Central Arkansas Transit Authority 2002).

\section{Case Study}

\section{Participants}

Six bus riders and 53 public transit stakeholders (community leaders, CATA board/staff members, and area experts on public transportation) participated in the case study.

Public Transit Stakeholders. This group included Little Rock City board members, CATA staff and board members, area mayors, the executive director of Metroplan, the Little Rock City manager, and several area experts on transportation and the poor.

Experts on services to the poor included one executive director of a public service agency that works on behalf of the poor, three case managers from this same organization, and one executive staff member from the Department of Human Services.

Bus Riders. Riders who took part in this case study comprised daily consumers of CATA. They included underrepresented minorities, those economically disadvantaged who were currently employed, and long-time users of the CATA system. Participants in this group included two men and four women. There were four African Americans and two European-Americans. Two members were daily bus rides at the lower end of the economic scale (working class at a service industry pay scale). Four participants had physical disabilities, were enrolled in programs at Goodwill, and were receiving assistance to help them become more independent and self-reliant through job training, job placement, or life skills development. 


\section{Data Collection}

Information for the case study was collected over a period of five months. The task force reviewed previous reports and surveys that involved CATA and its operations, conducted structured interviews, and performed an analysis of CATA and its operations compared to other transit systems in comparable-size cities. Participants were interviewed either face-to-face or within the context of a small group. A set of structured interview questions was developed by task force members to achieve uniformity in information and to assure that important themes were adequately captured by all participants who were interviewed.

\section{Findings and Recommendations}

Findings from this case study were organized into three separate categories: (1) funding and structural factors, (2) governance, and (3) operational conditions.

\section{Funding and Structural Factors}

A consistent theme that emerged from the case study was the funding crises in public transit. At the time of this case study, CATA was struggling to meet its already-reduced services and had no anticipated funds to expand services in needed areas. From its findings, the task force recommended two strategies: (1) seek additional funding for current operations by securing a countywide hotel/ motel lodging tax of $\$ 1$ per bed per night and (2) mount a campaign to pass a countywide, one-fourth cent sales tax dedicated to transit in the area. It was anticipated that such funding would act to secure a dedicated funding source for CATA and put an end to the yearly budget battles. Such funds would then allow CATA to not only fund its current operations more predictably and autonomously, but also would allow the operation to grow and develop as a public system. Ending the yearly budget battles, which are publicized, would create conditions where CATA could begin to rebuild its public image as a reliable transportation alternative.

\section{Governance}

A common theme that emerged from the interviews with those familiar with the structure of the CATA board was that its composition was problematic. The current structure of having City and County employees occupying key positions on the CATA board was perceived by participants as being a conflict of interest. Several participants believed that the current structure focused more on the status quo of service delivery and was more maintenance versus leadership oriented. From these findings, the task force recommended that City and County employ- 
ees should not serve as CATA board members. Instead, it was recommended that the board be restructured to include a mix of elected officials and other residents who have no major governmental or public agency affiliation. The task force anticipated that this change in composition would build a more independent and more regionally focused board that could effect change (Chan et al. 2003).

The case study also found that transit in Central Arkansas had outgrown the conditions present when the 1986 Interlocal Agreement was formed. The task force recommended that, in its place, a Regional Transit Authority be established. The authority would be governed by a board consisting of the mayors and the county judge. The Interlocal Agreement would create a legal entity separate from the previous jurisdictions. The authority would have the power to issue revenue bonds, but would not have an independent authority to tax. The Regional Transit Authority would be responsible for operating a transit system that satisfies the basic needs of equity, accessibility, and special needs, as well as for planning economic development, land use, and work access that is securely connected to transit. Decisions regarding transit would not be made in isolation, but rather as an integrated part of regional development (Chan et al. 2003).

\section{Operational Conditions}

Findings from this component of the case study were obtained primarily from bus riders and local experts on transportation and the poor. Both riders and experts perceived a lack of adequate service for those working shifts and nontraditional work hours in locations where no public transportation is available or is limited.

All the participants in this group were aware that major growth was occurring in the western region of the city where bus service is limited. In many instances, social service providers and case managers had little trouble getting jobs for their clients, but had great difficulty getting them to and from these jobs. Bus rider participants expressed overall distrust in public transit. They were acutely aware of services being cut and had no confidence that the routes they currently relied on, most particularly on weekends, would continue. Other barriers to adequate transportation expressed by riders were not living near a bus route, limitations in the number and frequency of routes, limitations in the hours and days of operation (limited on Sundays), and difficulty in trip chaining.

Based on these findings, the task force recommended that a reverse-commute service be added to assist those dependent on transit to reach work in suburban fringe areas. The task force also proposed expanded paratransit services for dis- 
abled riders and urged CATA to begin working with major employers to attract and retain employees who rely on public transit. A cost feasibility analysis would be needed to justify the implementation of these recommendations.

\section{Outcome of the Case Study}

On September 27, 2005, the Metroplan board of directors approved a final draft of METRO 2030, the region's federally mandated long-range transportation plan. METRO 2030 was built on previous efforts that produced METRO 2020 in 1995 and METRO 2025 in 2000. The policies put forth in METRO 2030 represent a series of strategies that determine the region's planning and transportation direction. In regard to public transit, the plan recommended that new funding sources be identified and developed with the goal of doubling the size and service of the bus transit system. Longer range plans included bus rapid transit, light rail, or commuter rail systems. The plan also called for proposals for dedicated local funding for transit projects. METRO 2030 recommended retaining current fixed routes, adding more routes, increasing frequency of routes, extending express service from Little Rock to West Little Rock, extending service hours, and providing Sunday service. The plan also included expansion of paratransit services over the planning period. In addition, during the planning period, funding for CATA would increase from $\$ 307$ million to $\$ 758$ million. The additional $\$ 451$ million represents $2-1 / 2$ times more service and service hours when compared to existing transit service. The additional funding is expected from a .25 cent local option sales tax levied in Pulaski County within the first five years of the plan. Such a strategy would require the referral of the tax to voters by the Pulaski Quorum Court, in addition to a successful campaign to gain voter approval (Metroplan 2005).

\section{Conclusions}

It is axiomatic that the success of an assessment on any organization and the services it provides lies in the utilization of its recommendations by its stakeholders. The findings and recommendations from this case study were presented to all the stakeholders mentioned above and to the general public. It was encouraging to find that several of the central recommendations (primarily around service delivery and funding) were reflected in Metroplan's METRO 2030 final draft.

As evidenced in this case study, no single solution will solve the problems related to public transit. Public transportation has become, in most metropolitan areas, 
conceptualized as a social service for the poor. To be productive participants in society, those who are economically disadvantaged must have access to reliable transportation that gets them to and from work every day. There is increasing pressure placed on those who rely on government subsidy to seek employment, and there are significant barriers to getting and keeping jobs for the poor. As these pressures mount, it is imperative that communities work toward improving the reliability and availability of public transportation. Any effort toward significant and lasting change must involve the entire community in a coordinated effort that focuses on several factors simultaneously. In an effort to bring about substantial change in services to the poor, organizations, such as the one presented in this article, must be assessed in such a way that considers the complex array of internal and external factors that impact that particular organization and the services it provides.

\section{Acknowledgments}

The first two authors were members of the transportation task force that assessed the Central Arkansas Transit Authority. The authors would like to thank the other task force members: Rolf T. Wigand, David Sink, Trent Shaskan, Janet M. Roderick, Clay Robinson, Jim Lynch, Marsha Guffey and Yupo Chan.

\section{References}

Brabo, L. M., P. H. Kilde, P. Pesek-Herriges, T. Quinn, and I. Sanderud-Nordquist. 1997. Driving out of poverty in private automobiles. Journal of Poverty 7 (1/2): 183-196.

Chan, Y., M. Guffey, K. Jones, J. Lynch, R. Mock, C. Robinson, J. Roderick, T. Shaskan, D. Sink, and R. Wigand, R. 2003. A call for regional leadership: Public transit in central Arkansas. Little Rock, AR: University of Arkansas at Little Rock.

Central Arkansas Transit Authority. 2002. Central Arkansas transit authority surveys: Onboard survey (Part II). Little Rock, AR: Central Arkansas Transit Authority.

Federal Transit Administration. January 2006. http//www.fta.dot.gov.

Larwin, T. F. 2005. Transit planning for the 21st century. ITE Journal 75 (8): 1-16.

Metroplan. 2005. METRO 2030. September. http//www.metroplan.org. 
Perry-Burney, G. D., and A. Jennings. 2003. Welfare to what? A policy agenda. Journal of Health and Social Policy 16 (4): 85-99.

\section{About the Authors}

KıM A. JONES (kajones@ualr.edu) is an associate professor in the School of Social Work within the College of Professional Studies at the University of Arkansas at Little Rock.

ROBERT C. MOCK, JR. (rcmock@ualr.edu) is the director of Office of Recruitment \& Retention at UALR.

SARAh T. Cearley (stcearley@ualredu) is an assistant professor in the School of Social Work within the College of Professional Studies at UALR. 
Journal of Public Transportation, Vol. 9, No. 4, 2006 


\section{Total Quality Transportation Through Deming's 14 Points}

Bhimaraya A. Metri, Management Development Institute, India

\section{Abstract}

Transportation organizations, particularly public transport corporations, have not followed the lead of manufacturing or other service industries in adopting Total Quality Management (TQM). In recent years, quality has become an important competitive strategy in the global market. In near future, due to World Trade Organization agreements, globalization, and competitiveness, transport organizations have no choice other than adopting TQM for their survival.

This article presents a background on TQM and addresses the imperatives of using this strategy in transport organizations. The article examines total quality transportation (TQT) and its organizational structure and implementation model in relation to Deming's 14 points. The model presented in this research provides enhanced tactics for transportation quality and customer satisfaction.

\section{Introduction}

There is a great demand for transport facilities to meet the burgeoning needs of economic and social development (Zhang and Kumaraswamy 2001). In many developing countries including India, regional transit routes are operated by government agencies (Kalaga et al. 2001) and transport corporations (either state or municipal) to provide bus services in regional routes/metropolitan cities. Many transport systems in metropolitan cities of developing countries are facing pressure due to heavy immigration and increased industrial and commercial activities 
(Shrivastav and Dhingra 2001). A study carried out by Shrivastav and Dhingra (2001) revealed that the limited capacity of public road transport has led to an enormous increase in the use of private and intermediate transport services. Moreover, in many instances, public transport services are not coordinated with other modes, resulting in commuter dissatisfaction due to delays, longer journey times, poor levels of service, high vehicle operating costs, and environmental pollution. Given these circumstances, the research presented in this article suggests that, to improve customer satisfaction, public transport systems must offer more efficient services. The growing attention given to the role of public transit as a part of the transportation system creates an increasing need for transport agencies to measure and monitor the performance of the services they provide (Boile 2001). Boile (2001) called upon transport agencies to measure their performance in terms of accessibility, safety, mobility, financial effectiveness, and service efficiency. The best way to meet the needs of today's transport agencies is to replace the traditional Taylor approach with Total Quality Management (TQM). The transitions associated with implementing TQM are not always easy, smooth, or orderly. But, since the world is changing, transportation organizations do not have a choice; they must make a commitment to challenge traditional approaches or face obsolescence (Rubach 1995).

Many transport agencies still labor under the remnants of the departmentalized Taylor approach, in which some employees plan improvements, others carry out the work, and still others inspect the projects to determine whether procedures and results are correct. In contrast, under TQM, all employees commit to improving the quality of the organization's service so that customer needs are not only met but also exceeded.

\section{Background of TQM}

TQM is a structural system for creating organization-wide participation in planning and implementing a continuous improvement process that exceeds customer expectations. The Japanese concept of total quality control has come to be known as TQM. The name "Total Quality Management" was coined by the U.S. Navy in 1985 (Walton 1993). Since then, TQM has been widely used in various organizations, particularly in the manufacturing industry. Today, a variety of models are available to transform a current enterprise into an organization focusing on TQM. The foundations of TQM are rooted in the teachings of Dr. W. E. Deming (Burati et 
al. 1991). His 14 points model, which has been practiced successfully in Japan and the United States (Walton 1993), is considered here for the transport industry.

\section{Total Quality Transportation}

The term Total Quality Transportation (TQT) is used instead of TQM to shift attention away from preconceived notions of TQM and to focus on the commitment to provide quality transport service, promote learning skills, and encourage pride in workers' efforts to deliver service. TQT users subscribe to a customer-oriented transport service philosophy of continuous improvement that involves

- commitment to meet or exceed customer requirements,

- participation by critical mass of stakeholders,

- using statistical tools for analysis,

- continuous review of processes,

- exercising strong quality leadership,

- providing training and retraining programs,

- safety improvement,

- analysis of current performance,

- green transport system, and

- meeting local needs and regulations.

\section{Deming's Approach to TQT}

Deming's approach to TQM utilizes a 14-point process to create an organizational environment in which statistical methods will be effective. The 14 points are intended to create strong management commitment to quality, process design, and control through statistical tools, continuous search for and correction of quality problems, and a purchasing policy that emphasizes quality rather than cost. Further, this model is designed to remove all barriers to employee participation and teamwork. It stresses effective communication between supervisors and employees, elimination of numerical goals and quotas for employees, and company-wide training and education. This model also addresses the importance of product design and quality information systems. Deming's 14 points for TQT are described below. A graphical representation of the proposed model is presented in Figure 1. 


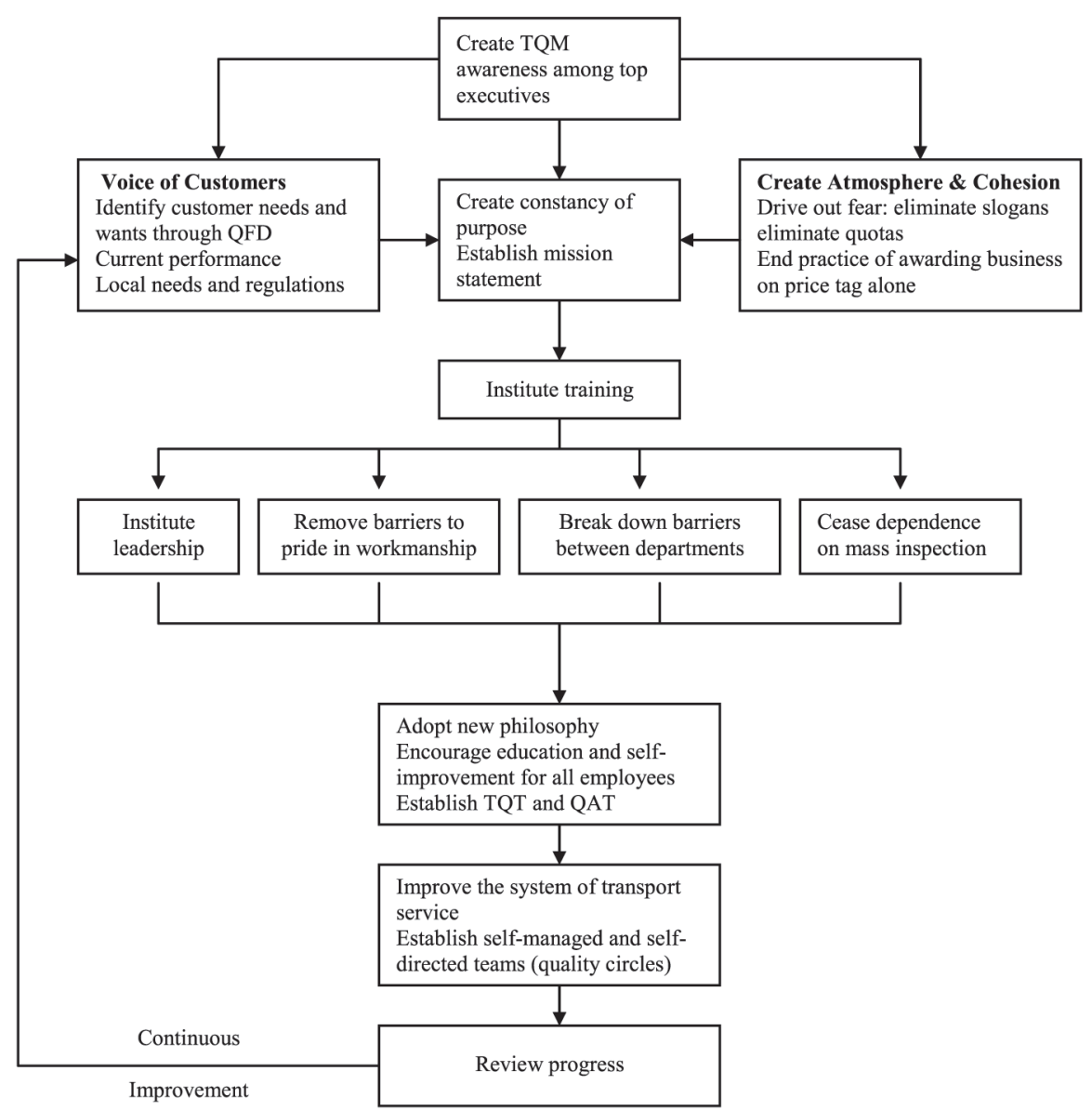

Figure 1. Proposed Model for Implementation of TQT

\section{Create Constancy of Purpose}

The customer is the most important part of transport service. Customer demands are always changing. It is mistake to presume that services offered at present can keep an organization solvent and ahead of competition. The transport agency must create a constancy of purpose by putting the customer first.

The transportation organization's highest priority must be to provide the best transportation services to its community at the lowest cost possible. The organization is responsible to both its community and its own workforce in maintaining a 
high level of excellence and value. Therefore, the transportation organization must strive to maximize efficiency and effectiveness through constant improvement.

To create a constancy of purpose necessitates the development of a mission statement for the transport corporation. The plan-do-check-act (P-D-C-A) cycle allows the statement to evolve as customer demand grows and changes. This flexibility permits innovation, which is achieved by putting resources into research, education, and maintenance of the transport system. Innovation generates new and improved services. For example, use of electric- and gas-based vehicles can reduce pollution in urban areas (Shridharan 2002). The corporate sector should lobby for electric-and gas-based vehicles for urban areas. A real concern is the availability of a wide network of service stations supplying gas or replacing discharged batteries with charged ones. Gas and battery industries can work together with the automakers industry to provide solutions with sustained business opportunities for themselves.

\section{Adopt New Philosophy}

In today's economic age, businesses cannot survive with commonly accepted levels of mistakes, defects, people on the job who do not understand the job and are afraid to ask questions, and management's failure to understand problems within the corporation.

Acceptable defective services and poor work performance are among the most severe roadblocks to better quality. Everyone working in a transport corporation can find ways to promote quality and efficiency, to improve all aspects of the transportation system, and to promote excellence and personal accountability. Employees, with the support of top management, should adopt a new work philosophy by meeting in cross-functional teams or quality circles to set priorities for staff training. The major benefit of the new philosophy is the creation of a continuous learning environment. The common thread in adopting a new philosophy is meeting the needs of those who pay for and use the services provided by the transportation organization.

\section{Cease Dependence on Mass Inspection}

Lasting quality comes not from inspection, but from improvements in the system. To achieve best economy and productivity, transport agencies should know what quality they are delivering. The organization's managers must be knowledgeable in the statistical control of quality. They must proceed under the new philosophy: the right service quality characteristics must be built in without dependence on 
inspection. The statistical control of the process provides the only way for transport operators to build quality service and the only way to provide managers evidence of uniform, repeatable quality and cost of service. One of the first steps for managers is to learn enough about the statistical control of quality to access the qualification of an operator by talking with them in statistical language.

\section{End the Practice of Awarding Business on Price Tag Alone}

Today's requirements for transport service suppliers are uniformity and reliability. Price has no meaning without a measure of quality. Without adequate measures of quality, business drifts to the lowest bidder, low quality and high cost being the inevitable results. Instead, the organization should seek the best quality in a long-term relationship with a single supplier for only one item. The results of implementing this strategy are longer lasting items and greater quality service at no additional cost. Transport agencies should select suppliers that can provide statistical evidence of quality. Since transport organizations tend to think of their suppliers as "partners" in their operations, they must consider joint planning for improvement and joint improvement activities to serve customers better than their competitors.

\section{Improve the System of Transport Service}

Quality can be built into all transportation activities and services and can be assured by continuous examination to identify potential improvements. This requires close cooperation between those who provide the services and those who consume them.

Improvement is not a one-time effort. Management is obligated to look continually for ways to reduce waste and improve quality. Every worker and every department must commit to constant improvement. Quality circles/cross-functional teams work together to improve transport service delivery. These groups may use basic quality tools to identify issues that need attention. For example, which faults are local and which ones belong to the system? The responsibilities should be given where this fault belongs. The use of statistical quality tools helps to identify trouble spots and their sources. Quality circles/teams continuously work to meet the needs of the people they serve, resulting in lower costs and improved quality of transport operations and services. Thus, improved transport service can result from focusing not only on achieving present performance levels, but more importantly, by breaking through existing performance levels to new, higher levels. 


\section{Institute Training}

Quality circles help the human resource division to select training programs that increase the job skills of both main and support staff. Training must be totally reconstructed. Statistical methods must be used to learn when training is finished and when further training would be beneficial. On-the-job quality improvement training ensures that every employee has a thorough understanding of customer needs for transport services.

\section{Institute Leadership}

The leader creates opportunities for all employees (good and bad performers) to interact and identify opportunities for improvement. The job of supervisor is not to tell employees what to do or to punish but to lead them toward better job performance. Leading consists of helping workers do a better job and of using learning by objective methods for those employees in need of individual help. Supervisors should be trained continually. They should receive training in synergetic or cooperative supervision and work in supportive teams to improve instructions and learning. Leadership training will help to introduce new best practices in transportation services to satisfy customer needs.

\section{Drive Out Fear}

Improved performance cannot occur unless employees in the transport organization feel comfortable to speak truthfully and feel confident that their suggestions will be taken seriously. Most workers are afraid to ask questions or to report trouble. Suggesting new ideas is risky; people fear punitive assignments or other forms of discrimination or harassment. To counter this fear, total quality encourages applying new methods, creating new solutions, and implementing innovative experiments. The economic loss from fear is appalling. To ensure better quality and productivity, employees must feel secure. In a secure environment, workers are not afraid to express ideas not afraid to ask questions, not afraid to ask for further instructions, and not afraid to report vehicles out of order, poor lighting, or other working conditions that impair quality service in transportation.

\section{Breakdown Barriers Between Departments}

According to Deming, people can work superbly in their respective departments, but if departmental goals conflict, the company could face ruin. Lack of coordination or disintegration between departments can lead to costly rework, unnecessary duplication of effort, and a heavy loss in resources. 
Quality Function Deployment (QFD) and quality circles improve cross-communication and encourage brainstorming among members of the transport organization. QFD helps to capture the "voice of the customer" and convert it into service design requirements. This strategy is not only a powerful tool for integrating departments of the transportation organization, but it also strongly promotes the principle of "do it right the first time" (Srividya and Metri 2000). Sharing a unified purpose and direction helps to improve the transport organization's services.

\section{Eliminate Slogans, Exhortations, and Targets for the Workforce}

Slogans, like those encouraging zero accidents or zero defects, and posters reinforcing the slogans do not help workers do a better job. Slogans, posters, and other such devices are management's lazy way out. A better approach is to provide the means to the desired ends. For instance, the transportation staff prevents waste and reduces accidents by managing its own quota-free environment. If the transport organization's focus is on improving its work processes, service quality will increase, efficiency and effectiveness will rise, and nonvalue-added activities will diminish.

\section{Eliminate Numerical Quotas}

Numerical quotas will not help workers do a better job. In fact, numerical quotas cost as much as loss in terms of poor materials and mistakes. In many factories at the end of the day, workers are idle the last hour or two. They have completed their quotas for the day and are waiting for the whistle to blow; they do no more work yet they cannot go to home. Numerical goals can even produce a negative effect because they generate frustration. Therefore, the quota system will not help the organization's competitive position or contribute to continuous improvement.

Instead of numerical quotas, hard work, pride, service, and growth should be emphasized. Removing quotas encourages employees to apply new ideas to old tasks. For instance, bus transportation schedules and stop locations are now planned to meet the community's needs. The goal is to fulfill the needs of the community, not to increase the number of people transported.

\section{Remove Barriers to Pride of Workmanship}

The transport industry cannot function properly without employees who are proud of their output and who feel respected as individuals and professionals. For example, inspection simply identifies defects but does not explain how to prevent them. Intrinsically, people want to provide service without defects. Leadership and continuous system improvement make this possible. To achieve pride in 
work, superiors must listen to the transport staff/employees and transport staff must listen to the recipients of their service (i.e., the community). Often, staff and community do not have the same knowledge base or purpose of work. Communicating the organization's mission and achieving respect among the staff and the community is one of the greatest challenges facing transport organizations.

\section{Encourage Education and Self-improvement for All Employees}

The transport organization needs not only good people, but people who are growing through education and life experiences as well. Both management and employees must continuously acquire knowledge to be of service to the community. They should be educated in new methods, including teamwork and statistical techniques. For instance, transport employees may receive training on ISO 14000 for providing environmental-friendly transport services to the community.

\section{Take Action to Accomplish Transformation}

The essence of TQT is an organization-wide focus on meeting the needs of those who use and/or pay for transport services. Every activity, every process, and every job in the transport organization can be improved. Everyone within the organization can be given an opportunity to understand the TQT program and their individual role within that effort. Improvement teams that include broad representation throughout the organization can help ensure success of initial efforts and create opportunities for cross-disciplinary dialog and information exchange.

Implementation of Deming's 14 points requires a special top management team, such as a quality council, with a plan of action to carry out the transport agency's quality mission. Workers or managers cannot accomplish this on their own. A critical mass of people in the organization must understand the 14 points. The critical mass would be formed from top down along the organizational hierarchical lines (Figure 2), and those involved would announce and define the new quality philosophy. Management teams called quality councils should take charge of changes in the system. They would be responsible for identifying and assigning the critical processes to the process quality teams (PQTs). In turn, the PQTs would direct the activities of the quality action teams (QATs). The QATs would focus on the critical issues, yielding some immediate results to show that TQT has worked. This tactic would help to strengthen and continue TQT in the transport organization.

At the same time, management would create a quality and cohesive environment and would also address such systematic issues as forging a new relationship with 
suppliers, doing away with the performance appraisal system, and introducing the "voice of customer" into all operations.

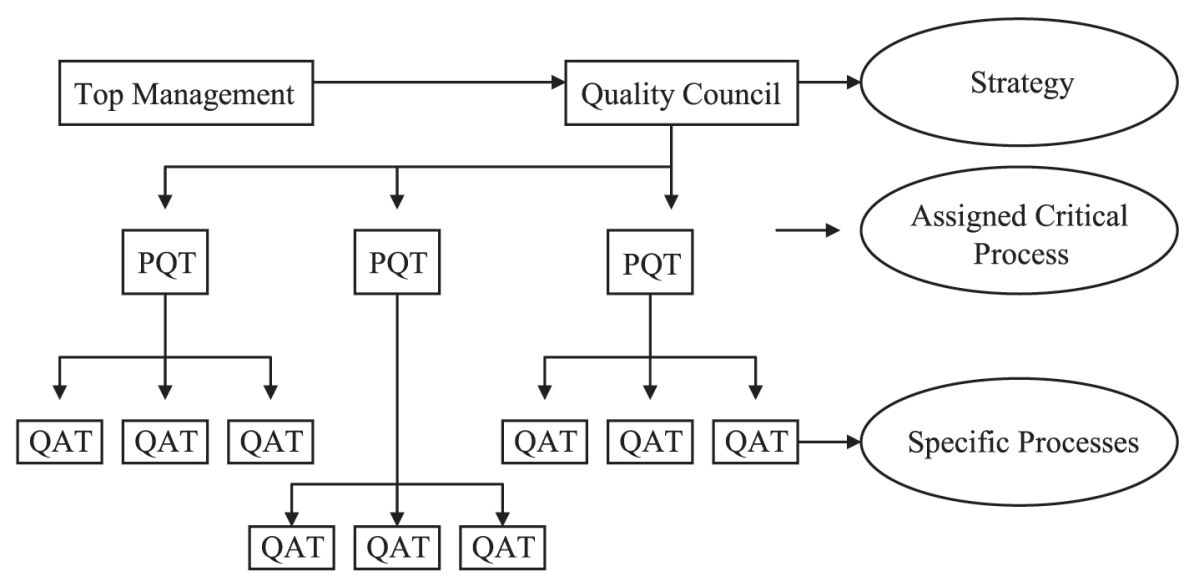

PQT: Process Quality Team QAT: Quality Action Team

\section{Figure 2. Organizational Structure for TQT}

\section{Conclusions}

This article has addressed the importance of TQM for transportation organizations. Total Quality Transportation (TQT) has been defined and Deming's 14point model has been presented for aiding TQT implementation. An organization structure and an implementation model have been proposed for immediate results of TQT and its successful implementation. The model is designed to guide top management in adopting TQT in their organizations.

Traditionally, transport organizations have been slow in adopting modern quality tools and techniques. Because of World Trade Organization agreements, in the near future, competitiveness will increase the demand for delivery of quality service in the transportation industry. TQT is a powerful strategy for improving quality. Due to global economic conditions, transportation organizations are at a crucial phase. Adoption of TQT is critical in helping organizations survive and compete in the growing international transport market. 


\section{References}

Boile, M. P. 2001. Estimating technical and scale inefficiency of public transit system. Journal of Transportation Engineering 127(3): 187-194.

Burati, J. L., M. F. Mathews, and S. N. Kalanidhi. 1991. Quality management in construction industry. Journal of Construction Engineering and Management 117(2): 341-359.

Kalaga, R. R., R. N. Datta, and S. K. Reddy. 2001. Allocation of buses in interdependent regional bus transit routes. Journal of Transportation Engineering 127(3): 208-214.

Rubach, L. 1995. Total quality forum VI speakers focus on changes. Quality Progress 28(2): 45-50.

Shridharan, L. 2002. Providing infrastructure needed: Paradigm shift in thinking. Yojana 46(2): 16-18.

Shrivastav, P., and S. L. Dhingra. 2001. Development of feeder routes for suburban railway stations using heuristic approach. Journal of Transportation Engineering 127(4): 334-341.

Srividya, A., and B. A. Metri. 2000. Improving reliability of building design using QFD approach. The Indian Concrete Journal 74(5): 249-253.

Walton, M. 1993. Deming management at work. New Delhi: Viva Books Private Ltd.

Zhang, $X$, and M. M Kumaraswamy. 2001. BOT-based approaches to infrastructure development in India. Journal of Infrastructure Systems 7(1): 18-25.

\section{About the Author}

BhimarayA A. MetrI (metri@mdi.ac.in) is associate professor of operations management at the Management Development Institute, Gurgaon, India. He holds a Ph.D. in quality management from the Indian Institute of Technology, Bombay. Dr. Metri's interests deal with total quality management and project management. He has published a number of papers in scholarly journals in the area of quality management. He is on the editorial board of the Journal on Consultancy. In addition, Dr. Metri supervises postgraduate research activity at the Ph.D. level. He has provided training/consultancy to several organizations in the areas of TQM, and he 
Journal of Public Transportation, Vol. 9, No. 4, 2006

has worked as a team member of the Principal Technical Agency (PTA) for PMGSY, Rural Road Projects in India. 


\title{
Tracing Individual Public Transport Customers from an Anonymous Transaction Database
}

G. Tseytin, International Business Machines, Rational Software, California M. Hofmann, M. O'Mahony, and D. Lyons, Trinity College, Dublin, Ireland

\begin{abstract}
Data mining concepts are used frequently throughout the transportation research sector. This article examines the concept of the market basket technique as a means of gaining more insight into public transport users' demands. The article proposes a method that uses various data attributes of passenger records to infer the same customer in a different week (i.e., attempts to track the same customer from week to week). The general idea behind the measure is that if two records are considered similar, ideally every trip in one customer record should have a close counterpart in the other record. The research develops a similarity function designed to maximize the percentage of positive ticket identification over a number of weeks. Once similarity has been established, customer travel patterns can be useful in helping the operator identify new routes, new timetables, and strategic decisions in relation to satisfying public transport customer demands.
\end{abstract}

\section{Introduction}

This study is in response to the suggestion from McCarthy (2001), who argued that regular customers of a supermarket might be recognizable from patterns of their choices registered in Electronic Point of Sale (EPOS) data, and that this would help determine their long-term histories and behaviors (Chen et al. 2004). Obviously, 
it depends on the range of options available for each customer and on the total number of customers (e.g., in the case of a fast food restaurant offering five types of sandwiches and five types of drinks and servicing 1,000 persons daily, it may be difficult to recognize a person by his or her pattern of choices).

An attempt is made here to trace individual customers from an anonymous transaction database. The aim is to infer relations of passenger behavior that have not been noticed or at least have not been confirmed previously. Finding potential relationships among the entities that are not directly represented in the data are considered to be as important as relationships of entities that are directly represented in the data. For example, can the travel patterns of bus passengers tell us about their work routine, shopping, or spare time behavior? Mahmassani (1997) elaborates on the importance of the dynamics of commuter behavior and provides an overview, focusing on day-to-day dynamics.

The main focus of this article is to develop a method that facilitates finding record sets of routine passengers, which then can be used to further analyze passenger behavior and dynamics. The article provides a brief background of the research project and elaborates on the dataset used as an input source. A novel method that measures similarity between passenger records is then introduced. Finally, the article presents the results after applying the method to a subset of the entire data source.

\section{Overview}

In this study, magnetic strip card tickets from a public transport operator are considered. The operator provides bus services in a medium-sized European city. Train services are provided by another organization within the same group of companies. There is a predominant arterial movement of public transport services toward the city center in the morning peak periods, satisfying a well-recognized demand, and out of the city in the evenings. The tickets are issued by the public group of companies, of which the operator is one. There was no competition in the market at the time of data collection for this research, either from other bus companies or other modes such as rail.

This type of ticket is generally the primary source of passenger data (Boyle 1998). Wayfarer has manufactured the registration system used by the operator. A magnetic strip card reader at the entrance of a bus verifies a ticket; its serial number is copied into the internal memory of the device, and then onto a magnetic tape. 
Other events registered on the same tape are the start of a bus journey and arrival at a specific stage (stages are selected bus stops); random stops between stages are not registered. The date and time of day, type of ticket, and route number are registered along with these events. Further, the data from every bus are copied into the transactional database.

Although there are many different types of prepaid magnetic card tickets, we will consider only weekly types (valid for a single week, starting on Sunday) and monthly types (valid for one calendar month). Within a week, a customer is not anonymous because all trip records for the same customer carry the same serial number of the ticket. All such trips taken together are comparable to a basket of items bought from a supermarket in a single visit. But, in the next week, the same customer, who is expected to use the same type of prepaid card, will have a different serial number. The question is whethercan be identified weekly ticket users from different weeks by analyzing their trip patterns.

The segmentation of the permanent stored data is on the transactional level; that is, data are stored permanently for each passenger boarding (Furth 2000). This applies regardless of whether the passenger pays with cash or has a prepaid magnetic strip card. Each piece/attribute of data is recorded as a 20-character string stored in ASCII text form. Data for a single day varies from 3 to $6 \mathrm{MB}$, depending on whether it is for a weekday, weekend, or public holiday. The file for each day averages roughly 74,000 pre-paid ticket validations.

Monthly tickets, largely similar to weekly tickets, provide an opportunity to verify whatever techniques we propose for customer identification, because they retain the same serial number throughout the month. Of course, we have to exclude weeks spanning two months, which leaves us with verification material for three (sometimes four) consecutive weeks. This article presents the results obtained for weekly portions of customer records for monthly ticket types, where the accuracy of the results can be evaluated from known customer identities. Evaluation of the same techniques for weekly types will be discussed as a separate problem.

\section{The Data}

The general course of processing is as follows. The "raw" data from a number of daily files are scanned sequentially. Dates and times of day contained in the records for the start of a bus journey and for the arrival at each stage are propagated to ticket records, along with the route number, direction number ("0" or 
"1"), and stage number (unique bus stop ID). Some corrupt data can be rejected at this stage. The type of every ticket is examined, and only tickets of selected types go to further processing. The enhanced ticket records are then split by weeks, and, finally, the week files are sorted by customer numbers (the ticket type is treated as part of the customer number), whereby they can be split into weekly records of individual customers. A weekly record consists of a sequence of trips; each trip is documented by day of the week, time of day, route number, direction number, and stage number. There is no information about where the customer alighted. The average number of trips per week per passenger is approximately 13 .

The next step is to convert the route and stage data to geographical coordinates so we can see for any two trips if they started at close locations or not. Geographical coordinates of each stage (there are approximately 1,000 stages) are known. From the direction of the trip (one of the two alternatives), we can derive the list of stages ahead of the boarding stage and approximate the intended direction of the customer. Some very short weekly records (three or fewer trips per week), as well as some considered corrupt (too quick a movement between geographically remote points), have been excluded. Thus, the objective of this study is to determine whether customers can be identified by their weekly "baskets," each containing about 13 trips starting from a choice of about 1,000 locations.

Figure 1 shows the contents of a sample basket from the week starting December 6, 1998, ticket type 691 (Weekly Student City zone) and ticket number 6197. The columns show the day of the week, time of departure, stage coordinates in meters, and stage name (typically, the error in the coordinates is within 50 meters, which is sufficient to enable identification of a particular bus stop).

Figure 2 shows another basket, starting December 13, with the same ticket type 691 but a different ticket number 6201 . This basket was chosen to be similar to the preceding basket displayed in Figure 1, and it is a plausible hypothesis that it was the same person in both cases. However, there is no way of verifying the hypothesis because tickets of type 691 are only valid within a week. This why in the following discussion we concentrate on monthly types where the serial numbers provide a clue.

Table 1 shows the ticket types considered. The numbers given for issued tickets represents the number of customers, after the filtering, for one sample week, starting September 6. 
1 18:10 (315103,236331) Stop A 2 10:49 (313271,238298) Stop B 2 17:48 (315103,236331) Stop A 3 10:18 (313274,238771) Stop C 3 13:45 (314876,235889) Stop D 3 14:03 (315914,234568) Stop E 3 18:05 (316801,231620) Stop F 3 18:52 (315759,235769) Stop G 4 10:31 (313272,239125) Stop H 5 10:01 (313520,238632) Stop G 5 17:55 (315103,236331) Stop A 6 10:23 (313272,239125) Stop B 6 20:21 (312888,240248) Stop I

\section{Figure 1. Sample Basket of Ticket \# 6197}

1 10:27 (313274,238771) Stop B 1 18:01 (315103,236331) Stop A 2 10:34 (313274,238771) Stop C 2 18:04 (315103,236331) Stop A 3 10:31 (313274,238771) Stop C 3 20:41 (313274,238771) Stop C 3 23:11 (315899,235067) Stop J 4 10:35 (313271,238298) Stop B 4 18:08 (315103,236331) Stop B 5 10:36 (313274,238771) Stop C 6 10:32 (313272,239125) Stop C 6 11:19 (314876,235889) Stop D 6 12:17 (315914,234568) Stop E 6 17:35 (315103,236331) Stop B

\section{Figure 2. Sample Basket of} Ticket \# 6201

Table 1. Ticket Types

\begin{tabular}{|ccc|}
\hline Ticket Type & Description & Issued Tickets \\
\hline 433 & Monthly Adult Short Hop Bus/Rail & 622 \\
457 & Monthly Student Short Hop Bus/Rail & 1216 \\
705 & Monthly Adult City zone (Airings...) & 397 \\
710 & Monthly Adult Travelwide & 160 \\
\hline
\end{tabular}

Unfortunately, most popular weekly ticket types have more customers (e.g., type 671, Weekly Adult City zone, has about 9,000 customers weekly). Hence, customer identification for those types is far more difficult than in the cases with known answers. 


\section{Measuring Similarity Between Customer Records}

The simplest idea for finding the same customer in a different week is to define a measure of similarity between two customer records and then to look for the best match for a specific customer record. The general idea behind the measure is that if two records are considered similar, ideally every trip in one customer record (denoted by $R$ ) should have a close counterpart in the other record (denoted by $R^{\prime}$ ). The idea of identifying similarity between customers was used prior to this work in the retail sector, but this is the first time it has been used on public transport magnetic ticket data and on public transport customers. Of course, we then have to define which single trip is considered similar to which other trip; a trip being defined by the starting location, direction, and time of day (we ignore day of week for the time being) should be defined in terms of closeness of the components. If the closeness were defined as a Boolean function with only two values, we could solve a discrete task of assigning to each trip in $R$ a close trip in $R^{\prime}$ (a sort of assignment problem). Using a fuzzy approach, each trip in $R$ is matched with each trip in $R^{\prime}$, producing a numeric value. This value will be high for similar trips and close to 0 for differing trips. If we add together the values for all pairs, only the pairs with a good match will contribute significantly to the sum. So, the higher the sum, the better the match.

The similarity function is defined in several stages:

- Defining the weight of a trip

- Estimating the direction vector of a trip

- Comparing two trips from different customer records

- Consolidating data per starting location

- Symmetrization

- Defining scaling factors

Some of the stages were added during experiments, but no estimation was made of the effect of every single improvement, although the general impression was that each of them improved performance slightly.

\section{Defining the Weight of a Trip}

There are two reasons to ascribe different weights to trips. One is that a trip is regarded not as an independent choice of the customer, but rather as a completion of the preceding trip because the customer had to change buses. This can be decided on the basis of the time elapsed since the previous boarding and the 
distance between the two locations. Distances are computed just as Euclidean distances, without reference to streets of the town or barriers such as railways, rivers, and canals. The estimation of the probable speed takes account of early morning and late evening hours when speed is higher because traffic is low, as well as of special express routes with few intermediate stops (recognized by route number); the estimated ratio of "town distance" to Euclidean distance is included in the constants used.

If the distance estimated from the time interval between the two boardings and the estimated speed turns out to be less than actual (Euclidean) distance, the weight of the trip is decreased by multiplying it by the ratio of the two distances.

The other reason for weighting is frequency of stages. A rarely used stage should contribute more to the differentiation of customers than a more popular stage (e.g., a location in the center of the town). The weight factor reflecting this is taken to be proportional to the negative logarithm of the stage frequency (the intuition behind this function is that in other tasks, based on the maximum likelihood principle, logarithms of frequencies have to be added together-no other serious reason, but a function with a similar behavior has to be chosen in any case).

\section{Estimating the Direction Vector of a Trip}

The length of the vector will correspond to the degree of certainty; it can be 1 , 0.25 , or 0 (if there is no information about the direction). If this trip is followed by another trip taken on the same day and the trip starts from a different location, the estimation of the direction is based on the next starting location. From all stages ahead on the same route, a stage closest to the next location is sought. If it is actually closer to the next location than to the starting location of the current trip, the direction from the current location to that stage is taken with the length of the direction vector equal to 1 . If there is no information about stages ahead, we take the direction to the next starting location with the vector length equal to 0.25 . If there is no next trip on the same day, the best guess for direction is the farthest stage ahead. In that case, the length of the distance vector is also 0.25 .

\section{Comparing Two Trips from Different Customer Records}

A similarity measure between two trips is defined as a fraction, with the denominator based on the distances between the corresponding parameters of the two trips, so the higher the distances the lower the value.

The denominator consists of 1 , plus the squared distance between the starting locations, divided by an appropriate scaling factor, plus the squared difference 
between the starting times of day, also divided by an appropriate scaling factor. The scaling factors are discussed later in this article.

The numerator consists of the product of the weights of the two trips multiplied by 1 plus the scalar product of the two direction vectors (thus, in the worst case, when the direction vectors are opposite and both of length 1 , the similarity will be reduced to 0 ).

\section{Consolidating Data per Starting Locations}

Typically, several trips in a customer record have the same starting location (e.g., in daily commuting from home to work). Bringing together all data for the same starting location should help estimate the role of this location in the other customer record. For a location in $R$, we add up similarity scores for all trips in $R$ starting from this location and all trips in $R^{\prime}$, as defined in the preceding section, to obtain a relevant figure. In this addition, some trips clearly not related to the current location will have a contribution close to 0 . It is the higher values, corresponding to similar trips, that matter, and their sum is divided by the sum of all weights from $R^{\prime}$ (which were used as factors in each of the constituent scores). This will estimate the role of the chosen location from $R$ and is denoted by $Z$. It will be compared with $W$, the total weight of the trips from $R$, starting at the location in question.

The maximum possible value for $Z$ is $2 W$ (attained when all scalar products are equal to 1 , and locations and times coincide), but actually it should be much lower. Matching the values of $W$ and $Z$ is a very sensitive point in the whole procedure. If we chose just to add up the values of $Z$ for all locations in $R$, it would give an unfair advantage to an $R^{\prime}$ record containing too many trips starting from the same location as one location in $R$. Some customer records actually have a very simple structure, just daily repetitions of almost the same trip, and in experiments such records (as $R^{\prime}$ ) were too often selected as best matches for $R$. Hence, we should prevent high values of $Z$ from making excessive contributions to the whole score. On the other hand, too low values of $Z$ showing that the location is not represented in $R^{\prime}$ should produce a negative effect on the total measure of similarity. In such instances, a special function of $W$ and $Z$ was defined for the contribution of the given location to the total score (in the end the whole sum is divided by the sum of all weights in $R$ to make the result less dependent on the number of trips in $R)$. We will denote the result by $\alpha\left(R, R^{\prime}\right)$. 
To define the function mentioned in the preceding paragraph, a computation was performed based on all matches between records of two neighboring weeks belonging to the same customer. This was a linear regression of $Z$ by $W$, giving a sort of expectation of $Z$ for each given value of $W$. Similarly, a quadratic regression was computed for the squared difference between $W$ and the predicted "mean" value, thus providing an estimation for the variance of $Z$ for given $W$. In every case the value of $Z$ is normalized according to these estimated values (in fact, the estimation for the variance obtained from the quadratic regression can be equal or less than 0 for small values of $W$, and these cases are excluded from the summation). Next, the normalized value of $Z$ is transformed by applying a function such that it is monotone and has an upper bound (in a somewhat arbitrary manner it was chosen to be $\left.1-\mathrm{e}^{-1.5(Z+1)}\right)$, and then multiplied by $W$.

\section{Symmetrization}

The similarity function $\alpha$, as defined above, is deliberately asymmetric in $R$ and $R^{\prime}$, and the initial idea was to look for the best match for $R^{\prime}$ based on properties of $R$. The asymmetry is further enhanced by the choice of the scaling factors mentioned above and is also dependent on $R$ (discussed below). However, in the final version, a symmetric similarity function was built by the following procedure. For a pair $\left(R, R^{\prime}\right)$ four values are computed: $\alpha(R, R), \alpha\left(R, R^{\prime}\right), \alpha\left(R^{\prime}, R\right)$, and $\alpha\left(R^{\prime}, R^{\prime}\right)$. By computing such vectors for a number of pairs when it is known in each case whether they belong to the same customer, we build a quadratic discriminant function to distinguish between the two cases (no apriori probabilities are used, hence the constant member of this function is arbitrary, but this does not affect the search for the maximum). The value of this function, denoted by $\delta\left(R, R^{\prime}\right)$, serves as the symmetric measure of similarity.

\section{Defining Scaling Factors}

The scaling factors used above are needed to define which distance between two starting locations is essential and which difference between starting times is essential. The underlying idea is that customers can choose arbitrarily or, for insignificant external reasons, between several available starting points if they are almost equally remote from the actual (unknown to us) starting location or from one another.

Which distances are significant depends on the individual's habits and should be defined from this individual's behavior, though there is a default value of a "small distance." To infer the typical small distance for a specific customer, distances are analyzed between all pairs of points in the weekly record. By sorting them in the 
ascending order, we expect to find a gap between "small" and "big" distances (we have a preset upper bound above, so only the gaps below the limit are considered). We are looking for bigger gaps, but only if a sufficient number of distances are below the gap. We multiply the size of the gap by the total weight of distances below it, and take the lower end of the gap with the highest product (the weight of a distance is the product of the weights of the two trips from which the starting points were taken). If this procedure yields 0 , the default value is used. The value obtained is the value by which the distance between the two locations is divided before squaring and adding to 1 , as mentioned earlier. (A more theoretically sound alternative to this primitive approach would be a kind of cluster analysis of the set of distances, but many clustering procedures are also based on ad hoc choices.)

For time differences a similar approach is used, but a distinction is made between morning trips on weekdays, which are expected to follow a more regular pattern, and all other trips. So three time bands are defined: the division between morning trips on weekdays and other trips on weekdays, the scaling factor for time differences of general trips, and another scaling factor for morning weekday trips. In all three cases, the same approach is used as for distances, with a priori upper limits and default values and the process of finding the "best gap."

The choice of scaling factors, based on a single individual, is one more source of asymmetry between $R$ and $R^{\prime}$, because only $R$ is used to define the values.

\section{Finding Best Matches among Other Customers}

As stated above, the simplest idea of finding the same customer in another week is, for a given customer $R$, to find the $R^{\prime}$ among the other week's customers that maximizes the value of $\alpha\left(R, R^{\prime}\right)$, or alternatively, of $\alpha\left(R^{\prime}, R\right)$ or $\delta\left(R, R^{\prime}\right)$. Table 2 presents the results for the week starting September 6, 1998.

Two obvious observations can be made from this table. First, the fewer the customers in a type, the better the results (with smaller choices it is harder to err). Second, of the three types of similarity measures, the best results are exhibited by $\alpha\left(R, R^{\prime}\right)$, the first function (which was designed with this type of search in mind).

Customer behavior might substantially change in the next week. The same customer may be simply absent in the other week (because he or she had less than four trips). Or, even if the same ticket is present in the other week, the pattern of usage might differ from the current week beyond recognition (for example, someone else was using the ticket while the owner was not in need of it). Figure 3 shows 
an example for a monthly ticket of the type 433, serial number 233 , in the weeks starting September 13, 1998, and September 20, 1998.

Table 2. Results for Week of September 6, 1998

\begin{tabular}{|lllll|}
\hline Ticket Type & 433 & 457 & 705 & 710 \\
\hline Number of customers & 622 & 1216 & 397 & 160 \\
Same customers present in the next week & 528 & 1007 & 340 & 147 \\
Percentage of all customers & 84.9 & 82.8 & 85.6 & 91.9 \\
Best match by $\alpha\left(R, R^{\prime}\right)$ is correct & 354 & 490 & 273 & 127 \\
Percentage of all customers & 56.9 & 40.3 & 68.8 & 79.4 \\
Best match by $\alpha\left(R^{\prime}, R\right)$ is correct & 254 & 268 & 205 & 92 \\
Percentage of all customers & 40.8 & 22.0 & 51.6 & 57.5 \\
Best match by $\delta\left(R, R^{\prime}\right)$ is correct & 345 & 445 & 262 & 121 \\
Percentage of all customers & 55.5 & 36.6 & 66.0 & 75.6 \\
\hline
\end{tabular}

$$
\begin{aligned}
& \text { First week } \\
& 0 \text { 19:57 }(316058,234400) \text { Stop L } \\
& 2 \text { 20:10 }(313520,238632) \text { Stop G } \\
& 2 \text { 20:54 }(316058,234400) \text { Stop L } \\
& 420: 33(316698,239152) \text { Stop M } \\
& 6 \text { 19:59 (317906,247034) Stop N } \\
& 621: 03(316058,234400) \text { Stop L }
\end{aligned}
$$

Second week

2 11:51 (316058,234400) Stop L

4 12:09 (326283,226966) Stop S

4 15:07 (313489,233710) Stop T

5 19:38 (322699,249962) Stop P

$622: 11(326058,227760)$ Stop Q

$622: 53(316043,234465)$ Stop R

\section{Figure 3. Example of Monthly Ticket Data}

It would be interesting to estimate the number of such cases, but to compute it from the data, we need a formalization of the meaning of "differ beyond recognition." For a fair assessment of the efficiency of our method, this definition should be independent from the functions we use in the search. Surveying examples of pairs with the lowest values of the similarity function shows that very often intuitively we can observe some similarity even if the function gives a low value.

In respect to customers with weekly tickets, their usage behavior may differ from that of monthly ticket users. It was actually observed that the percentage of customer records discarded due to low usage is much lower for weekly tickets; the 
obvious explanation is that if a weekly ticket user does not expect to travel much in the next week, this type of ticket will not be purchased.

The analysis presented here enables public transport companies to improve their operations in a number of ways. First, it helps the company to identify the difference in travel patterns of core users. Second, the transfers between different services allows the operator to see the demand for trips involving more than one service and could potentially provide useful information on the development of new services (e.g., in the case where there is a large number of travelers starting from origin $A$ and ending at origin $C$ with a transfer point at $B$, the operator might decide to offer services starting at $A$ and ending at $C$ ). The data can also be used to measure the possible waiting time at transfer points and to reduce this where possible.

\section{Conclusions}

This article introduced a method that facilitates finding customer ticket IDs without knowing the identity of a passenger for longer than the validity of the ticket itself. The method uses different sets of weights that are calculated to compare weekly journey patterns of individual passengers. Data attributes such as time, distance, direction, and starting location were used to calculate a weight, which then facilitates an estimate whether the two currently compared ticket IDs originate from the same customer.

The results revealed the following two main observations:

1. The fewer the customers in a ticket type, the better the results. This observation has, therefore, a negative influence for popular ticket types or for large networks with a small variety of ticket types.

2. The $\alpha\left(R, R^{\prime}\right)$ achieves the best results. Using $\alpha\left(R, R^{\prime}\right)$ on the ticket types 433, 457, 705 , and 710 resulted in a positive ticket identification of 56.9 percent, 40.3 percent, 68.8 percent, and 79.4 percent, respectively. The $\delta\left(R, R^{\prime}\right)$ produces the second best results, which are marginally below the results calculated by $\alpha\left(R, R^{\prime}\right)$.

The method successfully identifies a percentage of passengers and their ticket ID of the next validity period. Considering that behavioral studies are mostly carried out on a smaller subset of passengers, the proposed method may be sufficient to chain together passengers' weekly travel records. 


\section{References}

Boyle, D. K. 1998. Passenger counting technologies and procedures. Washington, DC: Transportation Research Board, National Research Council.

Chen Y. L., K. Tang, R-J. Shen, and Y-H Hu Y-H. 2004. Market basket analysis in a multiple store environment. Decision Support Systems, in press.

Furth, P. G. 2000. Data analysis for bus planning and monitoring. TCRP Synthesis 34. Washington, DC: Transportation Research Board, National Research Council.

Mahmassani, H. S. 1997. Dynamics of commuter behaviour: Recent research and continuing challenges. In Peter Stopher and Martin Lee-Gosselin, eds., Understanding Travel Behaviour in an Era of Change. Pergamon Press, pp. 279-313.

McCarthy, J. 2001. Phenomenal data mining: From data to phenomena. Computer Science Department, Stanford University. Available at URL:http://www-formal.stanford.edu/jmc/data-mining.html.

\section{About the Authors}

GREGORY TSEYTIN (tseytin@acm.org)was head of Intelligent Systems Laboratory at the Acad.V.I. Smirnov Research Institute for Mathematics and Mechanics at the University of St. Petersburg, Russia. He is currently an advisory software engineer at International Business Machines, Rational Software, California. His interests include object oriented logic and alternative formalizations of common thinking.

Markus Hofmann (mhofmann@tcd.ie) is a Ph.D. candidate at the Centre for Transport Research, Trinity College, Dublin (TCD), Ireland. He has focused on the utilization of transport data using data mining algorithms for several years. He has published in a number of journal and conference reports and has taught widely in the area of information technology. His other research interests include performance and level of service measures of public transport operators, data mining for transport planning, and knowledge management.

MARGARET O'MAHONY (margaret.omahony@tcd.ie) holds the Chair of Civil Engineering (1842) and is director of the Centre for Transport Research at Trinity College Dublin. She coordinates several internationally and nationally funded research projects and is a reviewer for the top transport research journals. The author of more than 90 publications, her interests include transport modelling, 
public transport policy, data analysis, innovative technologies applied to transport analysis, demand management, and environmental impacts of transport.

DonAL LYONS (donal.lyons@tcd.ie) graduated from University College Dublin in 1967 with a distinction in physics and with a B.Sc in mathematics. He received an M.Sc in statistics and operations research from TCD. He subsequently worked in the Irish Dairy Board as O.R. analyst, product executive, planning executive, and systems development manager. As a lecturer in the Statistics Department at TCD, his main research interest was data mining, primarily in the area of identification of semianonymous transactions. More recently, he has been the data warehouse manager at TCD. 


\title{
A Multidisciplinary Approach Toward Improving Bus Schedule Readability
}

\author{
Darius Sollohub, New Jersey Institute of Technology \\ Anand Tharanathan, Texas Tech University
}

\begin{abstract}
Printed schedules are critical to mass transit mobility, perhaps no more so than to bus transit users who often embark from locations where information is not provided. For economic reasons, they also rely heavily on transit. Schedules are their lifeline. After becoming concerned with the readability of its bus schedules, New Jersey Transit (NJT) enlisted an interdisciplinary research and design team from the New Jersey Institute of Technology (NIIT) to analyze, redesign, and test the agency's bus timetables over an 18-month period beginning in 2003. The process included precedent research, community outreach, graphic design, laboratory testing, and survey methods. It began with a literature survey and review of timetables produced by other agencies. Two focus groups were convened to incorporate user viewpoints. Based on these methods and acknowledging the institutional and production constraints of the agency, two prototype timetables were designed for one of the agency's most complex bus routes. The prototypes and the current schedule for the route were time-tested in a laboratory with 30 participants. A survey was given to the same participants. The analysis of the experimental data was partially inconclusive due to high error rates for all schedules tested. However, in the survey, a majority of participants showed preference for aspects developed in the prototypes, offering the agency important production recommendations regarding font sizes, text orientation and graphic display methods, as well as institutional directives regarding data transfer,
\end{abstract}


maps, zone designations, passenger information, and telephone contacts. This article recounts this process and offers to the larger transit community the conclusions of this interdisciplinary approach, not combined in this manner before, to make bus transit more attractive and efficient.

\section{Introduction}

Information is a critical component of mass transit mobility. Knowing where to take transit and when to board are important preconditions for use. In an age when information is increasingly provided digitally through the Internet, printed schedules remain important. Printed schedules are especially important to bus users, who are frequently of a lower income bracket with limited access to digital information and who often embark from locations where schedules are not provided. This article describes a research project entitled "Improving Public Transit Schedules-Timetables People Can Actually Read" that analyzed these conditions and developed prototypical solutions between January 2003 and July 2004. The participants, who worked as a team in this undertaking, were the project client, New Jersey Transit (NJT); the project sponsor, the New Jersey Department of Transportation (NJDOT); and the research provider, the New Jersey Institute of Technology (NJIT). At NJIT, the project was undertaken in an interdisciplinary manner employing faculty, researchers, and students from the disciplines of transportation planning, design, and human factors. The tasks of the project were fourfold:

1. To understand how schedules evolved, what standards had been developed, and what research had been undertaken to study them.

2. To analyze schedules currently being used and compare them to those of other agencies, in the process, reaching out to the community to do so.

3. To develop prototypes that sought to overcome the deficiencies identified.

4. Test and survey participants on how they used both the prototypes and the originals, side by side, in a controlled environment.

The resulting recommendations, both immediate and long term, are specific to the client's needs while at the same time relevant to a larger audience regarding this largely unexamined yet critical component of mobility. 


\section{NJT's Bus Schedules}

NJT is one of the few transit agencies that mass-produces hardcopy schedules for all its 231 bus routes. NJT estimates that it produces 20 to 25 million schedules per year, making it one of the largest schedule producers in the North America. Printed schedules complement automated and operator-assisted telephone service and a website that includes a trip planner. Currently, the agency receives 4.7 million calls per year and 71.7 million page views on its website. ${ }^{1}$ The overall layout and design of NJT bus schedules has evolved over the years, but follows basic standards and guidelines developed in 1972. The current schedule layout and information contained therein represent the accumulation of years of responses to staff recommendations, legal and liability issues, and policy/procedural changes. Schedules are constantly evolving; they are changed and reissued four times per year to accommodate schedule adjustments and other modifications. Physically, the timetables are 21 to 24 inches long, but can be as long as 36 inches. They fold down to a $3 \times 8 \frac{1}{2}$-inch packet and are distributed on buses and at stations and various other locations. Each schedule is available in pdf format on the agency's website.

The agency's bus schedules (see Figure 1 as a typical example) feature timetables, a map, and text notes. Each timetable consists of selected bus stop locations, or "time-point locations," which are printed in white text on a black background. Bus arrival/departure times or "time points" are listed below the time-point locations. In general, weekday, Saturday, and Sunday timetables for a specific direction are displayed on one side of the timetable. All bus schedules are printed in black ink on standard white paper. The map is not to scale and includes the names of selected streets and towns served. The map also indicates connecting bus routes and passenger rail lines. Other information, including notices, phone numbers, and fare information, is included as blocks of text.

The orientation of text blocks varies on each side of a typical schedule, with some blocks of text perpendicular to others. The cover, which includes the route number and the communities served, is in a box with a "portrait" orientation when folded, but, when unfolded, its long axis is perpendicular to the length of the sheet. The timetables appear in one long column parallel to the sheet's long axis, with time-point locations enclosed in text boxes at the top. To read the locations, one must rotate the schedule 90 degrees and then rotate back to read the corresponding time points. Morning trips begin at the top and proceed down chronologically. One reads the times for each trip horizontally from left to right. 
Journal of Public Transportation, Vol. 9, No. 4, 2006

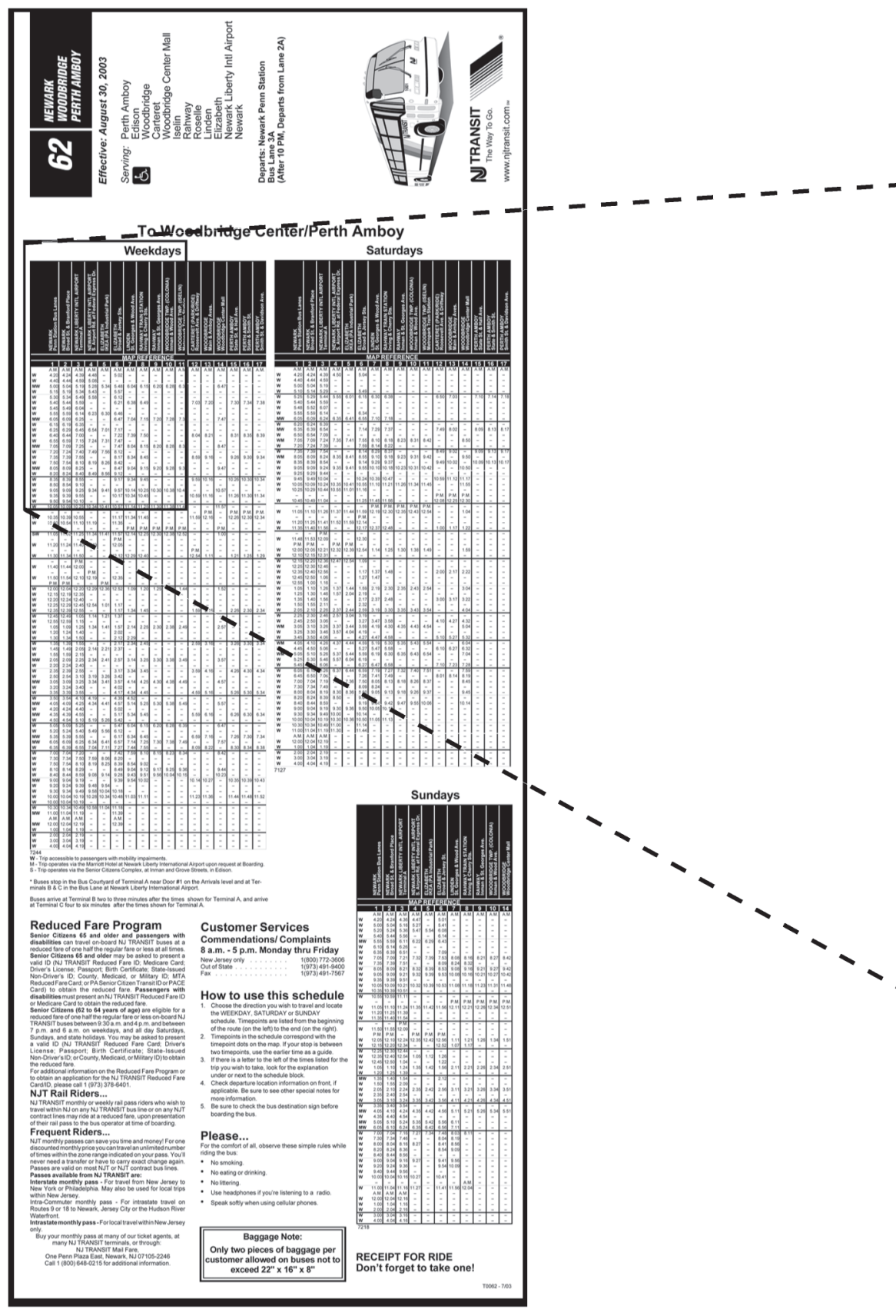




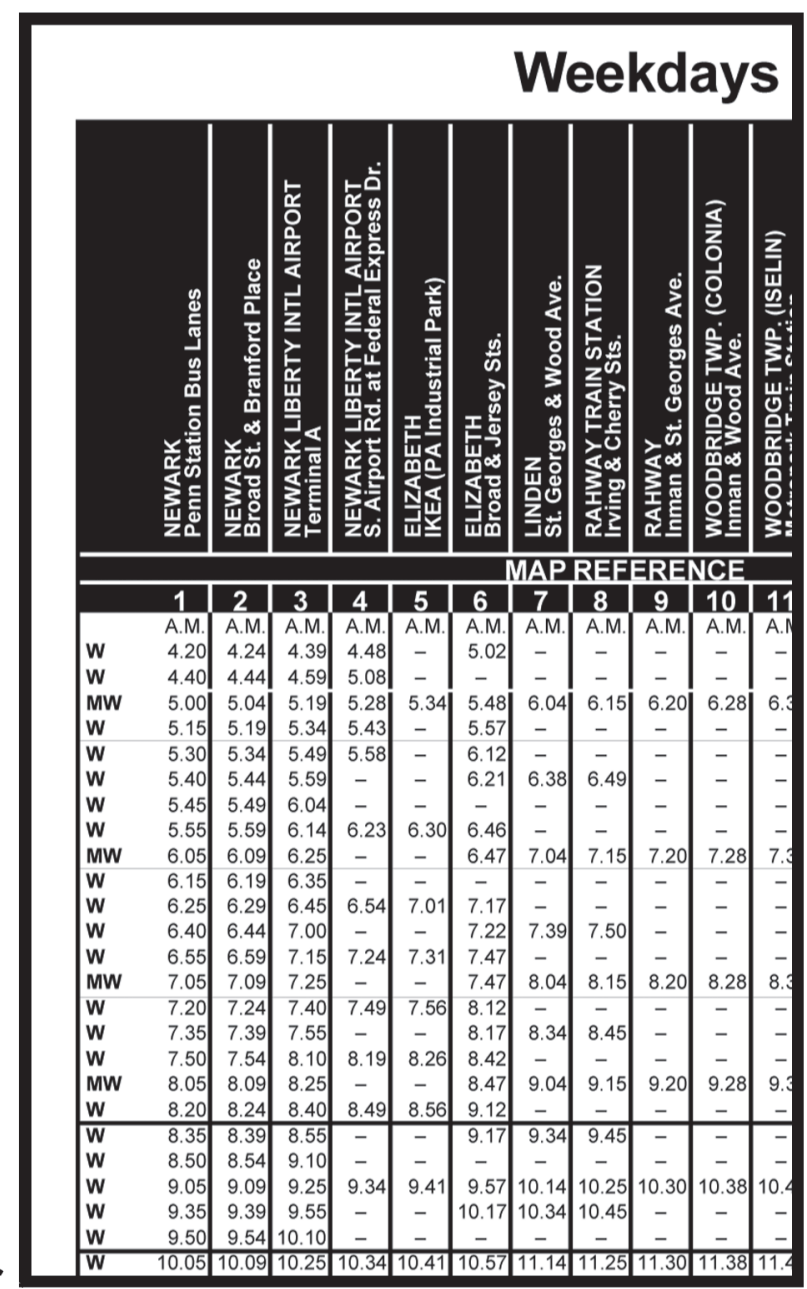

Figure 1. (Left) Front side of current 62 schedule and detail of timetable. Note the different orientation for time points and time-point locations.

(Above) Enlarged detail at actual size. 


\section{Precedents}

\section{Literature Survey}

The project began with a literature survey that provided a point of reference for reviewing NJT's current schedules and a scholarly foundation for prototype design. Topics reviewed in the literature included those regarding information display, display design, cognitive behavior, and understanding and interpreting information in printed displays. Essential findings of the survey are summarized below.

At a fundamental level, reading and deciphering bus schedules consists of a highly complex set of tasks involving many phases of human information processing. The human information processing model described by Wickens and Hollands (2000) requires many different mental processes essential to using schedules. These include short-term sensory storage for the initial search task of scanning the timetable. The accuracy and speed of recognition is greatest if the displayed stimuli are presented in a physical format that is maximally compatible with the visual representation of the unit in memory. Decision making is essential for determining the bus stop from the schedule. The user should be able to read schedules rapidly and accurately, with critical information recognized automatically to make quick and accurate decisions. Working memory describes the memorization of bus routes, time, and stops that are critical to effectively reading a schedule. Goettl, Kramer, and Wickens (1986) have found that the efficiency of a process increases when items of information are in close proximity. How many units in memory have to be held simultaneously, how many decisions have to be made, and what needs to be memorized to use a schedule, are important design benchmarks.

Typography is a critical component of schedule design. The Transit Cooperative Research Program (1999) generally recommends 10-point font size as a minimum and the avoidance of very narrow stroke widths in transit schedules. According to Wickens et al. (2004), contrast should be maximized by printing black letters on white background and the choice of fonts influence how fast users comprehend information. Roman fonts are recognized standards, according to McCormick and Sanders (1993). Phillips (1979) recommends that, in certain contexts, lowercase should be avoided. Nimmo-Smith and Wilkins (1987) have found that clarity and readability are improved by reducing the typical spacing between the letters and increasing the spacing between the lines. McCormick and Sanders (1993) have found that increasing the size of the initial letter of a word increases legibility significantly. Fisher and Tan (1989) specifically studied the highlighting of text and 
affirm its efficiency, but suggest caution as excessive use impedes the ability to find a target.

As schedules are typically made up of tables, lists, maps, symbols, and other items, the overall style that balances the document equally critical to effectiveness. Tufte (2001) shows many examples that maintain an optimum blend of graphic elegance, text representation, and information display, while Tullis (1983) cites the four important characteristics of display formats as overall density, local density, grouping, and layout complexity.

Other research focuses on specific features found in schedules. Fox and Wright (1972) show that tables should be short and simple to use with the least complications. They also find that columns should be grouped into blocks of approximately five items (Fox and Wright 1970). Tinker (1960) has found that times scanned vertically are better comprehended than those scanned horizontally. Tinker (1954) has also shown that economy of space too often overrides readability factors. Schneiderman (1998) suggests that proper alignment of the information and text boxes improves the overall visual quality. Sparrow (1989) finds that information should be consistent; if represented in a different manner its meaning can change.

Bartram, Crawshaw, and Sprent (1980) studied the two primary timetable styles: one that represents the route vertically known as the standard format, the other that represents it horizontally known as the reflected format. The reflected format has been shown to be more effective; it is easier to scan and routes are represented in an orientation that corresponds to the horizontal progression from left to right, a powerful western stereotype of motion direction. They also show that the 12hour system is more efficient than the 24-four hour system. In a later study (1983), they find that the need to rotate information undermines effectiveness and suggest that the location and time should be on the same axis.

The Transit Cooperative Research Program (1999) suggests that, wherever possible, route maps should accompany timetables and that these should be identical to those used at bus stops and signboards. All information aids should try to spatially orient the passenger by providing points of interest and legends in the maps. Further, the study suggests that timetables should read left to right and either a line or a space break should be given after every three to five rows to enhance readability of the tables. Whenever extensive variations occur in a route, separate route maps and separate timetables should be generated. Swanston and Walley (1984) 
indicate that a clear distinction of different zones of a route increases timetable legibility.

\section{Comparison to Schedules of Other Agencies}

Based on recommendations of NJT and consultation with American Public Transportation Association (APTA) staff, schedules were procured from several large transit providers. Also procured were schedules that had won APTA design awards in the prior three years. This survey, albeit unsystematic, yielded several commonalities (see Table 1). Most schedules follow a landscape format. In doing so, most indicate their time points as diagonal text. Most schedules provide some distinction between morning and afternoon/evening, a distinction that provides an additional layer of reference in reading long columns of text.

\section{Table 1. Survey of Other Transit Agencies Regarding Features Proposed}

\begin{tabular}{|l|c|c|c|}
\hline \multicolumn{1}{|c|}{ City } & $\begin{array}{c}\text { Angled } \\
\text { Timepoint } \\
\text { Locations }\end{array}$ & $\begin{array}{c}\text { Landscape } \\
\text { Format }\end{array}$ & $\begin{array}{c}\text { AM/PM } \\
\text { Distinction }\end{array}$ \\
\hline Dallas Area Rapid Transit (Dallas, TX) & $\sqrt{ }$ & $\sqrt{ }$ & $\sqrt{ }$ \\
Washington Metropolitan Transit Authority (Washington, DC) & & $\sqrt{ }$ & - \\
New Orleans Regional Transit Authority (New Orleans, LA) & $\sqrt{ }$ & $\sqrt{ }$ & - \\
Eastern Contra Costa Transit Authority: Tri Delta Transit (Antioch, CA)* & $\sqrt{ }$ & $\sqrt{ }$ & - \\
Bi-State Development Agency (St. Louis, MO) & $\sqrt{ }$ & - & $\sqrt{ }$ \\
King County Department of Transportation (Seattle, WA) & $\sqrt{ }$ & - & $\sqrt{ }$ \\
Metropolitan Atlanta Rapid Transit Authority (Atlanta, GA) & - & - & $\sqrt{ }$ \\
Chicago Transit Authority (Chicago IL) & - & $\sqrt{ }$ & - \\
Metro Transit (Minneapolis, MN) & $\sqrt{ }$ & $\sqrt{ }$ & $\sqrt{ }$ \\
Charlotte Area Transit System (Charlotte, NC)* & - & - & $\sqrt{ }$ \\
Regional Transportation District (Denver, CO) & $\sqrt{ }$ & - & $\sqrt{ }$ \\
Central Florida Regional Transit Authority (Orlando, FL)* & $\sqrt{ }$ & $\sqrt{ }$ & $\sqrt{ }$ \\
\hline Percentage & $66.67 \%$ & $58.33 \%$ & $66.67 \%$ \\
\hline
\end{tabular}

* APTA award winners

\section{Community Outreach}

\section{Focus Groups}

The study team solicited user input through two focus groups: one consisted exclusively of NJT employees who regularly use buses, the second of nonemployees whose bus transit use varied from regular to infrequent. Each group consisted of six people. Two existing NJT schedules were selected for discussion. The first was a single schedule for five routes-the $144,145,148$, and 164 -that primarily serve 
office workers commuting to Manhattan. The second-for route 62-was a more complex urban route used by a diverse group of riders. The same meeting format was used for both groups with NJT staff serving as facilitators, while research team members observed. The nonemployee participants were culled from a large database of customers that NJT maintains and were compensated for their time, as per agency standards. Meeting discussions covered several topics and issues relevant to schedule usability, format, and content. Some of the most significant outcomes of these discussions are presented below.

1. Most participants felt that current maps provide an adequate level of detail and information and should not be revised. Some indicated that established landmarks, such as churches and schools, should be indicated on the map but others expressed concern about placing too much detail on the maps. The seemingly random orientation of the north arrow was a concern for some members of the research team. However, none of the focus group members indicated this as a problem.

2. More explicit display of the customer service telephone numbers was widely recommended. Several participants in the nonemployee focus group indicated that making this prominent was their paramount concern.

3. Opinions were somewhat mixed over displaying weekday and weekend/holiday schedules on separate sides. Presently, bus schedules display weekday and weekend/holiday schedules to a particular direction on one side. So, for example, on the route 62 schedule "To Newark" timetables for both weekday and weekend/holiday appear on one side of the schedule. The research team hypothesized that having all the weekday timetables on one side and weekend/holiday timetables on the other would favor infrequent users who needed to plan on the same day. This measure would considerably reduce the need to flip the schedule when planning a round trip and would be consistent with the findings of Goettl, Kramer, and Wickens (1986) and Bartram, Crawshaw, and Sprent (1983).

4. Both groups agreed that using a numerical code to mark the time-point location on the map was useful. This was a feature unique to the route 62 schedule. The feature was being tested by NJT independent of the study.

Selected transit schedules obtained from other transit agencies were also presented to each of the focus group participants. Each participant was asked to respond to specific characteristics of these schedules. Preferences are summarized as follows: 
1. Provide shading on alternate columns. Many transit schedules employ shading of alternating columns, assisting readers in identifying time points with time-point locations.

2. Decrease the number of rows in one table by distinguishing between morning and afternoon/evening periods. This feature, as employed by other agencies, was generally preferable to NJT's current layout of one long table.

\section{Design}

\section{Prototype Design and Development}

Once the research team reviewed the related literature, analyzed NJT's and other agency's schedules, and received input from the focus groups, the design of prototypes began. Given the complexity of the 62 schedule (see Figure 1), the team selected it as a suitable challenge for prototype design and testing. NJIT also met on several occasions with NJT's graphics and printing staff to discuss production operations and identify potential barriers and impacts associated with recommended layout changes. To fairly evaluate any modifications, care was taken to eliminate any indicators that might identify the prototypes to test participants. All schedules tested were created using NJT's in-house graphics software and printing facilities on exactly the same paper. One prototype was designed giving primary importance to the direction of travel, following the same organizational logic of the existing schedule but with significant graphic modifications. This was named the "Directional Prototype" schedule (see Figure 2). The other prototype was designed by giving primary importance to the day of the week, and was named "Weekday/Weekend Prototype" schedule (see Figure 3). Other than this organizational difference, both prototypes shared the following features.

\section{Orientation}

Prototypes were designed so that all information was organized in a landscape format and time points were displayed at 30 degrees to the horizontal so that they would be read on a slant, thus eliminating the need to rotate schedules consistent with Bartram, Crawshaw, and Sprent (1983) (see Figure 2).

\section{Proximity and Morning-Afternoon/Evening Distinction}

The overall landscape orientation required that otherwise long columns be divided into two separate columns. The logical break point was whether trips began in the 
morning or afternoon/evening. This was consistent with Sparrow (1989) and Tufte (2001). This organization style was consistent with schedules of other agencies and supported in focus groups (see Figure 4).

\section{Zebra Pattern (Shading Alternate Columns)}

In the prototypes, alternate columns were shaded in a "zebra pattern." This pattern was introduced to avoid skipping between columns when a user reads down a column following Smith (1979) who found that proper highlighting attracts users' attention, thus providing a reference line that helps them read the schedule easily. This feature was also supported in focus groups (see Figure 2).

\section{Maps}

The maps were not changed, retaining the numeric code currently being tested. However, a new key describing map features and symbols was developed for the prototypes (see Figure 3).

\section{Zones}

In the NJT system, zones are used to calculate the trip fare. Bold lines that define the zones in the tables were included in the prototypes and were keyed to zone boundaries indicated on maps. This responds to Swanston and Walley's (1984) recommendations that suggest users translate information faster when separations between zones are shown clearly (see Figure 2).

\section{Font Size}

NJT schedules typically use font sizes below the 10-point minimum recommended by the Transit Cooperative Research Program (1999). Font sizes on the 62 schedule were at 5.5 point. Because of the finite area of the schedules, it was decided that font sizes would not be enlarged for the prototypes.

\section{Testing and Survey}

\section{Time- and Error-Based Laboratory Experiment}

Participants. Thirty subjects from the larger university community participated in the laboratory experiment. Participants were asked to respond to questions that allowed researchers to group them for a finer grain of analysis. Ages ranged between 17 and 65. Participants included high school (relatives of universityaffiliated individuals) and college students, professors, maintenance personnel, and office staff. They were grouped according to educational level as "up to high school," "college," and "advanced degree." Seventeen of the 30 participants spoke 
Journal of Public Transportation, Vol. 9, No. 4, 2006

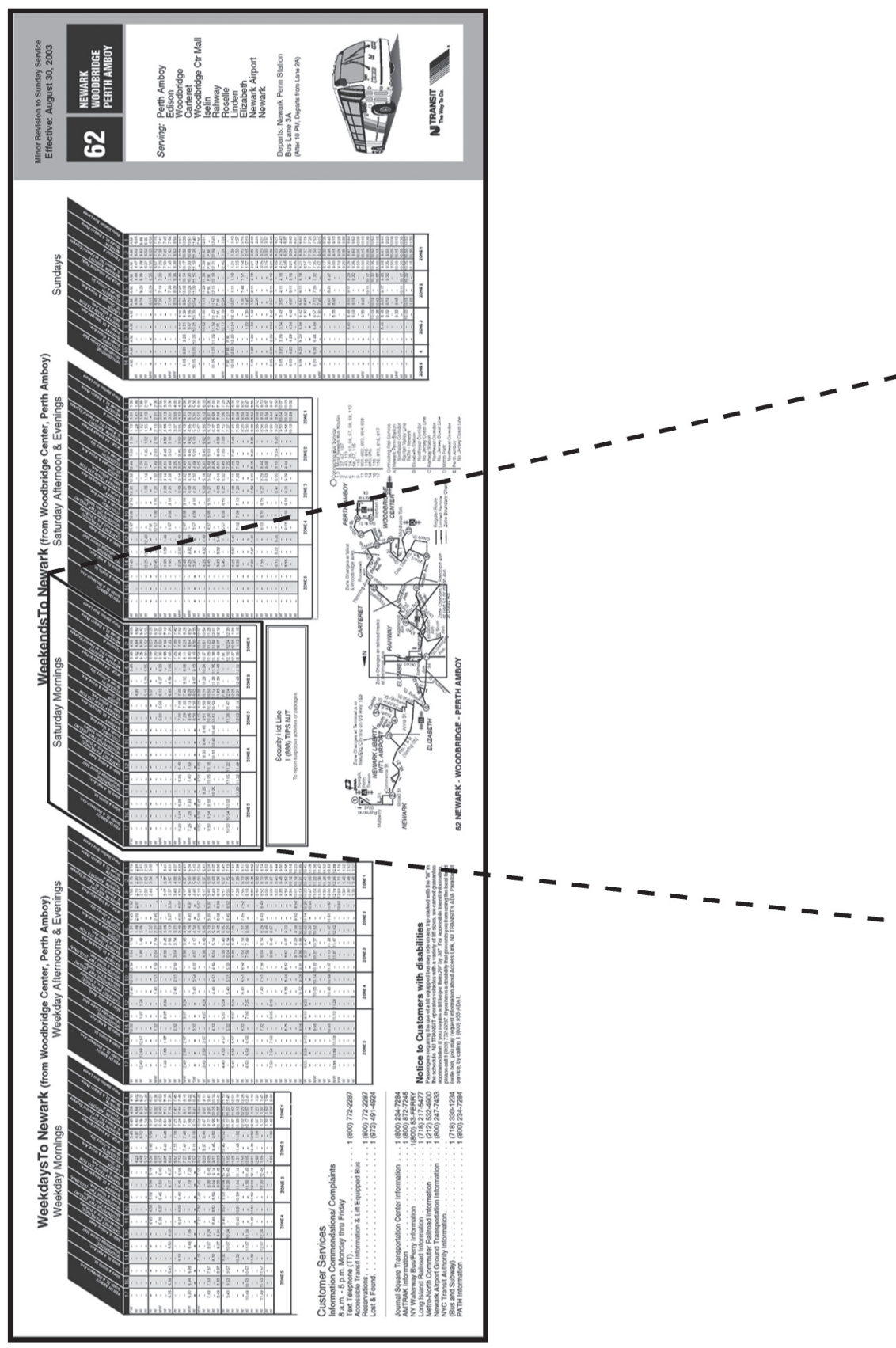




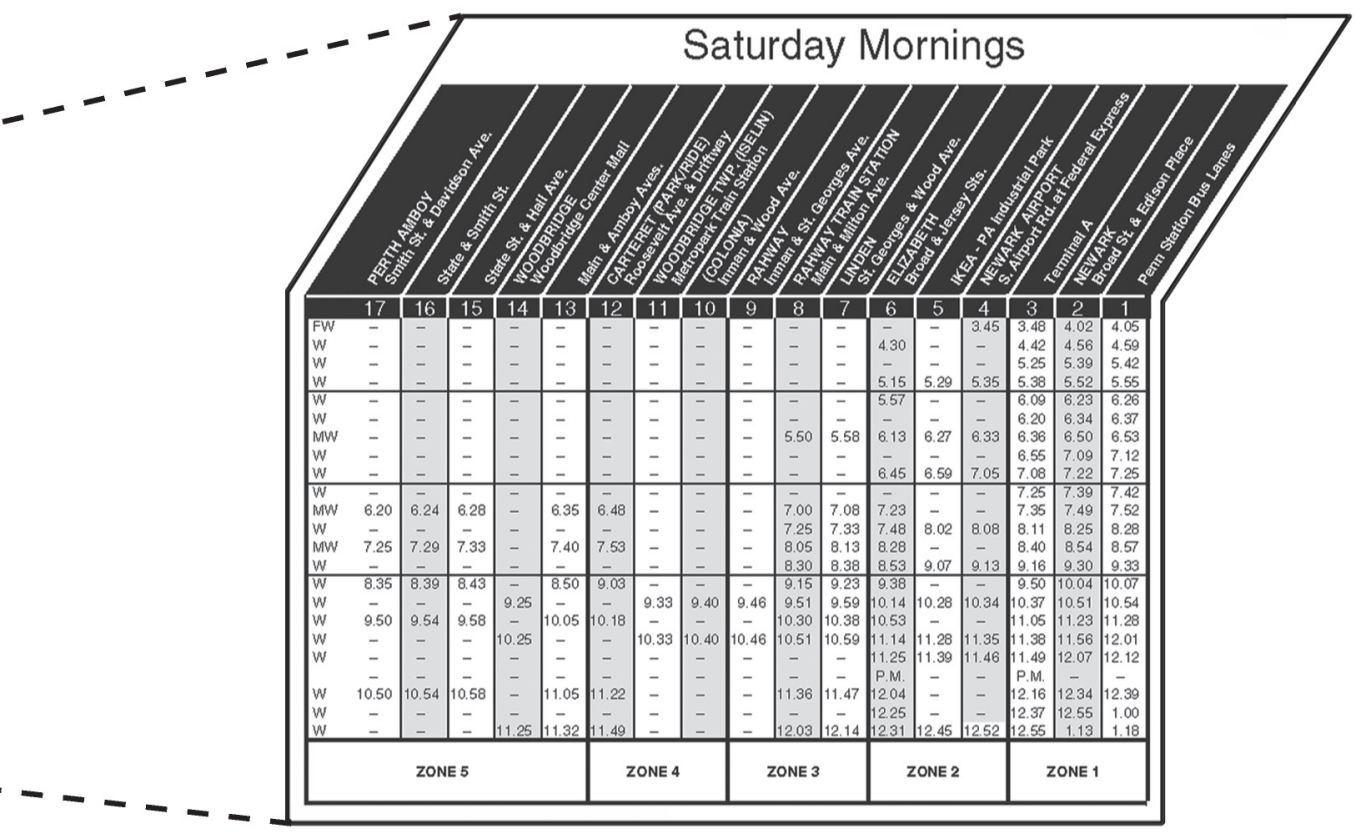

Figure 2. (Left) Front side of directional 62 prototype and detail of timetable. New features include slanted time points, white on black for headings, zebra patterns, and zone distinctions.

(Above) Enlarged detail at actual size. 
Journal of Public Transportation, Vol. 9, No. 4, 2006

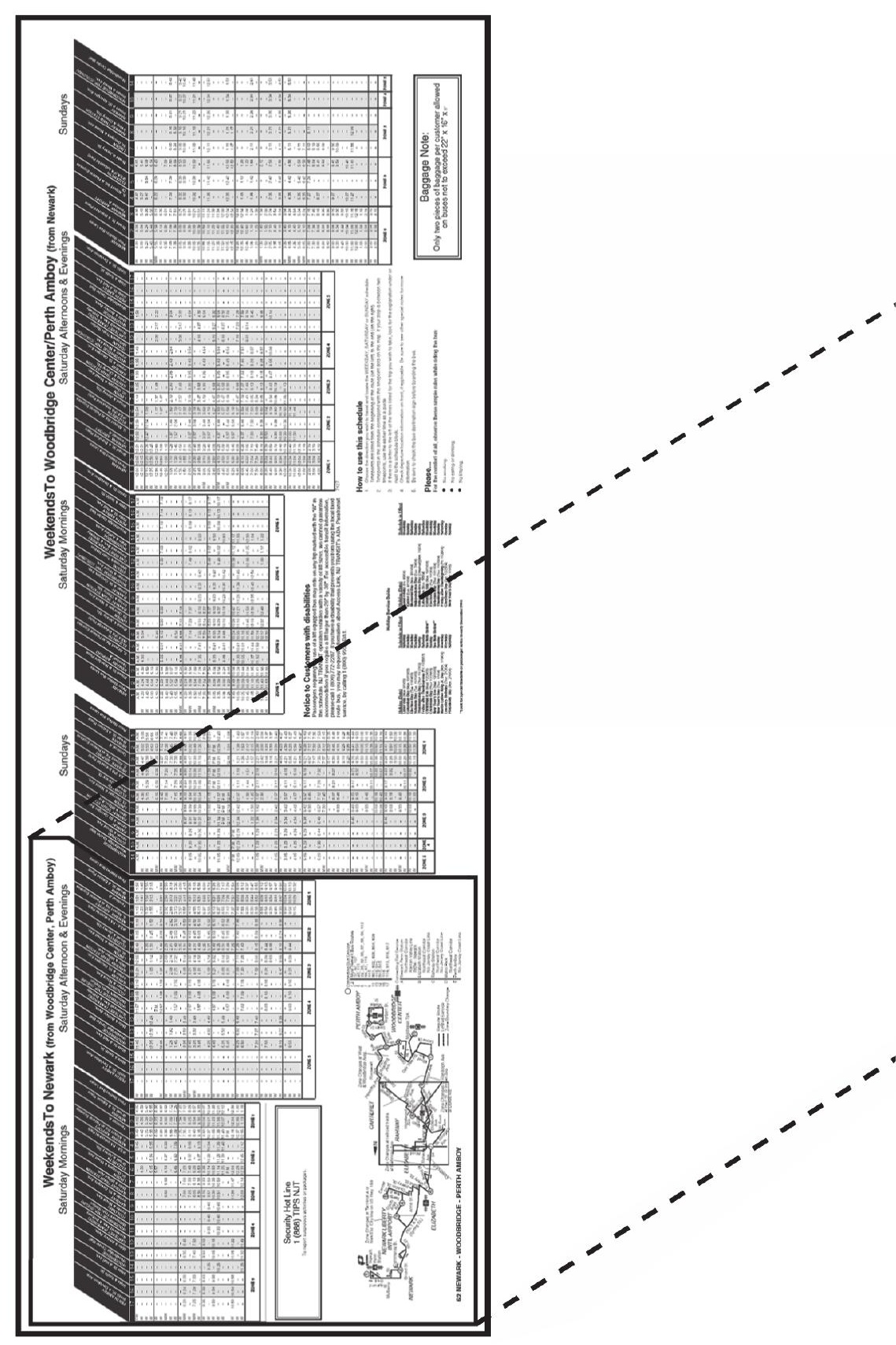

74 
Multidisciplinary Approach Toward Improving Bus Schedule Readability

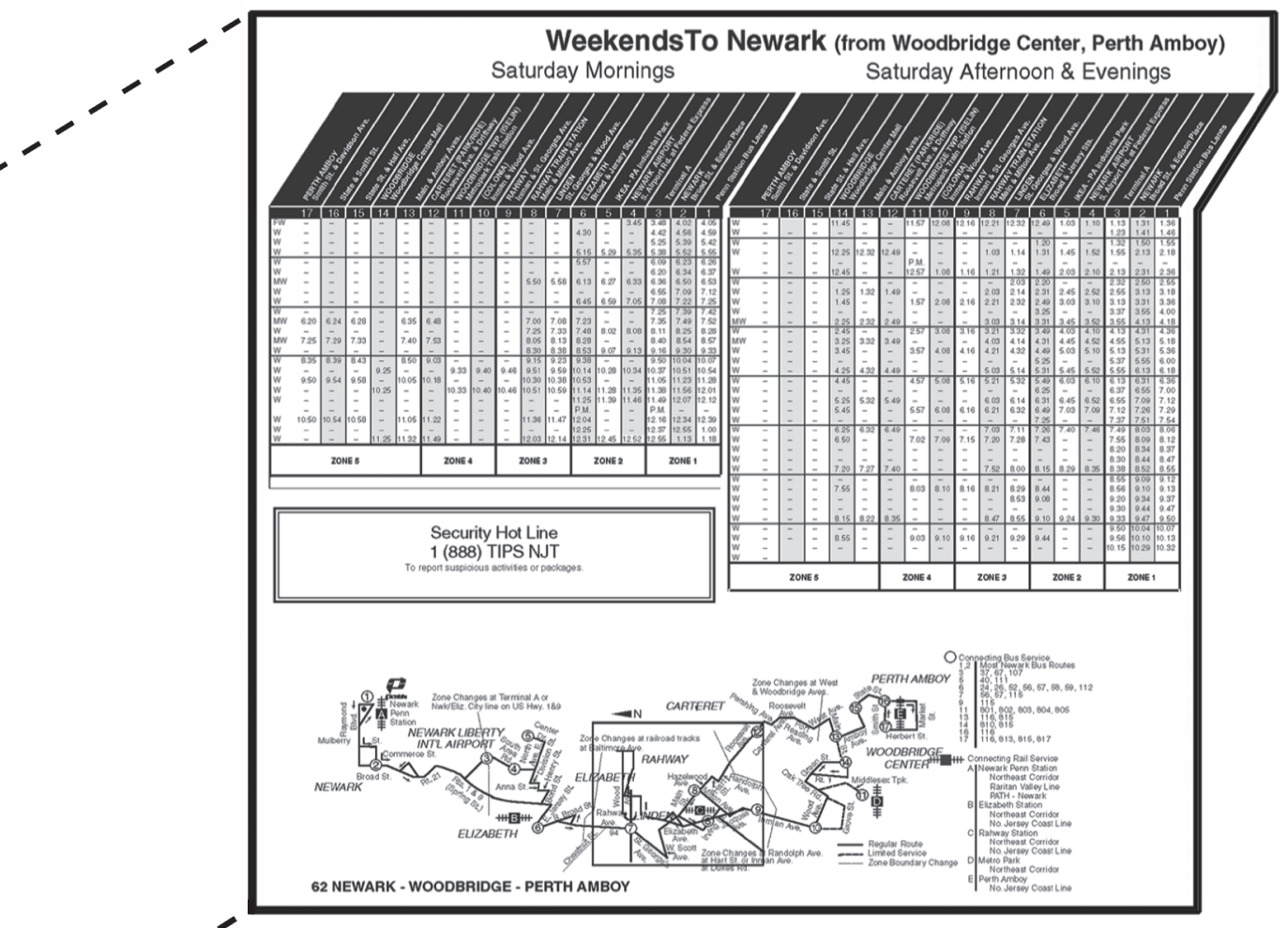

Figure 3. (Left) Reverse side of weekday/weekend 62 prototype showing detail of heading. Note the use of black on white as a visual cue compared to Figure 2.

(Above) Enlarged detail not actual size. 


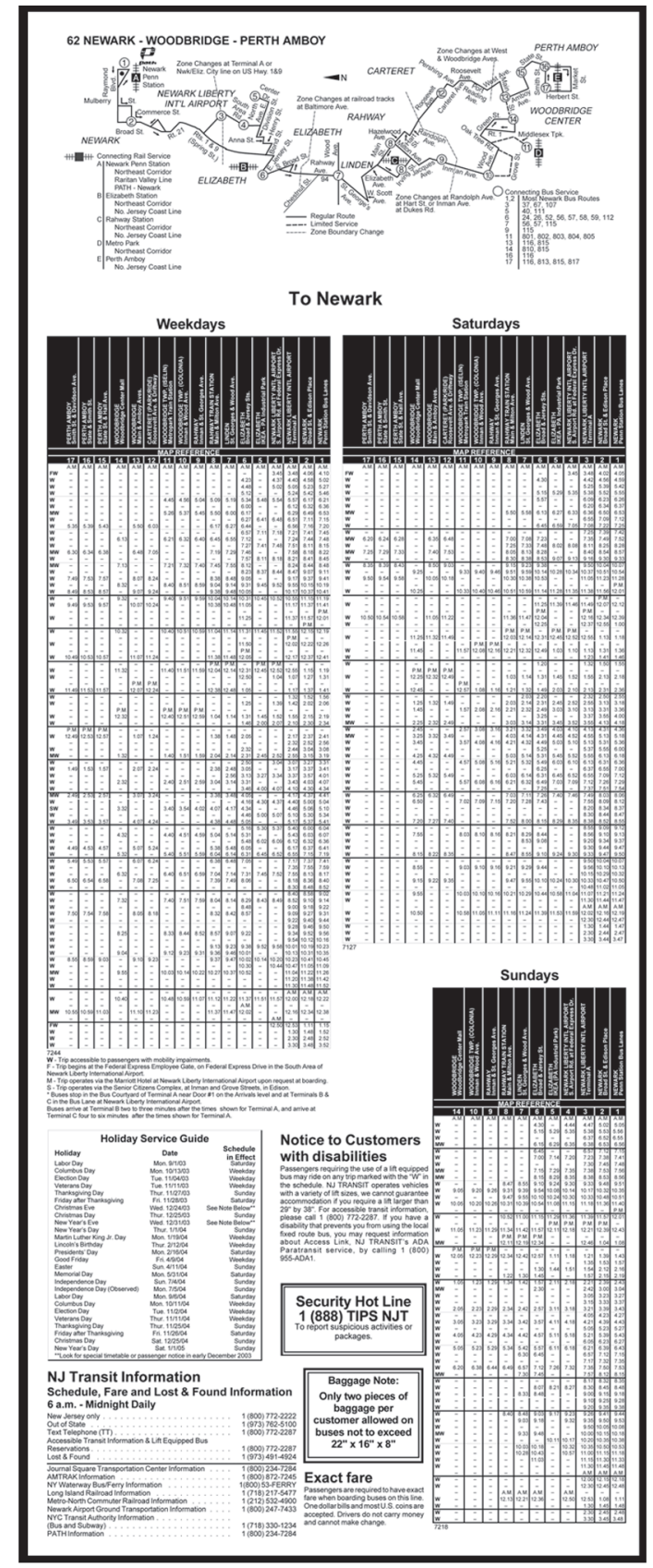




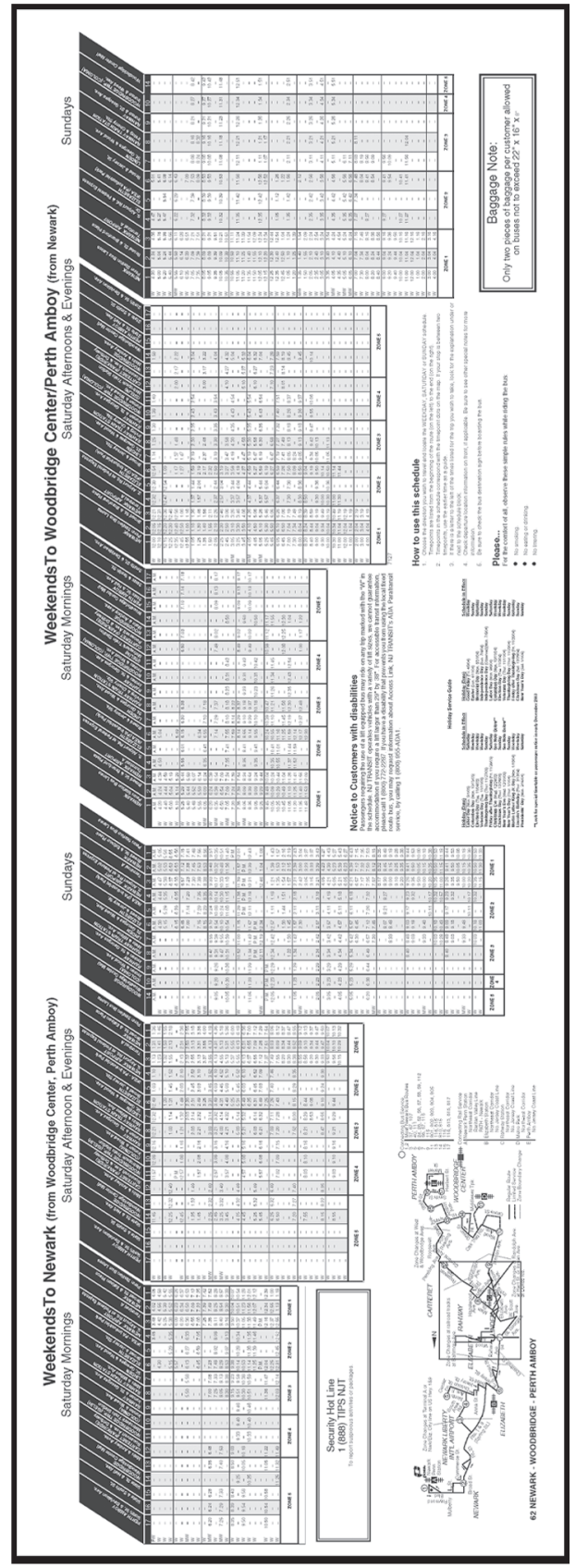

Figure 4. Changes to morning-afternoon/evening distinction showing timetables reorganized in landscape format. Morning and afternoon/ evening distinction in modification. 
English as their second language. Apart from educational level, no specific questions regarding literacy were asked. Familiarity and usage of the agency's bus schedules separated participants into four groups: "none," "rarely" (less than twice in the last six months), "frequently" (twice a month), and "very frequently" (twice a week).

Method. Researchers designed a time and error test with three phases for every participant. Each phase was designed to test a specific type of schedule. Participants were asked to answer 11 questions in each phase in the least possible time. The first question in each phase was a warm-up question and was not counted in the analysis. The remaining 10 questions in each phase were designed to test features that may affect reading and interpretation of the schedule. Prior to each phase, participants were given five minutes to familiarize themselves with a given schedule. Even though the questions in the three phases were similar with respect to the design feature they tested, the destinations, departure locations, and times differed. Researchers recorded the accuracy and time each participant took to answer a question on a specific schedule. A camcorder recorded the entire experiment with all devices placed out of the participants' field of view so as not to distract. To minimize the potential for answer translation errors, staff asked participants to verbally indicate their answer so that the experimenter could manually record the response and response time. Features tested for efficiency were the zebra pattern, the morning-afternoon/evening distinction, maps, and zones. Other information that had been graphically reorganized was also tested.

Statistical results of the time tests were largely inconclusive because of overall high error rates (see Table 2) and the relatively small sample size. Statistical power for the study would have been higher with a higher sample size. The only question that showed statistical significance ${ }^{2}$ was that dealing with different zone representations, which indicated that different zones were effectively recognized in the prototypes but not in the existing schedule $(F[2,46]=11.28, p<0.01)$. In looking at the error rates among different participants, those with an educational level "up to high school" had the highest error rate, committing almost twice as many errors as those made by participants with advanced degrees. This suggests a minimum cognitive capability, which could be marked as the baseline for proficiently reading bus schedules.

Generally, the overall poor performance in using the schedules at all education levels and ages clouded an empirical assessment of the modifications. The research team attributed this to the use of a smaller-than-recommended font, although 
Table 2. Error Rates and Overall Error Percentages for the Current Schedule and the Two Prototype Schedules

\begin{tabular}{|c|c|c|c|c|c|c|c|}
\hline \multirow[b]{2}{*}{$\begin{array}{l}\text { Question } \\
\text { Number }\end{array}$} & \multirow[b]{2}{*}{ Design Feature } & \multicolumn{2}{|c|}{ Current Schedule } & \multicolumn{2}{|c|}{ Directional Prototype } & \multicolumn{2}{|c|}{$\begin{array}{c}\text { Weekday/Weekend } \\
\text { Prototype }\end{array}$} \\
\hline & & $\begin{array}{l}\text { Number } \\
\text { of Errors }\end{array}$ & $\begin{array}{c}\text { Percentage } \\
\text { Error }\end{array}$ & $\begin{array}{l}\text { Number } \\
\text { of Errors }\end{array}$ & $\begin{array}{c}\text { Percentage } \\
\text { Error }\end{array}$ & $\begin{array}{l}\text { Number } \\
\text { of Errors }\end{array}$ & $\begin{array}{c}\text { Percentage } \\
\text { Error }\end{array}$ \\
\hline 1 & Zebra pattern & 5 & $17.90 \%$ & 6 & $21.40 \%$ & 8 & $28.60 \%$ \\
\hline 2 & Map & 13 & $46.40 \%$ & 12 & $42.90 \%$ & 19 & $67.90 \%$ \\
\hline 3 & Bus transfer & 2 & $7.10 \%$ & 4 & $14.30 \%$ & 2 & $7.10 \%$ \\
\hline 4 & Public holidays & 6 & $21.40 \%$ & 2 & $7.10 \%$ & 7 & $25.00 \%$ \\
\hline 5 & Zebra pattern & 9 & $32.10 \%$ & 7 & $25.00 \%$ & 2 & $7.10 \%$ \\
\hline 6 & Zones & 9 & $32.10 \%$ & 5 & $17.90 \%$ & 5 & $17.90 \%$ \\
\hline 7 & $\begin{array}{l}\text { Morning/evening } \\
\text { split }\end{array}$ & 6 & $21.40 \%$ & 5 & $17.90 \%$ & 7 & $25.00 \%$ \\
\hline 8 & $\begin{array}{l}\text { Weekend } \\
\text { schedules }\end{array}$ & 5 & $17.90 \%$ & 2 & $7.10 \%$ & 3 & $10.70 \%$ \\
\hline 9 & $\begin{array}{l}\text { Morning/evening } \\
\text { shift }\end{array}$ & 8 & $28.60 \%$ & 19 & $67.90 \%$ & 17 & $60.70 \%$ \\
\hline 10 & $\begin{array}{l}\text { Morning/evening } \\
\text { split }\end{array}$ & 5 & $17.90 \%$ & 2 & $7.10 \%$ & 4 & $14.30 \%$ \\
\hline Total & & 68 & $24.30 \%$ & 64 & $22.90 \%$ & 74 & $26.40 \%$ \\
\hline
\end{tabular}

font sizes were not specifically tested. The team discussed other possible causes. Regarding the maps, the questions required participants to read the map from right to left, subverting the powerful Western stereotype of motion from left to right. Another cause may have been the number of times the participant had to flip the schedule to view the map and the timetable concurrently. A specific question designed to test trips that began in the morning and concluded in the afternoon also showed high rates; a majority of participants overlooked the morning table, believing that the correct answer was in the afternoon/evening table. If the splitting of morning and afternoon/evening timetables is continued as a strategy, particular attention must be made to this idiosyncrasy.

\section{Evaluation of Subjective Questionnaire}

Upon completion of the time test, subjects were asked to respond to a questionnaire regarding the three schedules. This led to clearer results. The questionnaire asked participants to rank the schedules based on ease of use, reading, and interpretation comfort. The questionnaire also included seven questions about specific design features. Participants had to pick one format over the other, or had the option of remaining neutral. Results for each feature are summarized below.

Labeling Preference. Two styles of time-point location labeling were tested: one vertical, consistent with existing schedules; the other, the slanted labeling used in the prototypes and found in many other agency schedules surveyed. More than 
50 percent of the participants preferred slanted labeling and 2 of 30 participants were neutral. Only 10 of the 30 voted for the vertical format.

Zebra Pattern. More than 50 percent of the participants voted for the zebra pattern and stated that the alternate shading of columns made the bus schedules more readable. Only 3 of 30 subjects voted against the zebra pattern and 6 of the 30 remained neutral.

Zone Representation. Participants voted unanimously for the zone to be represented at the bottom of every table.

Heading Representation. In the prototypes, the headings were represented differently with respect to black on white or visa versa. In the current schedules, the headings are set in black on white backgrounds. In the prototypes (see Figures 2 and 3), the schedule heading on one side of the schedule used white fonts on black background while reversing it on the other. This was expected to catch the attention of the participants and help them in distinguishing between the two sides when using the timetable. The response to this modification was unfavorable, although there were many abstentions. Only 6 out of 30 subjects voted for the different representation, while 11 of the 30 voted for the black font on white background. Fourteen participants chose to be neutral regarding this issue.

Table Layout. Regarding the morning and afternoon/evening reorganization, more than 50 percent of the participants voted for the single table, without breakup. Twelve out of 30 participants voted for the breakup of tables into morning and afternoon/evening and 2 remained neutral (see Figure 4).

Other Information Representation. The prototypes introduced the pictorial representation for information regarding handicap facilities that is expressed in text on the current schedules. More than 50 percent of the participants preferred the pictorial format of representation. Six out of 30 were neutral and 6 preferred the text format.

Direction versus Day of Travel. More than 50 percent of the participants chose the "directional prototype" over the "weekday/weekend prototype." None of the 30 subjects chose to be neutral. Only 9 of the 30 chose the weekday/weekend mode of representation (see Figures 2 and 3 ).

\section{Ranking Data Analysis: Chi-Square Tests}

Participants were asked to rank the existing schedule and the two prototypes with rank 1 indicating most preferred and rank 3 the least. A chi-square test conducted 
on the ranking data revealed that between the two prototypes, the "directional schedule" was preferred, ranked more frequently as rank 1 and 2 as compared to rank 3 (Chi square value was $17.80>9.49$, the value for a 95 percent confidence interval and four degrees of freedom [also see Table 3]). The results show that subjects ranked the current schedule more frequently as rank 3 as compared to rank 2 or rank 1. Furthermore, the statistical analysis also showed that the ranking of the weekday/weekend schedule was evenly poised across the three ranks, showing no statistical significance. The results have been tabulated in Table 3.

\section{Table 3. Chi-Square Test for the Ranking of the Three Schedules}

\begin{tabular}{|l|c|c|c|c|}
\hline & Rank 1 & Rank 2 & Rank 3 & Row Total \\
\hline Current schedule & 5 & 7 & 18 & 30 \\
\hline Directional schedule & 15 & 12 & 3 & 30 \\
\hline Weekday/Weekend schedule & 10 & 11 & 9 & 30 \\
\hline Column total & 30 & 30 & 30 & 90 (Grand total) \\
\hline
\end{tabular}

Expected value for each cell $=($ Sum of row $\times$ Sum of columns $) /$ Grand total $=$ $(30 \times 30) / 90=10$

ChiSq $=2.500+0.900+6.400$

$$
\begin{aligned}
& +2.500+0.400+4.900 \\
& +0.000+0.100+0.100=17.800
\end{aligned}
$$

Degrees of freedom $=4$

$17.80>9.49$; for $95 \%$ confidence Interval, Degrees of Freedom $=4$

The following conclusions can be drawn from the questionnaire responses:

- The straight, long table was the only feature favored from the current schedule.

- All 30 participants preferred the zone representation incorporated in the prototypes.

- The majority of participants preferred the zebra pattern. Most also favored the slanted labeling and the pictorial format of representing other information in the schedules.

- The "directional prototype" schedule was preferred over the "weekday/ weekend prototype" by a majority of the participants. 


\section{Recommendations}

Based on the entire process, including the review of relevant literature, input from NJT staff, focus group feedback, and the results of the performance test and questionnaire, the following recommendations were made to the agency:

- Font size should be increased. The high overall error rates are most attributable to participants' difficulty in reading text that is almost half the minimum size recommended in generally recognized standards.

- The "directional prototype" schedule was preferred by participants by a more than two-to-one margin. It is also the organizational style currently in use. It should not be changed, despite evidence to the contrary found in the literature search, at least without considerable further study.

- Eliminate information not directly related to the service NJT provides. Much of the "other" information on NJT bus schedules has reportedly been added in response to customer feedback as well as concerns raised from NJT legal and administrative staff. Some of this information needs to remain, regardless of relevance to the user, but efforts to streamline, consolidate or reduce it, should be made.

- Morning and afternoon/evening time points should be retained in a single timetable although consideration should be given to distinguishing the periods using other display methods. Again, this contradicts findings of the literature search as well as the focus groups, but without further study, it should not be employed at this time.

- Adjacent columns should be distinguished from each other through the use of shading. Caution should be used when adopting this feature, however, as other schedules already use shading to denote peak hours or special exceptions.

- Time-point locations should be slanted so as to not require rotation. A wide margin of participants preferred this feature, which is also used by many other agencies.

- Time-point locations should be coded to locations on the map as it already is on the 62 schedule.

- Adopt the zone representation format used in the prototypes. This was a feature that showed conclusive statistical significance and a unanimous vote in the questionnaires. 
In discussing these changes with NJT staff, it is clear that implementation would likely impact production operations and require additional resources. While the recommendations listed above will probably improve the readability of NJT's bus schedules in the short term, the momentum created can be continued by focusing on issues that the study identified. Some of these are institutional concerns that transcend those of production, while others are opportunities for further research in this area. The following were recommended to NJT for further action:

- Develop and test additional prototype schedules using the methods established in this study. The lessons learned in this research provide a significant basis for developing new schedules. Conduct the same time-and-error based experiment with a larger group and expand the content of the study. Specifically, test the effectiveness of different font sizes, as this is probably the most critical attribute of readability. Additionally, different font styles should also be tested. New designs should focus on eliminating extraneous information and making the information more user-friendly. Different types of bus routes, serving a variety of demographic groups, should also be examined.

- Initiate a separate study that specifically probes literacy and schedule readability. This would be specifically geared toward bus transit users, many of whom are financially and/or educationally disadvantaged or use English as a second language.

- Initiate broad-based institutional discussions with staff to identify information to eliminate, thereby increasing space to allow for larger fonts. This could take the form of internal focus groups.

- Streamline routes so as to reduce complexity, perhaps based on a maximum number of time points allowable on a schedule.

- Develop a "one-call" system and eliminate the extensive list of phone numbers on current schedules.

- Investigate other scheduling software that could help facilitate new and improved concepts for schedule presentation. Current software used by NJT since 1989 has considerable limitations. Software that could facilitate changes more easily and cost-effectively should be explored. 


\section{Conclusions}

While this article underscores the essential role information plays in mass transit mobility, it stresses the critical importance of the means by which that information is conveyed. The attributes of those means-clarity, legibility, and readability-must not be taken for granted. This article offers clear directives regarding certain organizational styles and specific features; it also identifies specific areas for further research. While these results are specific to one of the most complicated schedules of a large agency and its methods respected that agency's production and institutional conventions, these results can nonetheless speak to the broader transit community. The interdisciplinary approach described here, coordinating community outreach, graphic design and time-based laboratory testing, not combined in this manner before, has proven valuable to NJT and offers a protocol that can be applied elsewhere. The continued pursuit of an effective way to assess and improve existing bus schedule layouts can lead to making bus transit more attractive and efficient.

\section{Acknowledgments}

This article reports the research conducted as part of FHWA-NJ-2003-028, "Improving Public Transit Schedules-Timetables People Can Actually Read". Research for this grant was undertaken in an interdisciplinary capacity that included three co-principal investigators at NJIT: George Fallat P.E., transportation engineer; Darius Sollohub, AIA, architect and graphic designer; and Dr. One-Jang Jeng, human-factors research scientist. They were assisted by graduate researchers Sahanah Rao, Savitha Rajah, Anand Tharanathan, and Nelisa Mejia. The New Jersey Department of Transportation sponsored the project, with Edward Kondrath as project manager. The New Jersey Transit Corporation was the beneficiary of the research, for which Jerome Lutin led the project team that included Janice Pepper, David Volk, Allison Demyanovich, Janet Clark, Robert Lilley, and Helen Hind. Lou Sanders of the American Public Transportation Association provided guidance to the effort.

\section{Endnotes}

${ }^{1}$ These figures are for rail and bus queries combined. The only breakdown available from NJT is that 65 percent of operator-assisted calls are from bus patrons. 
${ }^{2}$ An analysis of variance (ANOVA) was conducted to analyze the data. Statistical significance was concluded only if $\mathrm{p}<0.05$.

\section{References}

Bartram, D., M. Crawshaw, and N. Sprent. 1980. Intelligibility of timetables. Human Factors in Transportation Research 1: 319-327.

Bartram, D., M. Crawshaw, and N. Sprent. 1983. Structuring Timetable Information. Ergonomics 26 505-516.

Fisher, D., and K. Tan. 1989. Visual displays: The highlighting paradox. Human Factors 31: 17-30.

Fox, K., and P. Wright. 1972. Explicit and implicit tabulation formats. Ergonomics 15: $175-188$.

Fox, K., and P. Wright. 1970. Presenting information in tables. Applied Ergonomics 1: 234-242.

Goettl, B. P., A. F. Kramer, and C. D. Wickens. 1986. Display format and perception of numeric data. Proceedings of the Human Factors Society-30th Annual Meeting, Human Factors Society, pp. 450-454.

McCormick, E. J., and M. S. Sanders. 1993. Human factors in engineering and design. New York: McGraw Hill.

Transit Cooperative Research Program. 1999. Passenger information services: A guidebook for transit systems-TCRP Report 45. Washington, DC: National Academy Press.

Nimmo-Smith, M., and A. Wilkins. 1987. The clarity and comfort of printed text. Ergonomics 30: 1705-1720.

Phillips, R. 1979. Why is lower case better? Applied Ergonomics10: 211-214.

Schneiderman, B. 1998. Designing the user interface, strategies for effective humancomputer interaction. Boston, MA: Addison-Wesley.

Smith, S. L. 1979. Letter size and legibility. Human Factors 21: 661-670.

Sparrow, J. 1989. Graphical displays in information systems: Some data properties influencing the effectiveness of alternative forms. Behaviour and Information Technology 8: 43-56. 
Swanston, M. T., and C. E. Walley. 1984. Factors affecting the speed of acquisition of tabulated information from visual display. Ergonomics 27: 321-330.

Tinker, M. A. 1960. Legibility of mathematical tables. Journal of Applied Psychology 44: 83-87.

Tinker, M. A. 1954. Readability of mathematical tables. Journal of Applied Psychology 38: 436-442.

Tufte, E. 2001. The visual display of quantitative design. Cheshire, CT: Graphic Press.

Tullis, S. 1983. The formatting of alphanumeric: A review and analysis. Human Factors 25: 657-682.

Wickens, C. D, and J. D. Hollands. 2000. Engineering psychology and human performance. NJ: Prentice Hall.

Wickens, C. D., J. D. Lee, Y. Liu, and S.E.G. Becker. 2004. Introduction to human factors engineering. NJ: Prentice Hall.

\section{About the Authors}

DARIUS SollohUB (sollohub@njit.edu) is an associate professor and co-director of infrastructure planning at the New Jersey School of Architecture at NJIT, where he teaches architecture and infrastructure planning courses and studios, and coordinates community outreach. His research interests are in the areas of planning pedagogy, graphic design, infrastructure history, urban design, smart growth, and sustainable development.

ANAND Tharanathan (anand.tharanathan@ttu.edu) is a Ph.D. (experimental psychology) student in the Department of Psychology and a research assistant at the Visual Performance Laboratory at Texas Tech University. In 2004, he received his masters in industrial engineering from New Jersey Institute of Technology, Newark, New Jersey. 


\title{
A DSS Framework for Advanced Traffic Signal Control System Investment Planning
}

\author{
Houng Y. Soo and Dusan Teodorovic, \\ Virginia Polytechnic Institute and State University \\ John Collura, University of Massachusetts
}

\begin{abstract}
This article presents ongoing research on the initial development of a decision support system (DSS) framework for integrated emergency vehicle preemption and transit priority system investment planning. A conceptual intelligent DSS framework provides a holistic framework to perform analytical assessments of integrated emergency vehicle preemption and transit priority systems. Three analytical tools are presented for incorporation into future DSS design: the first addresses the potential impact of transit travel time reduction on transit operating costs; the second addresses the potential impact of reduced emergency vehicle crashes at signalized intersections on fire and rescue operating costs; and the third integrates fuzzy sets concepts and multiattribute decision-making methods to rank order transit signal priority strategy alternatives at the intersection level.
\end{abstract}

\section{Introduction}

Advances in microprocessor and communications technologies are making it possible for current traffic signal controllers and vehicle detection technology to accommodate both emergency vehicle preemption and transit priority strategies 
as part of an integrated system. However, investment planning for an integrated emergency vehicle preemption and transit signal priority system is not a trivial task. Two distinct service providers, fire and rescue providers and transit operators, with separate operational functions, resources, objectives, and constituents are involved. In addition, a variety of institutional and local concerns-ranging from the identification of the important stakeholders, to the assessment of emergency vehicle preemption and transit signal priority system impacts, to performing economic analysis to determine efficiency and effectiveness of an investment from a systems perspective, must be taken into account.

Currently, transportation planners and managers interested in deploying these advanced traffic signal control systems do not have an evaluation approach or a set of common performance metrics to make informed planning decisions. Planners and managers need a structured analytical approach to use as part of their investment planning process.

This need may be met by a decision support system that (1) is designed to assess simultaneously the impacts of integrated emergency vehicle preemption and transit signal priority systems for investment purposes, and (2) has the ability to process both quantitative and qualitative data at varying degrees of precision.

This article presents ongoing research on the development of a DSS framework for advanced traffic signal control system investment planning. This study builds and expands on previous research on economic evaluation frameworks, evaluation of preferential treatments of emergency vehicle preemption and transit vehicle priority at signalized intersections, emergency vehicle crash characteristics, and transit travel time reduction.

\section{Literature Review}

Emergency vehicle preemption and transit signal priority systems are similar from a systems perspective, in that they both consist of a vehicle detection system, a communications system, and a traffic signal control system. Together, as components of a system, they have the capability to provide preferential treatment to both emergency vehicles and qualified transit vehicles. Research suggests that both emergency and transit vehicles would benefit from preferential treatment strategies with minimal impact on other users (Collura, Rakha, and Gifford 2003).

Research to date has addressed the individual impacts of emergency vehicle preemption and transit priority systems from an operational perspective. Fire and res- 
cue providers are interested in emergency vehicle preemption to reduce response time, increase safety, and reduce emergency vehicle crashes at signalized intersections (Bullock, Morales, and Sanderson 1999). Transit operators are interested in transit signal priority to reduce transit travel time, improve schedule reliability, and reduce operating expenses (Chang et al. 2002). Evaluation frameworks, performance measures, and guidelines have been developed that are specific to either emergency vehicle preemption or transit vehicle priority and oriented toward the assessment of their specific operational performance characteristics. In addition, results from field measurements and simulations for both emergency vehicle preemption and transit signal priority are often imprecise in nature, making it difficult to benchmark performance characteristics accurately.

The travel impacts of an advanced traffic signal control system capable of integrated emergency vehicle preemption and transit signal priority operations and their respective stakeholders are shown in Table 1. The distribution of the 10 travel impacts illustrates the complex and interdependent nature of integrated emergency vehicle preemption and transit signal priority systems. The stakeholders

\section{Table 1. Advanced Traffic Signal Control System Travel Impact Distribution}

\begin{tabular}{|c|c|c|c|}
\hline $\begin{array}{l}\text { Preferential } \\
\text { Treatment }\end{array}$ & Objective & Travel Impact & Stakeholders \\
\hline \multirow{6}{*}{$\begin{array}{l}\text { Transit Signal } \\
\text { Priority }\end{array}$} & \multirow{3}{*}{ Reduces transit travel time } & Reduces transit O\&M costs & Transit service provider \\
\hline & & $\begin{array}{l}\text { Reduces travel time for } \\
\text { passengers }\end{array}$ & Transit passengers \\
\hline & & $\begin{array}{l}\text { Reduces passenger non-travel } \\
\text { time }\end{array}$ & Transit passengers \\
\hline & $\begin{array}{l}\text { Increases bus service } \\
\text { reliability }\end{array}$ & $\begin{array}{l}\text { Reduces transit passenger non- } \\
\text { travel time }\end{array}$ & Transit passengers \\
\hline & $\begin{array}{l}\text { Reduces other vehicle travel } \\
\text { time on arterial }\end{array}$ & $\begin{array}{l}\text { Reduces travel time for others } \\
\text { on bus route }\end{array}$ & Motorist \\
\hline & $\begin{array}{l}\text { Increases other vehicle travel } \\
\text { time on side streets }\end{array}$ & $\begin{array}{l}\text { Increases travel time on side } \\
\text { streets }\end{array}$ & Motorist \\
\hline \multirow{4}{*}{$\begin{array}{l}\text { Emergency } \\
\text { Vehicle } \\
\text { Preemption }\end{array}$} & Reduces EV travel time & $\begin{array}{l}\text { Saves lives } \\
\text { Reduces injury } \\
\text { Reduces fire damage } \\
\end{array}$ & $\begin{array}{l}\text { General public } \\
\text { (elected officials) }\end{array}$ \\
\hline & Reduces EV crashes & $\begin{array}{l}\text { Reduces accident costs at } \\
\text { signalized intersections }\end{array}$ & Fire and rescue provider \\
\hline & $\begin{array}{l}\text { Increases delays to other } \\
\text { vehicles }\end{array}$ & $\begin{array}{l}\text { Increases travel time for other } \\
\text { drivers and passengers }\end{array}$ & Motorist \\
\hline & Increases delay to transit & $\begin{array}{l}\text { Increases travel time for transit } \\
\text { passengers }\end{array}$ & Transit passengers \\
\hline
\end{tabular}


are the recipients of these positive and negative impacts. Planners and managers must consider input from elected officials, the general public, transit passengers, nontransit users, emergency service providers, and transit operators in their investment decisions. This requires coordination among the major stakeholders to address institutional, technical, and financial issues. Traditionally, each service provider has planned and costed their version of the system separately. Table 1 suggests that the benefits from reduced operating costs to the two service providers (transit and fire and rescue) may be eclipsed by the impact to the general public, transit riders, and motorists (Soo et al. 2004).

Previous research has produced useful information on key transit performance characteristics such as transit travel time reductions (Chang 2002), schedule reliability (Chang et al. 2002), nontransit delay (Ngan 2003), and stakeholder concerns (Noyce 1996; Gifford, Pelletiere, and Collura 2001; Levin et al. 1999). Their information reinforces the uncertainty and imprecision of the available data. These results, while dependent on the method of collection as well as geometric and operational conditions, are useful in providing "order of magnitude" estimates to improve our understanding of the impacts of transit signal priority, but they do not have the precision desired for use in more systematic mathematical modeling.

Fuzzy sets theory is a convenient mathematical device for treating imprecise (uncertain, subjective, and ambiguous) data. Fuzzy sets theory has been applied in mathematical modeling of traffic and transportation processes that include traffic control, traffic assignment modeling, vehicle modeling, scheduling and dispatch modeling, cost-benefit analysis, and transportation investment planning (Teodorovic 1994).

\section{Decision Support System Development}

\section{Decision Support System Framework}

DSS is made up of computer technology solutions that can be used to support complex decision making and problem solving. A generic intelligent DSS consists of four components: database management module, model management module, knowledge management module, and user interface module. The structure of a conceptual intelligent DSS framework designed to assess the impacts of integrated emergency vehicle preemption and transit signal priority systems is shown in Figure 1. 


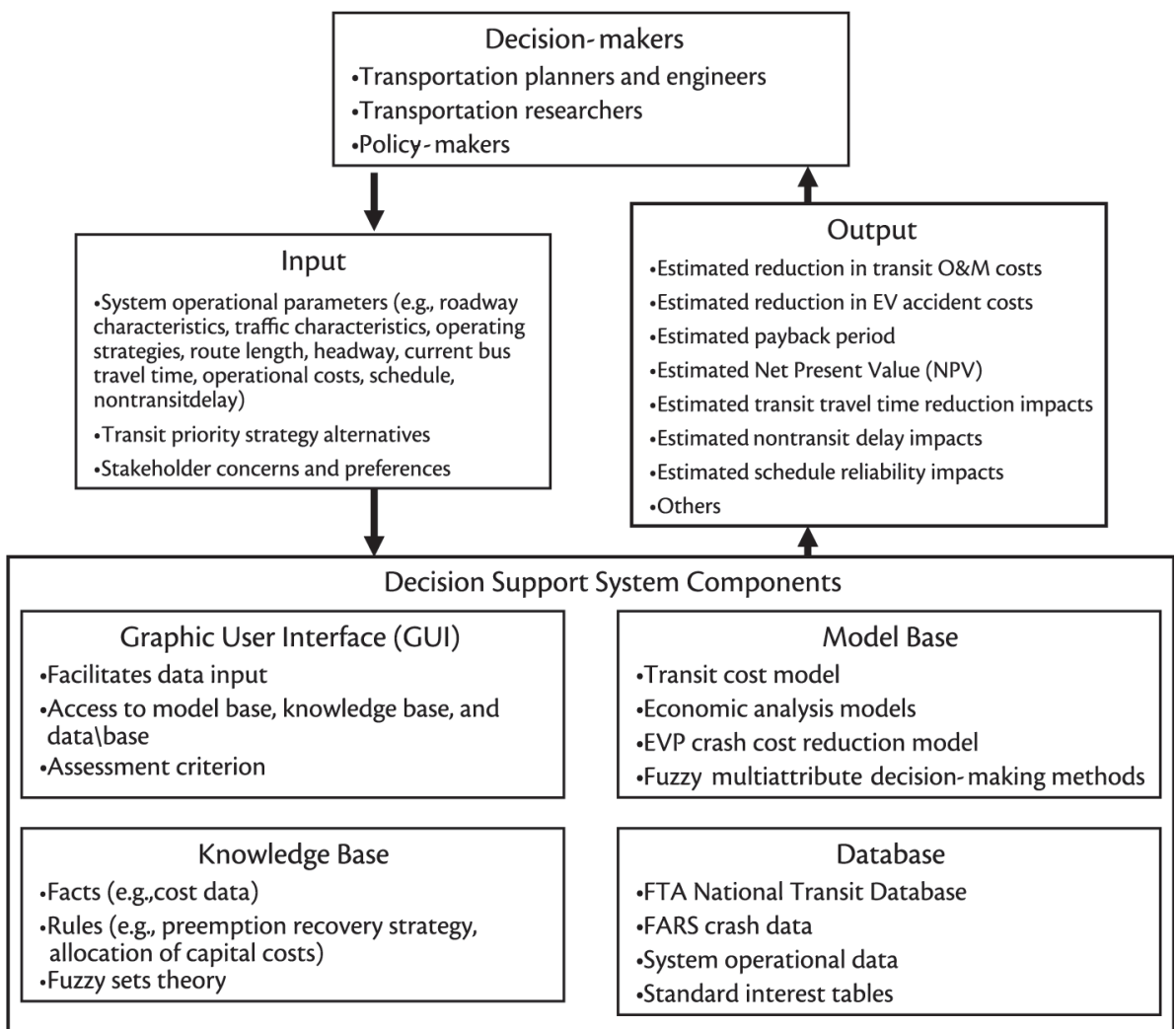

Figure 1. DSS Framework

This DSS is intended for transportation planners and engineers, transportation researchers, and policy-makers. User input would include system operational parameters (roadway characteristics, traffic characteristics, and system operational strategies), transit signal priority alternatives, and stakeholder concerns and preferences. Desired DSS output include graphic and numeric results relating to economic analysis (payback period, capital recovery period, NPV, etc.), operational performance (transit run-time reduction, schedule reliability impacts), operating cost savings, and transit signal priority strategy alternatives.

The database management module contains operational and financial data for transit operations, fire and rescue operations, accident and safety statistics, as well as system operational data. 
The model management module provides the environment for storing, retrieving, and manipulating models. It links the user to the appropriate mathematical models, optimization methods, analytical tools, and procedures to perform various types of analyses.

The knowledge base module contains problem-specific rules and facts relating to transit operations, fire and rescue operations, advanced traffic signal control systems costs, as well as the ability to use soft computing techniques. This module makes available expert knowledge to substitute human expertise for missing algorithms. The incorporation of intelligent DSS functionalities in the form of soft computing adds the ability to process both quantitative and qualitative data at varying levels of precision.

The user interface module provides the means for the user to interface with the DSS and to (1) access the database, model base, and expert knowledge base; (2) input information such as performance characteristics; (3) display and analyze data and formulate and evaluate alternative decisions; and (4) view output displays.

\section{Analytical Tools}

Research in the development of this conceptual DSS framework has generated three analytical tools that could be incorporated into the DSS. The first addresses the potential impact of transit travel time reduction due to transit signal priority on transit operating costs. The second addresses the potential impact of reduced emergency vehicle accidents on signalized intersections due to emergency vehicle preemption. The third utilizes soft computing techniques in the form of fuzzy sets theory concepts to deal with the imprecision normally associated with transit signal priority strategy alternative performance characteristics.

Transit O\&M Cost Impact. A potential impact of transit signal priority is reduced transit travel time. Transit service providers are interested because of the potential to save operating costs; transit passengers are interested because of the potential to reduce both travel time and nontravel time. In the austere public fiscal environment, both efficiency (Will society benefit from this investment?) and cost effectiveness (Can we afford to do this?) are important factors to be considered in the decision-making process. Efficiency measures the economic feasibility of an investment from a societal perspective and is an outcome of a benefit-cost analysis. It answers the question "Are the total net benefits received by society 
as a whole increased by the project?" Cost effectiveness addresses the question "Will this improvement generate enough money to pay for its development and operation?" and measures the financial feasibly of a project. Ideally, society should benefit from the deployment of an advanced traffic signal control system and the cost of deployment should be recouped directly from operating and capital cost savings (ECONWest and Parsons Brinckerhoff Quade \& Douglas 2002; Lee and Carroll 2001; Morlok, Brunn, and Blackman 1991).

Figure 2 presents a simple three-step spreadsheet model to estimate the impact of reduced transit $O \& M$ costs and whether that reduction is sufficient to warrant the investment costs. The model answers the question "Can we afford to do this investment?"

- Step 1 computes the operating cost savings based on the total transit travel time reduction.

- Step 2 computes the investment costs and annual costs associated with this deployment.

- Step 3 provides the results of several assessments: payback period analysis, capital recovery period analysis, and net present value analysis. The payback period represents the amount of time that it takes for a project to recover its initial cost ignoring the time value of money. It answers the question "How quickly can the investment be recovered based on savings in operating costs associated with the transit signal priority system?" The capital recovery period represents the amount of time it takes for a project to recover its initial cost taking into account the time value of money. Finally, net present value analysis projects the present value of future savings expected from an investment.

A system-level analysis was conducted using data collected at the Virginia Tech/ George Mason University/Virginia Department of Transportation integrated emergency vehicle preemption and transit signal priority operational field test on U.S. 1 in Northern Virginia. The results suggest that planners and managers may need to consider apportioning the investment costs of integrated emergency vehicle preemption and transit signal priority systems. Traditionally, fire and rescue service providers and transit service providers each estimated deployment costs from a myopic perspective. The notion of cost sharing among the two service providers and the municipality recognizes the interactive role of these agencies in providing quality service to the public. 

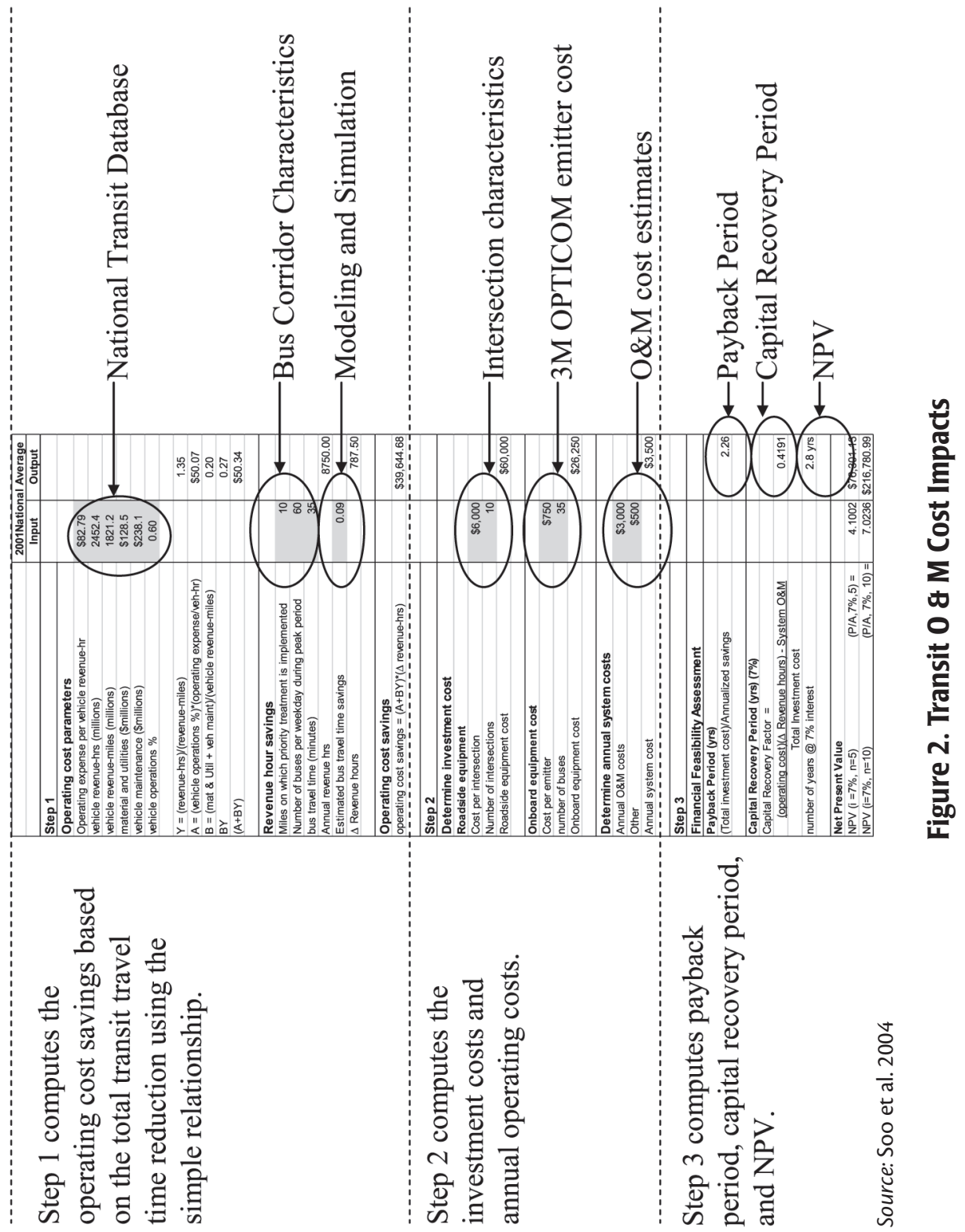
Emergency Vehicle Crash Reduction Operating Cost Impact. A potential impact of reduced emergency vehicle crashes on signalized intersections is reduced fire and rescue operating costs. Operational experience suggests that the deployment of emergency vehicle preemption may decrease the number and severity of accidents involving emergency vehicles and other vehicles at signalized intersections. Reducing emergency vehicle crashes at signalized intersections will reduce the cost to repair emergency vehicles damaged in crashes, reduce the cost of vehicle insurance, and reduce nonavailability time awaiting repairs. A simple spreadsheet model that can be used to assess average savings is presented in Figure 3. The number of emergency vehicle crashes and their distribution on signalized and nonsignalized intersections and nonintersections can be determined from fire and rescue operational data or from regional accident report databases. Historical information can also be used to estimate average repair cost.

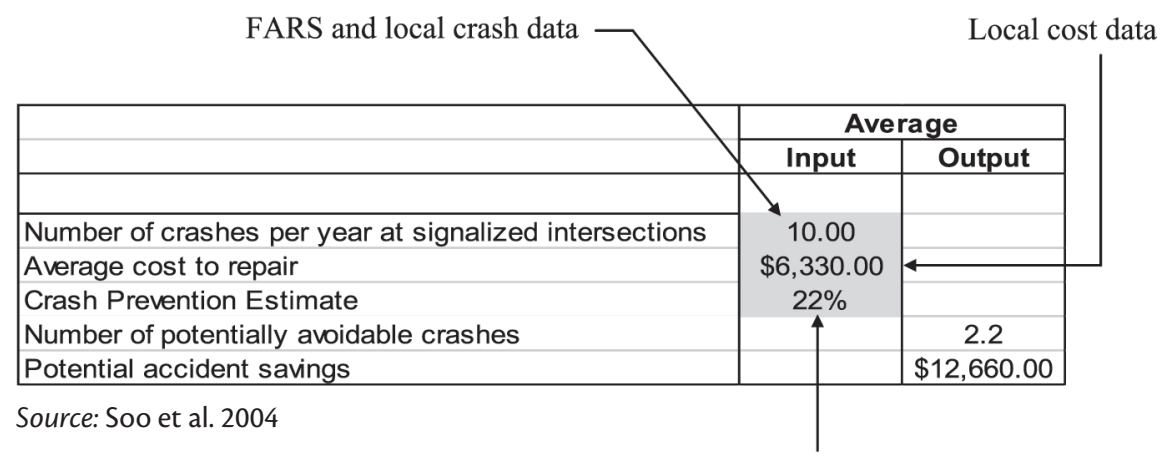

Extracted from St Paul data

Figure 3. Emergency Vehicle Crash Reduction Operating Cost Impact

The example shown in Figure 3 suggests that a 22 percent crash reduction to a fire and rescue provider with 10 signalized intersection crashes per year and an average repair cost of $\$ 6,330$, can potentially save $\$ 12,660$ in operating costs (Gkritza et al. 2004; Soo et al. 2004).

Fuzzy Multiattribute Decision Making. Determining the most preferred transit signal priority strategy alternative for an intersection is not a trivial task. Beforeand-after operational data for deployed transit signal priority systems is limited, and the available data is not standardized, is dependent on geometric and operational conditions, and is characterized by imprecision. In addition, stakeholders representing multiple constituencies (e.g., elected officials, traffic representatives, 
transit representatives, emergency service providers, transit riders, nontransit operators, community organizations, and pedestrians) often have conflicting interests that must be incorporated in the decision process.

To this end, a systematic evaluation tool using multiattribute decision-making (MADM) methods and fuzzy sets concepts was developed to quantify the expected impacts of transit travel time reductions, nontransit delays, and service reliability as they relate to alternative transit signal priority strategies with varying stakeholder preferences (Soo, Collura, and Teodorovic 2005).

Three fuzzy set concepts will be used to derive triangular fuzzy numbers for use in fuzzy MADM methods. The concept of triangular fuzzy numbers will be used to describe the impact of transit signal priority strategy alternatives on transit travel time reduction; linguistic variables will be used to describe their impact on nontransit delay; and the intersection of fuzzy sets will be use to uniquely measure the impact of the four alternatives on schedule reliability. Linguistic variables will also be used to determine stakeholder preference-based weighting for the three criteria.

Linguistic variables are used when criteria cannot be quantified. Values of linguistic variables are words such as "not important," "important," and "very important." Figure 4 presents the membership function of fuzzy sets "not important," "important," and "very important." Their corresponding triangular fuzzy numbers are $(0,0,5),(0,5,10)$, and $(5,10,10)$, respectively.

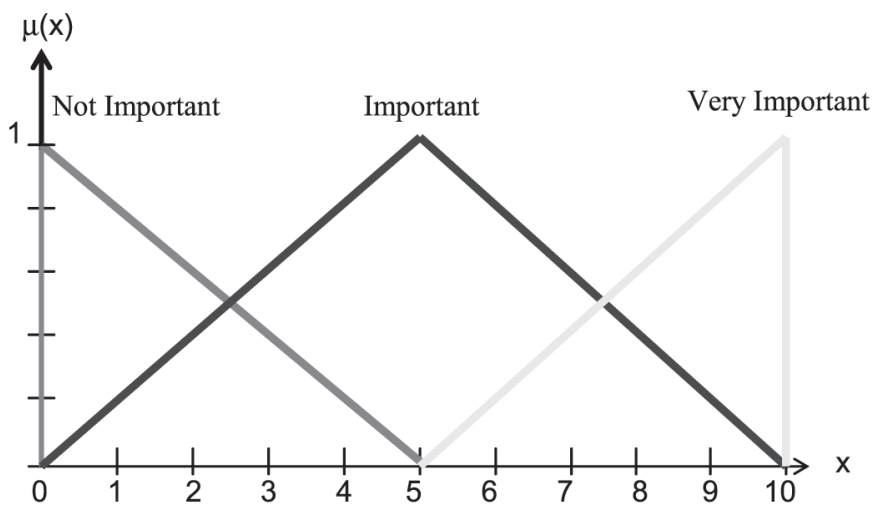

Figure 4. Membership Function of Fuzzy Sets "Not Important," "Important," “Very Important" 
The resultant decision matrix can be ranked using standard fuzzy MADM methods such as the weighted sum method (WSM) and the Technique for Order Preference by Similarity to Ideal Solutions (TOPSIS) (Chen and Hwang 1992).

Fuzzifying Transit Travel Time Reduction Performance Data. The impact of various transit signal priority strategy alternatives on transit travel time reduction is a key criterion. Transit travel time reduction is an important consideration for transit operators interested in operating efficiency and schedule adherence. Travel time reduction is important to transit riders because it can potentially decrease invehicle and out-of-vehicle travel time. Results from deployments and simulation indicate that the degree of transit travel time reduction is a function of the type and combination of transit signal priority strategy used.

Transit travel time reduction can be described by triangular fuzzy numbers (Teodorovic and Kikuchi 1991). Triangular fuzzy numbers represent a special set of fuzzy numbers. Their name is derived from the shape of their membership function. Figure 5 shows the triangular fuzzy number $A=\left(a_{1}, a_{2}, a_{3}\right)$ where $a_{1}$ is the lower (left) boundary of the triangular fuzzy number, $a_{2}$ is the number corresponding to the highest level of presumption, and $a_{3}$ is the upper (right) boundary of the triangular fuzzy number.

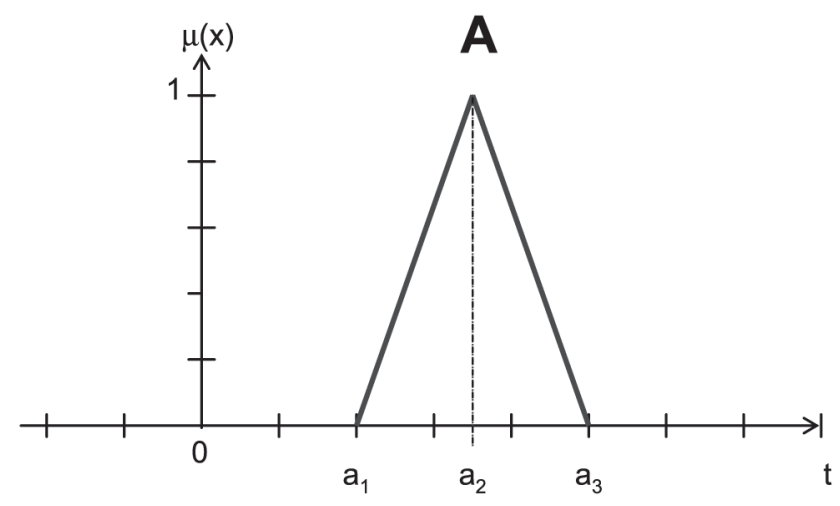

\section{Figure 5. Membership Function of Fuzzy Set A}

The base of the triangular fuzzy number $A,\left(a_{1}\right.$ and $\left.a_{3}\right)$ in Figure 5 , is used to represent the confidence interval range of the transit travel time reduction, and a2 denotes the approximate mean. The triangular fuzzy number representing a transit travel time reduction of $2 \%-4 \%$ would have $a_{1}=2 \%, a_{2}=3 \%$, and $a_{3}=4 \%$. 
Fuzzifying Nontransit Delay Performance Data. The potential impact of transit signal priority on nontransit delay is of considerable concern among all the stakeholders (Gifford et al. 2001). Results from deployments and simulations indicate that nontransit vehicles along the priority route generally benefit from transit signal priority while nontransit vehicles on cross streets experience some increased delay (Chada 2004). Researchers have found that the degree of nontransit delay is strongly related to the volume/capacity $(\mathrm{v} / \mathrm{c})$ ratios of both the approach and cross streets. Approach $\mathrm{v} / \mathrm{c}$ ratios between approximately 0.20 and 0.90 are best suited for transit signal priority applications. Cross-street performance impacts are minimal at low cross-street $\mathrm{v} / \mathrm{c}$ ratios $(0.25 \leq \mathrm{v} / \mathrm{c} \leq 0.5)$, moderate at cross-street $\mathrm{v} / \mathrm{c}$ ratios of 0.8 , and significant at cross-street $\mathrm{v} / \mathrm{c}$ ratios above 0.9 (Ngan 2003). The membership function that linguistically represents the impact on cross-street performance across the entire range of $\mathrm{v} / \mathrm{c}$ ratios is shown in Figure $6 \mathrm{a}$. Figure $6 \mathrm{~b}$ represents the conversion scale to translate the linguistic terms of Figure 6a. Using Figures $6 \mathrm{a}$ and $6 \mathrm{~b}$, a cross-street $\mathrm{v} / \mathrm{c}$ ratio of 0.6 (moderate impact) is converted to a triangular fuzzy number of $(0,5,10)$.

Fuzzifying Schedule Reliability. Transit signal priority has the potential to improve bus schedule reliability. The notion of schedule reliability, also referred to as schedule adherence, is simply to get buses to arrive at bus stops on schedule (i.e., within a certain threshold range). Several different measures of effectiveness have been identified. These performance measures include: on-time performance, time reliability, perceived on-time performance, spacing, and arrival reliability (Chang et al. 2002). Arrival time reliability measures the deviation of actual arrival times versus scheduled arrival times and is useful because the majority of transit passengers go to work usually at the same time each day and rely on consistent arrival schedule windows to arrive at work on time.

The intersection of fuzzy sets is used to assess the value of a set of arrival times in relation to the acceptable threshold. The membership function of fuzzy set $\mathbf{A}$, shown in Figure 7, represents an acceptable threshold between 1.5 minutes early and 4 minutes late. The fuzzy sets $\mathbf{B}_{1^{\prime}} \mathbf{B}_{2^{\prime}}$, represent the arrival times approximately 1 minute late and approximately 3 minutes late, respectively. The shaded area represents the intersection of these arrival times to the acceptable arrival time threshold. The truth values ( 0.8 and 0.38 ) correspond to the highest membership of the intersection of $\mathbf{B}_{1}$, and $\mathbf{B}_{2}$ to $\mathbf{A}$ and uniquely define the performance of these two arrival times with respect to the threshold range. 


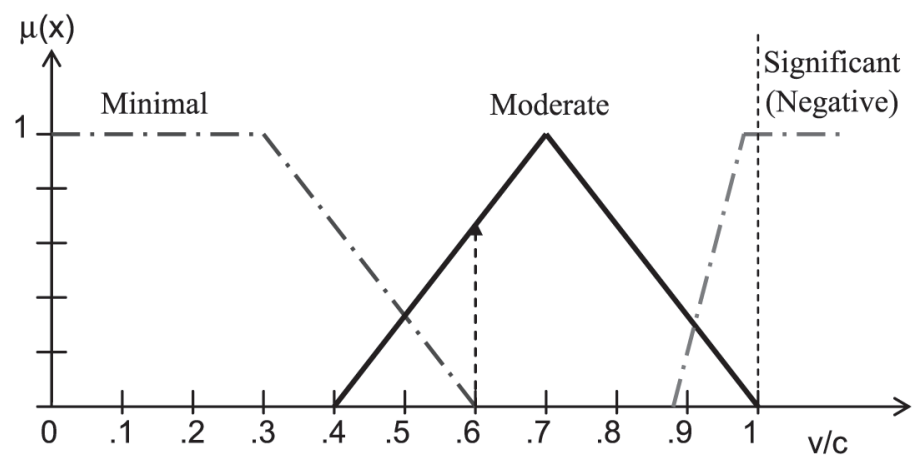

6a. Membership Function for Nontransit Delay

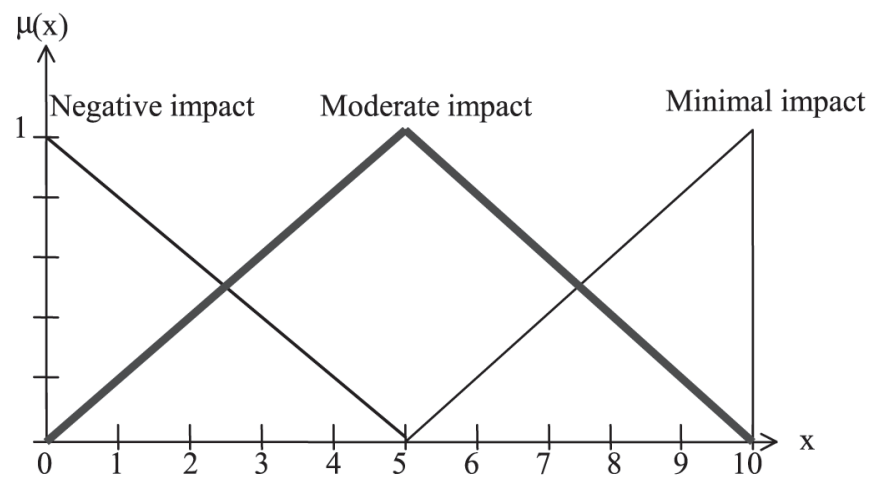

6b. Membership Function for "Negative Impact,"

"Moderate Impact", "Minimal Impact"

\section{Figure 6. Fuzzifying Nontransit Delay}

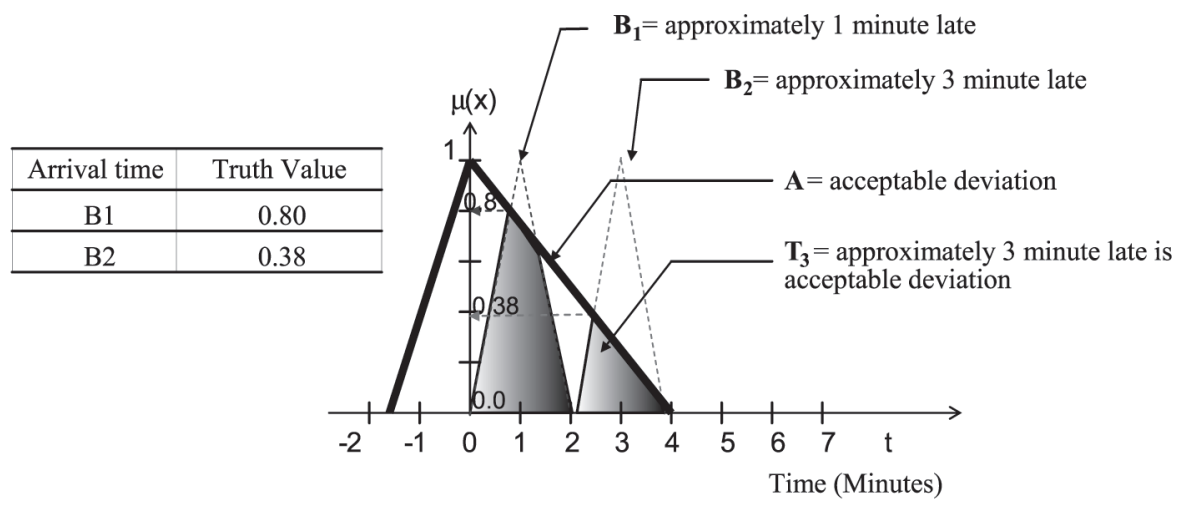

Figure 7. Fuzzifying Schedule Reliability 
Fuzzifying Stakeholder Concerns. Stakeholder objectives, needs, and preferences are important considerations. Potential stakeholders include elected officials, traffic representatives, transit representatives, fire and rescue providers, and transit riders.

Researchers have found that there is a general lack of knowledge and understanding of priority systems on the part of the traffic and transit officials and the public (Noyce 1996; Chada 2004). Results from interviews with stakeholders indicate that while there is significant interest in signal priority and preemption, it is not top priority among elected officials, traffic or transit agencies. In general, stakeholder concerns regarding implementation of transit signal priority are centered about system costs and traffic disruptions, schedule adherence, impact on ridership, and interoperability (Gifford et al. 2001).

Linguistic variables "not important," "important," and "very important" (Figure 4) will be used to represent stakeholder preferences to the three criteria of transit travel time reduction, nontransit delay, and schedule reliability. The triangular fuzzy numbers for these linguistic variables are: $(0,0,5),(0,5,10)$, and $(5,10,10)$, respectively.

Illustrative Example. The following example applies the concepts previously presented to rank order four transit signal priority strategy alternatives based on alternative performance attributes (criteria) and stakeholder preferences. The technical approach is to solve a multiattribute problem that involves a set of $\mathrm{m}$ alternatives $\mathbf{A}_{i}(i=1,2, \ldots, m)$. These alternatives are to be evaluated with respect to $n$ criteria (or attributes) $\mathbf{C}_{\mathbf{j}}(\mathrm{j}=1,2, \ldots, n)$. The weighting vector, $\mathbf{W}$, will represent the relative importance of the criteria to the stakeholders. The decision objective is to rank order all the alternatives in terms of their overall preference value.

1. Determine the alternatives and relevant criteria to be evaluated.

Transit travel time reduction:

$\left(A_{1}\right)$ signal optimization $2 \%-5 \%$

$\left(A_{2}\right)$ green extension $0 \%-9.7 \%$

$\left(A_{3}\right)$ green extension and red truncation $1.4 \%-20 \%$

$\left(A_{4}\right)$ green extension, red truncation, and queue jump $\quad 0 \%-18 \%$

The approach volume capacity ratio is between 0.5 and 0.8 , and the cross-street volume capacity ratio is 0.6 . 
The acceptable arrival threshold is 1 minute early and 5 minutes late. The approximate arrival times for the four alternatives are

$\left(A_{1}\right)$ signal optimization

$\left(A_{2}\right)$ green extension

$\left(\mathrm{A}_{3}\right)$ green extension and red truncation

$\left(\mathrm{A}_{4}\right)$ green extension, red truncation, and queue jump approx. 2 min. late approx. $1.5 \mathrm{~min}$. late approx. $1 \mathrm{~min}$. late approx $.0 .5 \mathrm{~min}$. late

2. Identify relevant participants in the decision process. Relevant stakeholders include elected officials, traffic representatives, transit representatives, emergency service providers, and transit riders. Their concerns and preferences with regard to the three criteria are shown in Table 2.

Table 2. Stakeholder Preferences

\begin{tabular}{|l|l|l|l|}
\hline & $\begin{array}{l}\text { Transit Travel } \\
\text { Time Reduction }\end{array}$ & $\begin{array}{l}\text { Nontransit } \\
\text { Delay }\end{array}$ & $\begin{array}{l}\text { Service } \\
\text { Reliability }\end{array}$ \\
\hline Elected officials & Very Important & Very Important & Very Important \\
Traffic Representatives & Not Important & Very Important & Important \\
Transit Representatives & Very Important & Important & Very Important \\
Emergency Service Providers & Not Important & Important & Not Important \\
Transit Riders & Very Important & Not Important & Very Important \\
\hline
\end{tabular}

3. Convert alternative performance measures to fuzzy numbers. Using the techniques previously described, the alternative performance measures are converted to triangular fuzzy numbers and arrayed in the form a decision matrix (Figure 8).

C1

Transit travel time reduction
$\mathrm{C} 2$

Nontransit delay

Service reliability

$\left.\begin{array}{llll}(2.00,3.50,5.00) & (5.00,10.00,5.00) & (0.70,0.70,0.70) \\ (0.00,4.90,9.00) & (0.00,5.00,10.00) & (0.77,0.77,0.77) \\ (1.40,10.70,20.00) & (0.00,5.00,10.00) & (0.85,0.85,0.85) \\ (0.00,9.00,18.00) & (0.00,5.00,10.00) & (0.93,0.93,0.93)\end{array}\right]$

$\mathrm{A}_{1}$ (Signal optimization)
$\mathrm{A}_{2}$ (Green extension)
$\begin{aligned} & \mathrm{A}_{3} \text { (Green extension \& red } \\ & \text { truncation) }\end{aligned}$
$\begin{aligned} & \mathrm{A}_{4} \text { (Green extension \& red } \\ & \text { truncation \& queue jump) }\end{aligned}$$\quad\left[\begin{array}{lllll}(2.00,3.50, & 5.00) & (5.00,10.00,5.00) & (0.70,0.70,0.70) \\ (0.00,4.90, & 9.00) & (0.00,5.00,10.00) & (0.77,0.77,0.77) \\ (1.40,10.70,20.00) & (0.00,5.00,10.00) & (0.85,0.85,0.85) \\ (0.00,9.00,18.00) & (0.00,5.00,10.00) & (0.93,0.93,0.93)\end{array}\right]$

Figure 8. Decision Matrix 
4. Generate stakeholder preference-based criteria weights. Stakeholder preference for each criterion is determined using Table 2 and Figure 4 (see Table 3).

Table 3. Stakeholder Preference-Based Criteria Weights

\begin{tabular}{|lccc|}
\hline & \multicolumn{1}{c}{$\mathrm{C} 1$} & $\mathrm{C} 2$ & $\mathrm{C} 3$ \\
& $\begin{array}{c}\text { Transit travel } \\
\text { time reduction }\end{array}$ & $\begin{array}{c}\text { Nontransit } \\
\text { delay }\end{array}$ & $\begin{array}{c}\text { Service } \\
\text { reliability }\end{array}$ \\
Elected officials & $(0,5,10)$ & $(5,10,10)$ & $(5,10,10)$ \\
Traffic representatives & $(0,5,10)$ & $(5,10,10)$ & $(0,5,10)$ \\
Transit representatives & $(5,10,10)$ & $(0,5,10)$ & $(5,10,10)$ \\
Emergency service providers & $(0,5,10)$ & $(0,5,10)$ & $(0,0,5)$ \\
Transit riders & $(5,10,10)$ & $(0,0,5)$ & $(5,10,10)$ \\
\hline Average & $(2,7,10)$ & $(2,6,8)$ & $(3,7,9)$ \\
Normalized weight & $(0.10,0.35,0.50)$ & $(0.10,0.30,0.45)$ & $(0.15,0.39,0.45)$ \\
\hline
\end{tabular}

5. Rank the alternatives using multiattribute decision-making methods. The results of steps 3 and 4 are shown in the normalized decision matrix presented in Figure 9.

$$
\begin{array}{lll}
\mathrm{C}_{1} & \mathrm{C}_{2} & \mathrm{C}_{3}
\end{array}
$$

$$
\mathbf{D}=\quad \begin{aligned}
& \mathbf{A}_{1} \\
& \mathbf{A}_{2} \\
& \mathbf{A}_{3} \\
& \mathbf{A}_{4}
\end{aligned}\left[\begin{array}{llll}
(0.10,0.35,0.50) & (0.10,0.30,0.45) & (0.15,0.35,0.45) \\
(0.00,2.45,4.75,2.50) & (5.00,10.00,10.00) & (7.00,7.00,7.00) \\
(0.70,5.35,10.00) & (0.00,5.00,5.00,10.00) & (7.70,7.70,7.70) \\
(0.00,4.50,9.00) & (0.00,5.00,10.00) & (9.30,9.30,9.30)
\end{array}\right]
$$

Figure 9. Normalized Decision Matrix

The alternatives can be ranked ordered using WSM or TOPSIS. For this example, sensitivity analysis and computational experiments indicated that TOPSIS was more responsive to stakeholder preference. Results indicate that $\mathbf{A}_{1}$ (signal optimization) was the preferred alternative when the majority of stakeholders did not consider transit travel time reduction important, and $\mathbf{A}_{\mathbf{3}}$ (green extension and red truncation) was the preferred alternative when the majority of stakeholders considered transit travel time reduction important. 


\section{Summary and Recommendations}

The conceptual DSS framework and three analytical tools presented outline a systematic technique to perform analytical assessments of integrated emergency vehicle preemption and transit signal priority system impacts. These tools use cost factors, accident reduction factors, and soft computing techniques to transform quantitative and qualitative performance data for input into mathematical modeling methods commonly used to support decision making.

Recommendations for future work include:

1. Develop analytical tools to address the potential impact of reduced emergency vehicle travel time on saving lives, reducing injury, reducing property damage, and assessing system level impacts.

2. Expand the fuzzy MADM framework to include other criteria such as investment costs and safety. Cost data may include, for example, infrastructure costs to modify an intersection to accommodate a queue jump or to relocate bus stops from near side to far side to accommodate a green extension. Safety impacts include both transit and pedestrian safety.

3. Link a series of intersections and use dynamic programming to determine the best mix of transit signal priority strategy alternatives along a corridor.

4. Apply fuzzy MADM methods to analyze the performance of integrated signal control systems with various priority strategies.

5. Expand the application of fuzzy MADM methods to other branches of transportation and traffic engineering such as transportation safety analysis where recommendations for safety improvements must consider multiple criteria (e.g., geometric designs, traffic control devices, rules enforcement, infrastructure maintenance, driver behavior and qualification, pedestrian and bicycle traffic, and population demographics) and often require expert knowledge to interpret.

\section{Acknowledgments}

The authors acknowledge support of the Washington Regional Council of Governments, the Virginia Department of Transportation, and the Maryland Department of Transportation for this research. The authors wish to thank Professor Antoine Hobeika, Professor Kostas Triantis, and Dr. Sam Tignor, Virginia Polytechnic Institute and State University, and Professor Jonathan Gifford, George Mason Univer- 
sity, for their guidance and advice on this research. The authors also wish to thank the anonymous reviewers of the Journal of Public Transportation for their helpful comments.

\section{References}

Bullock, D., J. M. Morales, and B. J. Sanderson. 1999. Impact of signal preemption on the operation of the Virginia Route 7 corridor. ITS America.

Chada, S. 2004. Critical factors for transit signal priority. CD-ROM. Washington, DC: Transportation Research Board National Research Council.

Chang, J., J. Collura, F. Dion, H. Rakha. 2002. "Evaluation of service reliability impacts on traffic signal priority strategies for bus transit". Annual Meeting of the Transportation Research Board. National Research Council, Washington, DC.

Chang, J., ed. 2002. An overview of transit signal priority. Washington, DC: ITS America.

Chen, S. J., and C. L. Hwang. 1992. "Fuzzy multiple attribute decision making: Methods and applications". Lecture Notes in Economics and Mathematical Systems 375. Berlin: Springer-Verlag.

Collura, J., H. Rakha, and J. Gifford. 2003. Guidelines for the planning and deployment of emergency vehicle preemption and transit strategies. Washington, DC: Virginia Tech Transportation Institute and George Mason University School of Public Policy.

ECONWest and Parsons Brinckerhoff Quade \& Douglas. 2002. TCRP Report 78 Estimating the benefits and costs of public transit projects: A guidebook for practitioners. Washington, DC: Transit Cooperative Research Program.

Gifford, J., D. Pelletiere, and J. Collura. 2001. Stakeholder requirements for traffic signal preemption and priority in the Washington, D.C., region. Journal of the Transportation Research Board 1748: 1-7.

Gkritza, K., J. Collura, S. Tignor, D. Teodorovic. 2004. An analysis of the characteristics of emergency vehicle operations in the Washington D.C. region. CD-ROM. Washington, DC: Transportation Research Board National Research Council. 
Lee, D., and A. Carroll. 2001. Benefit-cost evaluation of a highway-railroad intermodal control system. Cambridge, MA:U.S. Department of Transportation, Volpe National Transportation Systems Center.

Levine, J., S. Park, S. Underwood, and R. Wallace. 1999. Stakeholder preferences in advanced transportation system planning. Journal of Public Transportation 2(1): 25-45.

Morlok, E. K., E. C. Brunn, and K. J. Blackman. 1991. Advanced vehicle monitoring and communication systems for bus transit: Benefits and economic feasibility. Washington, DC: University Research and Training Program, Office of Technical Assistance, Federal Transit Administration.

Ngan, V. 2003. A comprehensive strategy for transit signal priority. ITE Journal (November): 28-32.

Noyce, D. A. 1996. Barriers to implementation of signal priority systems for transit operations: Lessons learned from advanced traffic management systems. College Station, TX: Department of Civil Engineering, Texas A\&M University.

Soo, H., J. Collura, A. Hobeika, and D. Teodorovic. 2004. An analytical frameworkfor evaluating the impacts of advanced traffic signal control systems for emergency vehicle preemption and transit priority. CD-ROM, ITS America's 14th Annual Meeting and Exhibition.

Soo, H., J. Collura, and D. Teodorovic. 2005. Towards the development of an advanced traffic signal control system for advanced traffic signal control systems investment planning. CD-ROM, Transportation Research Board Annual Meeting.

Teodorovic, D. 1994. Fuzzy sets theory applications in traffic and transportation. European Journal of Operational Research 74: 379-390.

Teodorovic, D., and S. Kikuchi. 1991. Application of fuzzy sets theory to the saving based vehicle routing algorithm. Civil Engineering Systems 8: 87-93.

\section{About the Authors}

Houng Soo (hsoo@vt.edu) has more than 25 years of experience in engineering and engineering management with the U.S. Army Corps of Engineers. Over the last four years he has been involved in research relating to economic evaluations of Intelligent Transportation Systems with an emphasis on emergency vehicle pre- 
emption and transit signal priority as a graduate research associate at the Virginia Polytechnic Institute and State University. Dr. Soo received his Ph.D. in civil engineering (transportation) from the Virginia Polytechnic Institute and State University, his MBA from Florida Institute of Technology, his M.S. (nuclear engineering) from the University of Washington, and his BSEE from Polytechnic Institute of Brooklyn. Dr. Soo is also a registered professional engineer.

John ColluRA (jcollura@umass.edu) is a professor of civil engineering at the University of Massachusetts. Dr. Collura has more than 25 years of experience in transportation research and education with an emphasis on public transportation planning, management, and performance evaluation, and the application of information-based technologies. He also teaches courses in public transit design and operations, and in public transit planning and analysis. Dr. Collura received his Ph.D. in civil engineering (transportation) from the North Carolina State University, his MSCE (transportation) from Villanova University, and his BSCE from Merrimack College. Dr. Collura is also a registered professional engineer.

Dusan TeOdorovic (duteodor@vt.edu) is a Professor Emeritus in the Department of Civil and Environmental Engineering at the Virginia Polytechnic Institute and State University. He received his B.S., M.S. and Ph.D. degrees in transportation engineering at the University of Belgrade. Dr. Teodorovic has more than 25 years experience in transportation research and education. His areas of emphasis include: transportation planning, transportation networks, transportation modeling, air transportation, operations research, and fuzzy and neuro modeling. He is published widely in international journals and has served as professor of transportation engineering and operations research at the University of Belgrade; as visiting professor in the Department of Civil Engineering at the Technical University of Denmark; Operations Research Program at the University of Delaware; and National Chiao Tung University, Taiwan. 
Errata/Editor's Note: The following paper is a reprint of the original paper that appeared in Volume 9, No. 1. In the original paper, Dr. Gregory Price was not included as co-author. We regret the error.

\title{
A Study of the Impact of APTS on Service Quality Perceptions of Elderly and Disabled Riders
}

\author{
Julian M. Benjamin, North Carolina A\&T State University \\ Gregory N. Price, Jackson State University
}

\begin{abstract}
New transportation technology that directly impacts consumers should be evaluated by the people who are affected. Automated dispatching has become standard practice for paratransit services. This article summarizes a study analyzing consumer response to the Mobility Manager at a demonstration site in Winston-Salem, North Carolina.

The Mobility Manager was applied to the TransAID demand-responsive mini-bus service for people who are elderly or who have disabilities. Survey data from two questionnaires, before and after the implementation of the Mobility Manager for the same subjects, were used to examine travel behavior and perceived service quality. These travelers reported service improvements such as easier telephone access and shorter travel times. The respondents' travel patterns after implementation of the Mobility Manager remained stable. This article also provides econometric estimates of the change in the number of trips as a function of the change in travel attributes affected by implementation of the Mobility Manager. Changes in the number of trips by survey respondents were treated as a Poisson random variable. Results from a Poisson regression show that the primary beneficiaries of the Mobility Manager were riders with disabilities. Perceived service attributes that significantly affected changes
\end{abstract}


in trips were length of trip, number of stops picking up additional passengers, and physical comfort.

\section{Study Background}

The Advanced Public Transportation Systems (APTS) program of the Federal Transit Administration in the 1990s involved projects that demonstrated the application of advanced technologies to transit systems (Casey et al. 1991). The APTS program evaluated these new technologies in practical demonstration projects. The system selected as the site for this study was the mini-bus dial-a-ride for special populations in Winston-Salem, North Carolina. As one of the APTS demonstration sites, new transit technologies including automated computer dispatch, automatic vehicle location, and smart cards were tested and evaluated. Taken together, these technologies made up the Mobility Manager, a geographic information system combined with a management information system. The Mobility Manager assisted the transit agency in scheduling, routing, billing, and administration tasks.

The technology was tested in a mini-bus system called TransAID, which was part of the public transit system of Winston-Salem (WSTA). Winston-Salem is a small city (2000 U.S. census population of 182,874) and is part of the Piedmont Triad, which consists of three cities with similar size about 30 miles apart in north central North Carolina. TransAID is a public paratransit system with curb-to-curb dial-aride service.

TransAID services are provided in eight 15-passenger mini-buses (vans) that are equipped for non-disabled passengers and 11 vans equipped for wheelchairs. Weekday hours of operation in Winston-Salem and in Forsyth County are 5:30 A.M. to 6:30 P.M. Limited service is provided for dialysis patients on Saturdays.

\section{Study Design}

The evaluation of this project used procedures summarized in "Evaluation Guidelines for the Advanced Public Transportation Systems Operational Tests" (Casey and Collura 1993). These techniques were based on methodologies developed for the earlier UMTA demonstration program. Subsequently, there have been many advances in travel analysis procedures that have particular relevance to project evaluations. These findings were summarized by Benjamin (1994) and included travel activity diaries, stated preference techniques applied to complex decisions, 
the application of computer technology to data gathering, and the application of new econometrics procedures. This study investigated the application of many of these procedures to the evaluation of APTS by applying them in a case study. Results of the stated and revealed preference elements of the before study were reported in Ben-Akiva et al. (1996). These study methods are combined into a before and after study design in this article.

\section{Study Objectives}

The objectives of this study were twofold. First, the study provided before and after comparisons of perceived service quality improvements from using the WSTA Mobility Manager. These improvements include various aspects perceived by users including telephone answering, travel time, and impacts on consumer travel behavior. Second, we considered the decision by TransAID passengers to take additional trips to determine the extent to which the implementation of Mobility Manager induced more ridership via the enhancement of service attributes.

\section{Before and After Surveys}

The before survey was completed in the summer of 1994 just before the phase 1 demonstration project started. The survey was designed to collect both baseline evaluation data and consumer demand information from current riders. The survey consisted questions in four areas: current travel behaviors, current transit system performance, stated anticipated travel behaviors after the APTS was implemented, and subject demographics.

The after study took place two years later following implementation of the Mobility Manager and replicated the before questions except for the stated preference travel questions.

Current travel behavior was recorded during the week prior to contact with the respondent. Detailed questions were asked about travel by trip purpose for each day of the week. Trip making for an entire one week period was investigated because of the low trip rate by the elderly and persons with disabilities; 78 percent of these respondents reported in the before study that they traveled by TransAID only once during the study week.

Questions on current transit service quality consisted of measures of the method used to contact TransAID to reserve a trip to and from home, responsiveness of the telephone service, and vehicle travel time. Each question asked about the last time that TransAID was used so that measures of service quality could be averaged across subjects. These questions were tailored to the anticipated improvements 
in the quality of service by the Mobility Manager, which would make it more efficient to schedule trips and make travel time shorter as a result of more efficient routing.

Questions on future responses included scenarios that represented different hypothetical services. In anticipation of service improvements by the Mobility Manager, questions addressed how far in advance vans must be reserved, the ability to confirm calls immediately, travel time, and time required to call for return trips after the Mobility Manager was placed in to operation.

\section{Respondent Descriptions \\ Response Rate and Attrition}

The before study questionnaire was completed by 266 respondents. Of this total, 176 respondents were reported to still be TransAID riders by the Winston-Salem Transit Authority (WSTA) at the time of the after study. For the after study, the 176 subjects were initially contacted by mail. Current phone numbers were obtained for 162 respondents, and 100 surveys were completed. The 62 subjects who did not respond consisted of:

- 12 for whom there was no answer after five callbacks,

- 8 who had passed away,

- 14 who reported that they no longer use TransAID,

- 13 whose phone numbers were disconnected,

- 9 who did not live at the most recent phone numbers,

- 2 whose phone numbers had been changed to nonpublished numbers,

- 2 who had no recollection of their last trip on TransAID, and

- 2 who refused to participate.

\section{General Socioeconomic Statistics}

The initial data analysis was presented by Benjamin (2000). During the before study, TransAID served people with disabilities ( $2 / 3$ of the survey respondents), children under 12 years of age (30 respondents), and adults 65 years of age or older (162 respondents). The largest percentage of attrition occurred for younger riders (e.g., 50 riders before, 2 riders after), which may be due in part to HeadStart children entering public schools. The next largest attrition rate was for those over 
65 years of age and was partly due to mortality and to changes in dwelling places for this age group.

Most people reported having a high school education in both studies, with the highest attrition rate for those reporting only elementary education. This, again, may have been due to the HeadStart youngsters. Among all the users, only 5 out of 272 respondents were employed in the before study and only 2 in the after study. Among those reporting to have a disability in the before study, 95 were sight impaired, 101 were hearing impaired, 81 noted that the nature of their disability was "difficulty in reaching and grasping," 139 had difficulty walking, and 83 used a wheelchair. In the after study, the largest group had difficulty walking (65 of 101).

\section{Service Usage and Quality Before Mobility Manager}

Van Service Usage Patterns for Initial Respondents. The larger number of the responses before the Mobility Manager provided information for a more detailed analysis of service utilization and quality. In the before study, 45 percent of the respondents rode TransAID the week prior to the first survey but only 30 percent rode it during the second survey. The trips reported were unequally distributed among days of the week. The largest number traveled on Monday (47\%) with other trips distributed among the remaining days of the week. Only 2 percent of the sample reported riding on Saturday, and there was no service provided on Sunday. Similar results were reported in the second survey. (These travel patterns are illustrated for the last trip in Table 3.)

In a summary of trips made according to disability type and trip purpose, for the first trip taken, 76 percent of these users traveled for medical reasons. The majority of people rode for medical reasons in each disability group in the before and after studies, and the disability group with the largest percentage of medical trips was for those who had difficulty walking. Virtually all of the trips were round-trips, and most people traveled only once during the week. The average number of one-way trips reported during the survey week was 3.6. About one third of the respondents made a second round-trip, and about one fourth made more trips. Thirty-seven subjects made five round-trips, and only one subject reported making a sixth trip (for medical purposes) before and, at most, five round-trips after.

\section{Service Quality Before Mobility Manager}

All questions about quality of service referred to the last time the service was used. This section summarizes responses before implementation of the Mobility 
Manager. Almost 80 percent of the respondents said that the last time they called for service they did not get a busy signal, only 14 percent felt rushed, 5 percent complained of lack of courtesy, and 6 percent reported a lack of accuracy. Respondents reported talking an average of 2.8 minutes and holding for a mean of about 1 minute.

The vehicle usually arrived on time (65\%), although the vehicles were frequently either early (14\%) or late (20\%). The mean time of early pick-up was 3.9 minutes; the mean late pick-up time was 8 minutes. However, 29 percent of the riders indicated that the vehicle had failed to pick them up at some time in the past. For the last return trip, the van arrived at the destination within 5 minutes of schedule 200 times but there was a reported late arrival of one hour or more by 17 people.

Riders reported an average in-vehicle travel time of 22.2 minutes, with a standard deviation of 22.1 minutes. While traveling, respondents observed an average of 4 people in their vans. When they arrived early, it was only for an average of 1.5 minutes; when the vehicle arrived late, the average reported time was 9.1 minutes, with a standard deviation of 25.6 minutes.

During the week before the first survey, 26 percent of the respondents had ridden the fixed-route transit an average of 1.4 times, indicating that there could be some shift to the fixed-route mode. Sometime in the past, 10 percent of the respondents reported that they had been in an accident on the vehicle and that assistance was required. It took an average of 34 minutes for assistance to arrive, with two hours being the longest wait.

\section{Van Service Usage Patterns}

Practically all the trips (more than 95\%) taken by children under 18 in the survey group were for educational (other) purposes. This proportion is unique to this age group, and adults between 18 and 65 years old also had a significant amount (about 20\%) of educational trips. That the youngest group has such a high proportion of educational trips fits in with the fact that TransAID was designed in part to serve families with children attending HeadStart programs. Van service reservation patterns for this age group indicate that for close to 60 percent of the trips taken, the van service was not called, implying that the service was scheduled in advance and worked like a school bus that picks up at home. For the remaining 40 percent, the service was requested a minimum of 24 hours in advance. As in the other age groups, the proportion of users reserving the van the same day as the 
scheduled trip was negligible ( $0 \%$ for children under 12 , under $5 \%$ for all the other respondents).

For respondents above 65 years old, at least 60 percent of the trips were made for medical purposes. More than 50 percent of the trips were reserved 24 hours in advance. Other trip purposes for this group were for shopping and nutrition, each representing close to 10 percent of the trips, indicating that TransAID was helping with some of their daily activities.

\section{Comparison of Before and After Surveys}

A comparison of results for those who took both surveys was calculated for key questions in the study. The HeadStart children in the first phase all aged out of using these services before the second phase and were therefore not included in any analysis based on the after data. Table 1 lists some responses to key questions asked before the Mobility Manager and responses by the same people in the after survey.

Table 1. Perceived Effects of APTS

\begin{tabular}{|l|l|c|}
\hline Reported Before & Reported After by Same Respondents & After Percent \\
\hline Picked up early/late & Picked up on time & $21 \%$ \\
\hline Picked up early/late & Same & $13 \%$ \\
\hline & Lower travel time & $57 \%$ \\
\hline Dropped off late & Same & $37 \%$ \\
\hline $\begin{array}{l}\text { Called more than 24 hours in } \\
\text { advance }\end{array}$ & Same & $80 \%$ \\
\hline & Lower phone time & $57 \%$ \\
\hline Not polite on phone & Same & $90 \%$ \\
\hline Busy signals & More busy signals & $80 \%$ \\
\hline
\end{tabular}

The extent the implementation of the Mobility Manager favorably impacted service quality perceptions by riders was not absolutely definitive. The following sample proportions, with t-statistics in parentheses, suggest that the implementation of the Mobility Manager may have impacted favorably on service quality perceptions. Of those respondents reporting that TransAID last picked them up 
early or late in the first survey, 21 percent $(t=5.1)$ reported that TransAID last picked them up on time in the second survey, 5 percent $(t=2.3)$ reported that TransAID last picked them up early in the second survey, and 8 percent $(t=2.9)$ reported that TransAID last picked them up late in the second survey. Given the travel times reported in the first survey, 57 percent $(t=11.5)$ of the respondents in the second survey reported spending less time riding TransAID from their home. For respondents who reported in the first survey that were dropped off at their destination late, only 37 percent $(t=7.6)$ reported that TransAID dropped them off late in the second survey. Of those respondents in the first survey reporting that they did not request their last trip on TransAID at least 24 hours in advance, 80 percent $(t=20)$ reported scheduling their last trip at least 24 hours in advance in the second survey. For reported times spent talking to TransAID officials on the telephone in the first survey, 57 percent $(t=11.5)$ reported spending less time talking in the second survey. Of those respondents in the first survey who reported that TransAID officials were not polite on the telephone, 90 percent $(t=$ 30) reported they were polite in the second survey.

Although fewer people reported traveling on TransAID in the second survey, of those who rode TransAID in the first survey, 85 percent reported traveling slightly more frequently by TransAID after the Mobility Manager. However, a chi-square test revealed that there was no significant difference for the total group in trip rates for different trip purposes and days of the week.

To the extent that perceptions of quality were related to the attributes measured in the sample proportions cited above, one implication was that the Mobility Manager had a favorable impact. Such an implication was, of course, only suggested by the reported sample proportions. Further caution was warranted by the fact that there was some evidence suggesting that perceptions of service quality were lower for respondents in the second survey in some areas. For example, of those respondents in the first survey reporting the number of busy signals when attempting to contact TransAID officials on the telephone, 80 percent $(t=20)$ reported an increase in the number of busy signals in the second survey.

\section{Effects of Mobility Manager on Ridership Trips as a Function of Travel Attributes}

Presumably, consumer response to the implementation of Mobility Manager should have resulted in an increased number of trips. If, for example, consumers, as 
utility maximizers, realized higher utility as a result of enhanced travel attributes, the extent to which the implementation of Mobility Manager enhanced travel attributes on TransAID should induce more ridership. Five questions in the followup survey were designed to measure travel attributes such as ease of scheduling, physical comfort, and trip length. Each question provided answers on a five-point integer scale, with 1 indicating strong agreement and 5 indicating strong disagreement. ${ }^{1}$

Both surveys recorded the number of trips on TransAID by respondents. To determine the effect of the Mobility Manager on ridership, we posit the relationship between the change in number of trips and the service attributes plausibly affected by Mobility Manager as follows:

$\Delta$ Trips $=\mathrm{T}_{\mathrm{i}}=f($ Travel Attributes)

$$
=f(\text { Easy, Long, Stops, Riders, Comfort })
$$

where:

Easy

is the extent to which it was easy to schedule a trip on TransAID

Long represents the extent to which it takes long to complete a trip on TransAID

Stops indicates the extent to which TransAID makes many stops for other passengers

Riders signifies the extent to which there were too many passengers on TransAID

Comfort is the extent to which a passenger was comfortable while riding TransAID

All variables were based on the perception of the respondent in the second survey, after implementation of the Mobility Manager.

The rate of incidence of the number of trips was modeled as the arrival rate in a random Poisson process. This modeling approach is discussed in the Supplemental Material section. 


\section{Results}

Table 2 presents the mean and standard deviation for the dependent and independent variables. Column 1 in Table 3 reports the Poisson regression estimates of equation (1). ${ }^{2}$ As a goodness-of-fit measure, Table 3 also reported the value of Pseudo- $\mathrm{R}^{2}{ }^{3}$ All of the parameter estimates conformed to a priori expectations and were significant except for the variables Riders and Comfort. Column 1 also reports the estimated coefficient $\alpha$, which was generated from testing equation (1) for mean variance equality, a restriction required for a Poisson random variable. ${ }^{4}$ The insignificance of $\alpha$ at any reasonable level of significance implied that $T_{i}$ could have been modeled as a Poisson random variable. The sign on Easy suggested that the more difficult scheduling a trip was on TransAID, the higher the probability of additional ridership by a respondent. This, of course, seems rather implausible, but it may capture the effects of riders willing to tolerate difficulty scheduling as a result of it being positively correlated with other favorable attributes associated with TransAID after the implementation of the Mobility Manager. Long was negative and significant, suggesting that the probability of ridership increased with decreases in trip duration. The positive and significant sign on Stops indicated that the probability of ridership increased as the number of passenger pick-ups decreased. The insignificance of Rider and Comfort suggested that the probability of ridership changes was not affected at all by perceptions of the number of passengers and their comfort.

\section{Table 2. Summary Statistics}

\begin{tabular}{lccccc}
\hline Variable & Mean & $\begin{array}{c}\text { Standard } \\
\text { Deviation }\end{array}$ & Minimum & Maximum & N \\
\hline Number of & & & & & \\
Additional Trips & 1.46 & 4.74 & 0 & 33 & 99 \\
$\left(\mathrm{~T}_{\mathrm{i}}\right)$ & 1.78 & .767 & 1.0 & 5.0 & 99 \\
Easy & 2.28 & .858 & 1.0 & 5.0 & 99 \\
Long & 3.24 & .959 & 1.0 & 5.0 & 99 \\
Stops & 4.12 & .824 & 1.0 & 5.0 & 99 \\
Riders & 1.0 & 1.11 & 1.0 & 5.0 & 99 \\
Comfort & & & & & \\
\hline
\end{tabular}

Note: Two observations were lost due to survey respondents not responding to the questions quiring a categorical response 
Table 3. Poisson and Negative Binomial Regression Estimates

\begin{tabular}{|l|l|l|l|l|}
\hline Variable & $(1)$ & $(2)$ & $(3)$ & $(4)$ \\
\hline Constant & .498 & .254 & .209 & .192 \\
& $(.626)$ & $(.412)$ & $(.752)$ & $(.153)$ \\
\hline Easy & -.276 & -.193 & -.627 & -.432 \\
& $(.148)^{*}$ & $(.112)^{*}$ & $(.178)^{* * *}$ & $(.234)^{*}$ \\
\hline Long & -.306 & -.257 & -.384 &. .223 \\
& $(.113)^{* * *}$ & $(.129)^{* *}$ & $(.122)^{* * *}$ & $(.163)$ \\
\hline Stops & 2.22 & 1.35 & 2.82 & 1.75 \\
& $(.303)^{* * *}$ & $(.783)^{*}$ & $(.325)^{* * *}$ & $(.521)^{* * *}$ \\
\hline Riders & .002 & .002 & .067 & .032 \\
& $(.105)$ & $(.157)$ & $(.127)$ & $(.148)$ \\
\hline Comfort & .037 & .032 & .300 & .248 \\
& $(.108)$ & $(.234)$ & $(.121)^{* * *}$ & $(.127)^{*}$ \\
\hline Pseudo-R & .231 & .284 & .293 & .302 \\
\hline Sample Size & 99 & 99 & 83 & 83 \\
\hline$\alpha$ & 4.93 & $\ldots$ & 3.32 & $\ldots$ \\
& $(3.62)$ & $\ldots .$. & $(3.02)$ & $\ldots$ \\
\hline V & $\ldots .$. & 1.02 & $\ldots$ & 1.37 \\
& & $(.95)$ & & $(1.03)$ \\
\hline NR & $\ldots$ & .063 & $\ldots$ & .054 \\
\hline$\chi^{2}$ & $\ldots$ & .095 & $\ldots$ & .073 \\
\hline
\end{tabular}

Note: Standard errors were in parentheses.

* Significant at the .10 level.

** Significant at the .05 level.

*** Significant at the .01 level.

The adequacy of the Poisson specification in equation (1) for modeling additional trips on TransAID suggested that the implementation of the Mobility Manager engendered additional trips by enhancing the utility of riders as a result of shorter trips (Long), and a fewer number of stops per trip picking up other passengers (Stops).

Given that approximately 84 percent of the sample consisted of TransAID riders who self-reported some type of disability, the insignificance of the variables Riders and Comfort could have reflected a failure to control for the handicap status of TransAID riders. To explore this possibility, a discriminate analysis was conducted to determine which of the TransAID riders' handicap status can discriminate between those respondents who reported taking more trips on TransAID in the 
second survey and those who did not. The discriminant analysis revealed that the handicap status of TransAID riders did indeed provide explanatory power for discriminating between two groups, with handicapped riders more likely to report taking additional trips on TransAID in the second survey.

Column 3 in Table 3 shows the results of a Poisson regression estimated for the sample of riders who self-reported having a disability. As was the case for the Poisson specification in column 1 , the sign and significance of $\alpha$ and $\chi^{2}$ for testing Poisson specification in column 3 against the negative binomial in column 4 , suggests the adequacy of the Poisson specification over the sample of riders self-reporting a disability. The results in column 3 differed from the results in column 1 in that the variable Comfort was positive and significant. The variable Riders was still positive but insignificant. Apparently for riders with disabilities, the level of comfort was proportional to the number of passengers on TransAID. Thus, to the extent that the Mobility Manager was able to reduce the number of passengers per trip on TransAID, it induced additional trips by TransAID riders with disability. For public transit riders with disabilities that restricted mobility and/or required visits for medical care, it seems reasonable that ease of scheduling and physical comfort would have been important factors determining the desirability of public transit. Thus, the results reported in Table 3 suggest that the Mobility Manager, to the extent that it improved the attributes associated with travel on TransAID, and increased ridership, did so for disabled passengers with disabilities by enhancing the passenger utility attributes of trip length, number of stops picking up other passengers, and rider comfort.

\section{Conclusions}

The new technology used by TransAID directly affected consumers, and it was that effect that is reported in this study. The van service was used primarily by people above 65 years old to take medical trips ( $1 / 3$ of all trips reported in the survey). The use of the TransAID vehicles in part reflects the preferences and constraints of the riders and reflects trip purpose, weekday, and time-of-day restrictions by funding agencies.

Several key findings resulted from the survey. First, there was substantial attrition. The total attrition here was 63 percent. Of these subjects, there were only two who refused to participate (less than 1\%). Attrition may be due to changes in travel behavior over time, substitution of other modes, or the transient nature 
of this population. The remaining people included a large number who moved or changed phone numbers. This suggests that future research on new transit technologies, such as the Mobility Manager, should over sample the relevant population.

Second, the results of the second survey suggested that implementation of the Mobility Manager in Winston-Salem improved customer satisfaction with stable ridership on TransAID. The data suggest that the Mobility Manager impacted favorably on perceived service quality evidenced by shorter travel times, improved customer service through fewer telephone difficulties such as being put on hold, and decreased late drop-offs. However, overall ridership decreased because of attrition, but riders reported stable individual use of the service between the two surveys. Restrictions from funding agencies may have combined with consumer preferences and constraints for limited changes in travel patterns.

The Poisson regression results suggest that the Mobility Manager enhanced the attractiveness of travel by TransAID. For respondents with disabilities who highly rated comfort and ease of service, the Mobility Manager increased the use of TransAID.

Reactions of other travelers who began riding TransAID during the study period were assumed to be similar. Results were viewed in light of the sampling restrictions and the small population size. The results reported here must be interpreted as findings from retrospective questions. Although questions were asked about the last trip taken and the last week, the ability to recall details may have been limited for some members of these special groups. Finally, this case study suggests that the potential usefulness of a technology such as the Mobility Manager, from the consumers' perspective, is its ability to improve the perceived quality of service. Given the linkage between perception of service quality and ridership, future research on new transit technologies should explore which technologies will best increase ridership. 


\section{Appendix}

As the number of trips was reported as a count variable in both surveys, we specify the change in the number of trips $\left(T_{i}\right)$ as a Poisson random variable:

$$
\operatorname{Prob}\left(T_{i}=n\right)=f(T i)\left[\exp \left(-\lambda_{i}\right) \lambda_{i}^{n}\right] / n !
$$

where:

$T_{i}$ is the additional number of trips on TransAID reported by respondent $I$

$n$ equals $0,1,2, \ldots . \mathrm{N}$

$e \quad$ is 2.71828

$\lambda_{i} \quad$ represents the expected value of $T_{i}=$ Variance of $T_{i}$

A regression model was formulated by specifying the Poisson parameter $\lambda_{i}$ as a deterministic function of the presumed exogenous variables Easy, Long, Stops, Riders, and Comfort, with an unknown parameter vector $\beta$. We estimate the following specification:

$$
\lambda \mathrm{i}=\exp \left[\beta_{0}+\beta_{1} \text { Easy }+\beta_{2} \text { Long }+\beta_{3} \text { Stops }+\beta_{4} \text { Riders }+\beta_{5} \text { Comfort }\right]
$$

A Poisson specification such as equation (1) was a member of the class of Generalized Linear Models (GLM), the parameters will be estimated with a nonlinear weighted least squares maximum likelihood procedure. ${ }^{5}$ The log likelihood for the number of additional trips $\mathrm{T}_{\mathrm{i}}$ is:

$$
L(\beta)=\Sigma\left[T_{i} !-\exp \left(X_{i} \beta\right)+T_{i} X_{i} \beta\right]
$$

where:

$X_{i} \quad$ is a vector of exogenous variables

The gradient and Hessian, respectively, are:

$$
\begin{aligned}
& \partial L(\beta) / \partial \beta=\Sigma\left[X_{i}^{\prime}\left(T_{i}-\exp \left(X_{i} \beta\right)\right)\right]=0 \\
& \partial^{2} L(\beta) / \partial \beta \partial \beta^{\prime}=\Sigma\left[-X_{i}^{\prime} X_{i} \exp \left(X_{i} \beta\right)\right]<0
\end{aligned}
$$


The first order condition was nonlinear in $\beta$ and can be estimated with a numerical maximum likelihood procedure, or by an iterative nonlinear least squares procedure. Because the Hessian was negative definite, convergence to a unique solution was assured.

To further assess the explanatory power and adequacy of a Poisson regression specification for additional trips by passengers on TransAID, column 2 of Table 4 reported and tested the results of a Poisson specification versus a negative binomial specification of equation (1). ${ }^{6}$ The negative binomial specification was tested as an alternative to the Poisson specification with a Lagrange Multiplier Test, where the Poisson specification was viewed as the restricted model. ${ }^{7}$ The insignificance of the $\chi^{2}$ for the Lagrange Multiplier Test statistic $N R^{2}$ in column 2 indicates that the restricted Poisson regression specification cannot be rejected against the negative binomial alternative.

\section{Endnotes}

${ }^{1}$ The questions related to the Regression Model specifications were as follows:

a. It was easy to schedule a trip on TransAID.

b. It does not take long to complete a trip on TransAID.

c. TransAID made many stops picking up other passengers.

d. There were too many passengers on TransAID vehicles.

e. I am physically comfortable when riding TransAID.

${ }^{2}$ All results were obtained with the use of LIMDEP (Version 7.0) Econometric Software.

${ }^{3}$ Specifically, the goodness-of-fit measure was the Pseudo- $R^{2}$ of McFadden (1974) defined as $R^{2}=1-\left(\log L_{\Omega}\right) /\left(\log L_{\omega}\right)$, where $L_{\Omega}$ was the maximum of the likelihood function when maximized with respect to all of the parameters, and $L_{\omega}$ was the maximum of the likelihood function when maximized with respect to a constant term only.

${ }^{4}$ If dependent variable Ti has a Poisson distribution, the mean of the dependent variable $T_{i}$ was $\lambda_{i}=\lambda_{i}\left(X_{i}, \beta\right)$. Cameron and Trivedi (1990) show that a test for mean-variance equality was based on the hypothesis test: $H_{0}: \operatorname{var}\left(T_{i}\right)=\lambda_{i}$ versus the alternative: $H_{A}: \operatorname{var}\left(T_{i}\right)=\lambda_{i}+\alpha g\left(\lambda_{i}\right)$, where $g\left(\lambda_{i}\right)$ was a function specified to equal 
$1, \lambda_{i}$, or $\lambda_{i}{ }^{2}$. A test for mean-variance equality was a t-test for the significance of $\alpha$ in the auxiliary regression: $\Sigma w_{i} g\left(\lambda_{i}\right)\left\{\left(T_{i}-\lambda_{i}\right)^{2}-T_{i}-\alpha g\left(\lambda_{i}\right)\right\}=0$, where $\Sigma w_{i} g\left(\lambda_{i}\right)$ was a weight based on a consistent estimate of $\beta$-the fitted value for example. If the $t$-test on the coefficient $\alpha$ was insignificant, the null hypothesis of mean-variance equality cannot be rejected, suggesting the adequacy of a Poisson specification for the dependent variable-additional number of trips on TransAID.

${ }^{5}$ See Nelder and Wedderburn (1972) and Price (1995).

${ }^{6} \mathrm{~A}$ negative binomial random variable can be viewed as a realization of random variable from a specific compound Poisson distribution (Cameron and Trivedi 1986), where the mean varies linearly with the variance-or there was overdispersion. The overdispersion parameter in a negative binomial regression can be obtained from an auxiliary regression of the form $\left[\left(T_{i}-\lambda_{i}^{2}\right] / \lambda_{i}-1=v \lambda_{i}+k_{i}\right.$, where $v$ was the overdispersion parameter, and $k_{i}$ was a heteroskedastic stochastic error term. A negative binomial regression specification results when the estimate of $v_{i}$, was added as a variable to the Poisson regression specification.

${ }^{7}$ The Lagrange Multiplier Test procedure was based on an auxiliary regression where the residuals of the Poisson regression were regressed against all the variables initially included in the Poisson specification plus the estimated overdispersion parameter $v$. This was an approach suggested by Engle (1982), and we implement it here by viewing the Poisson specification as a restricted model, and the negative binomial specification as an unrestricted model. The test-statistic, distributed as a chi-square $\left(\chi^{2}\right)$ with degrees of freedom equal to the difference in the number of parameters between the negative binomial and Poisson regression specifications, was determined by the product of the unadjusted $R^{2}$ from the auxiliary regression times the number of observations $(N)$. If $N x R^{2}$ exceeds the critical value of the chi-square statistic, the null hypothesis that the overdispersion parameter $v$ has a zero coefficient that would have to be rejected.

\section{Acknowledgments}

This project was funded in part by the Urban Transit Institute of North Carolina A\&T State University, which was funded in part by U.S. Department of Transportation. Valuable research assistance was provided by William Nelson, a student in the transportation program at North Carolina A\&T State University. We also thank the manager of the Winston-Salem Transit Authority, Nedra Woodyethe, and the manager of TransAID, Suzanne Telechea, for their assistance with this 
project and Professor John Stone of NC State University for his assistance with the before study questionnaire.

\section{References}

Ben-Akiva, M., J. Benjamin, G. Lauprete, and A. Polydoropolou. 1996. Impact of Advanced Public Transportation Systems on Travel by Dial-a-Ride. Transportation Research Record 1557: 72-77.

Benjamin, J. 1994. Current trends in data gathering. Final Report. Prepared for the USDOT/FHWA.

Benjamin, J. 1995. Initial data analysis of the phase 1 before survey. Unpublished memorandum.

Cameron, A. C., and P. K. Trivedi. 1986. Econometric models based on count data: Comparisons and applications of some estimators. Journal of Applied Econometrics 1: 29-53.

Cameron, A. C., and P. K Trivedi. 1990. Regression based tests for overdispersion in the Poisson model. Journal of Econometrics 46: 347-364.

Casey, R., and J. Collura. 1993. Evaluation guidelines for the Advanced Public Transportation Systems operational tests. USDOT/FTA Report Number FTAMA-26-0007-94-2.

Casey, R., L. Labell, S. Prensky, and C. Schweiger. 1991. Advanced public transportation systems: The state of the art. USDOT/FTA Report No. DT-VNTSC-UMTA91-2.

Engle, Robert F. 1982. A general approach to Lagrangian Multiplier diagnostics. Annals of Econometrics, 20: 83-104.

LIMDEP 7.0: User's manual and reference guide. 1995. Econometric Software Inc., Bellport, NY.

McFadden, Daniel. 1974. The measurement of urban travel demand. Journal of Public Economics 3: $303-328$.

Nelder, J. A., and R. W. Wedderburn. 1972. Generalized linear models. Journal of the Royal Statistical Society 135: 370-384.

Price, G. N. 1995. The determinants of entry for black-owned commercial banks. Quarterly Review of Economics and Finance 35: 289-302. 


\section{About the Author}

JULIAN BenJAmin (benjamin@ncat.edu) is a professor in the Department of Economics and Transportation/Logistics at North Carolina A\&T State University. He received his Ph.D. from the Department of Civil Engineering at the State University of New York at Buffalo. His research has focused on special transportation and travel demand analysis. He has many publications in these areas with several that look at the application of demand analysis to planning services in a special transportation agency. He is a former member of the GATE (an early special transportation agency) Board of Directors.

Gregory N. Price, Ph.D, (gprice@murc.org) is Director of the Mississippi Urban Research Center (MURC) and Professor of Economics at Jackson State University, in Jackson, Mississippi. An applied econometrician and theorist, his current research interests include the effects of religiosity on economic behavior, the empirics of social capital and racial stigma, income distribution and redistribution, and the intergenerational effects of slavery. His research has been published in a wide variety of journals such as Review of Black Political Economy, Review of Economics and Statistics, American Economic Review, and Review of Development Economics. Dr. Price is President-elect of the National Economic Association and a former Program Director for Economics at the National Science Foundation. 


\section{EDITORIAL BOARD}

Robert B. Cervero, Ph.D.

University of California, Berkeley

Chester E. Colby

E\&J Consulting

Gordon Fielding, Ph.D.

University of California, Irvine

David J. Forkenbrock, Ph.D.

University of lowa

Jose A. Gómez-Ibáñez, Ph.D.

Harvard University

Naomi W. Ledé, Ph.D.

Texas Transportation Institute
William W. Millar

American Public Transportation Association

Steven E. Polzin, Ph.D., P.E.

University of South Florida

Sandra Rosenbloom, Ph.D.

University of Arizona

Lawrence Schulman

LS Associates

George Smerk, D.B.A.

Indiana University

Vukan R. Vuchic, Ph.D., P.E.

University of Pennsylvania
The contents of this document reflect the views of the authors, who are responsible for the facts and the accuracy of the information presented herein. This document is disseminated under the sponsorship of the U.S. Department of Transportation, University Research Institute Program, in the interest of information exchange. The U.S. Government assumes no liability for the contents or use thereof
Complimentary subscriptions can be obtained by contacting:

Lisa Maitland, Assistant to the Editor

Center for Urban Transportation Research (CUTR)

University of South Florida

Fax: $\quad 813.974 \cdot 5168$

Email: jpt@cutr.usf.edu

Web: $\quad$ www.nctr.usf.edu/journal.htm

\section{SUBMISSION OF MANUSCRIPTS}

The Journal of Public Transportation is a quarterly, international journal containing origina research and case studies associated with various forms of public transportation and related transportation and policy issues. Topics are approached from a variety of academic disciplines, including economics, engineering, planning, and others, and include policy, methodological, technological, and financial aspects. Emphasis is placed on the identification of innovative solutions to transportation problems.

All articles should be approximately 4,000 words in length (18-20 double-spaced pages). Manuscripts not submitted according to the journal's style will be returned. Submission of the manuscript implies commitment to publish in the journal. Papers previously published or under review by other journals are unacceptable. All articles are subject to peer review. Factors considered in review include validity and significance of information, substantive contribution to the field of public transportation, and clarity and quality of presentation Copyright is retained by the publisher, and, upon acceptance, contributions will be subject to editorial amendment. Authors will be provided with proofs for approval prior to publication.

All manuscripts must be submitted electronically, double-spaced in Word file format, containing only text and tables. If not created in Word, each table must be submitted separately in Excel format and all charts and graphs must be in Excel format. All supporting illustrations and photographs must be submitted separately in an image file format, (i.e., TIF, IPG, Al or EPS), having a minimum $300 \mathrm{dpi}$, and include all sources and written permissions. Each chart and table must have a title and each figure must have a caption.

All manuscripts should include sections in the following order, as specified:

Cover Page - title (12 words or less) and complete contact information for all authors First Page of manuscript - title and abstract (up to 150 words)

Main Body - organized under section headings

References - Chicago Manual of Style, author-date format

Biographical Sketch - of each author

Be sure to include the author's complete contact information, including email address, mailing address, telephone, and fax number. Submit manuscripts to the Assistant to the Editor, as indicated above. 